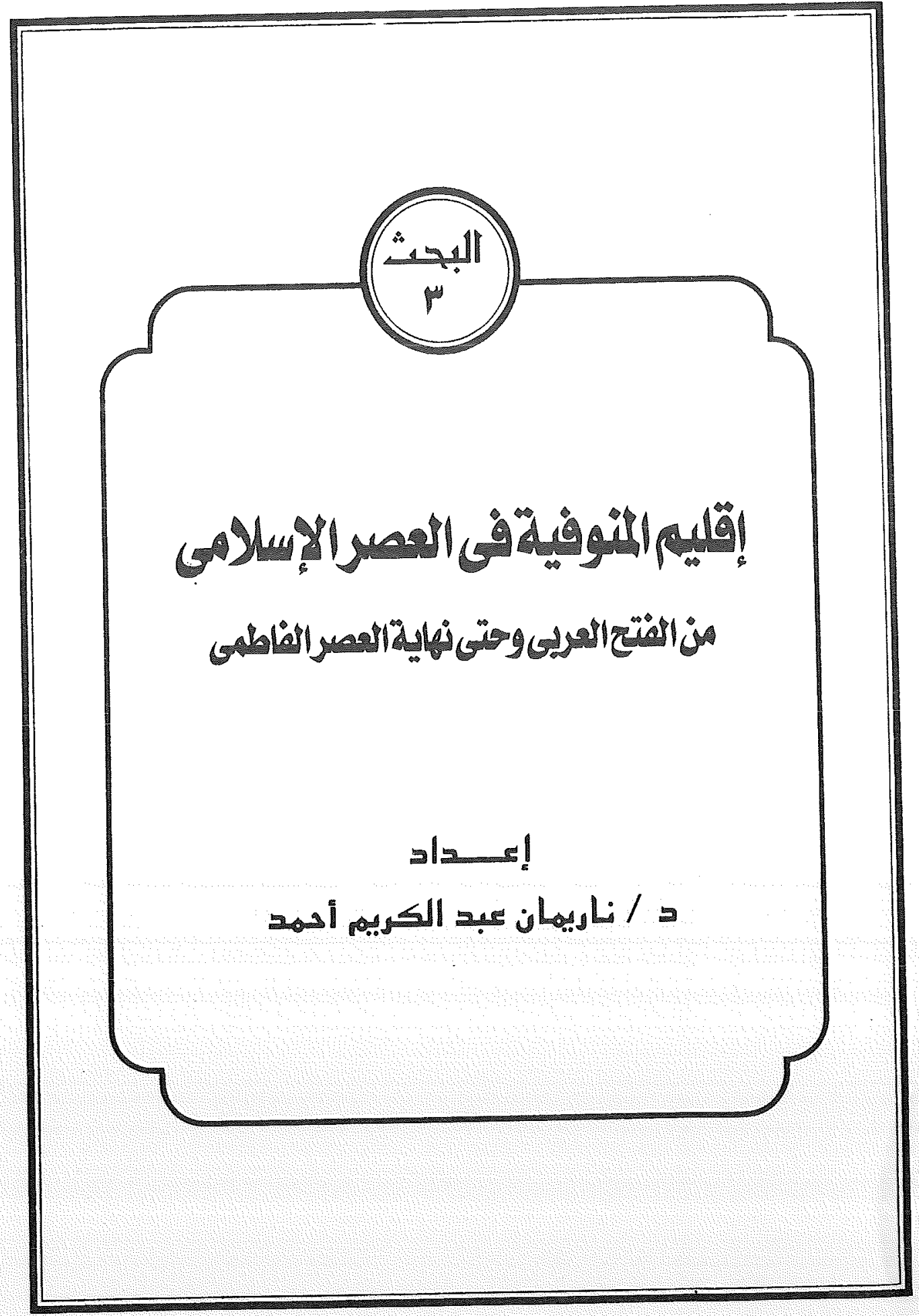





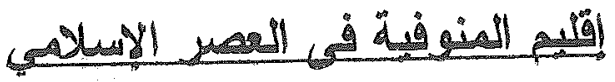

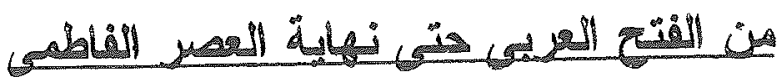

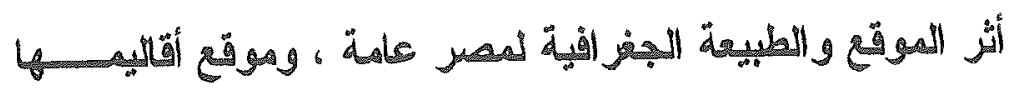

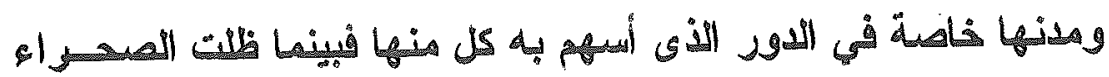

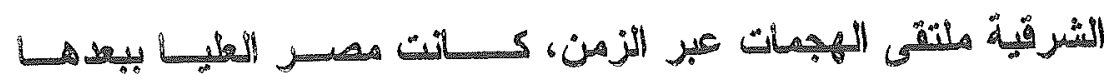

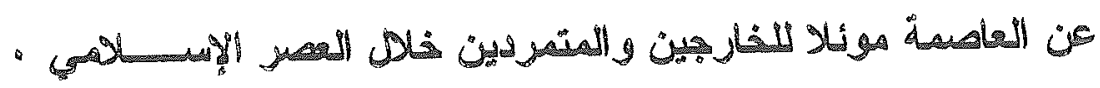

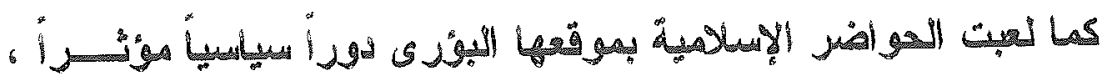

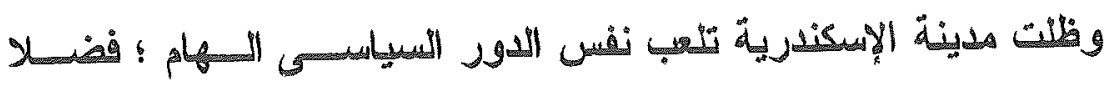

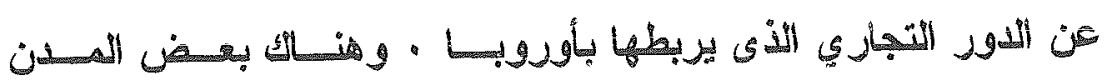

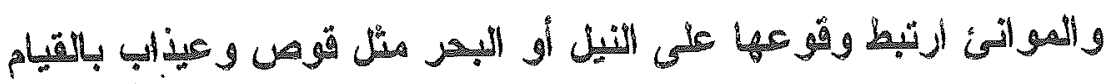

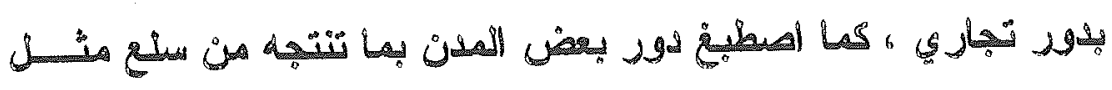

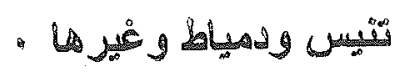

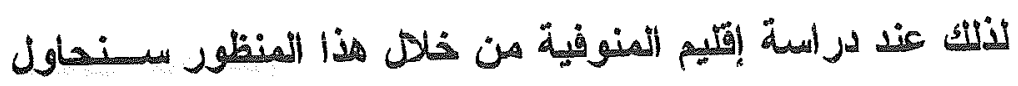

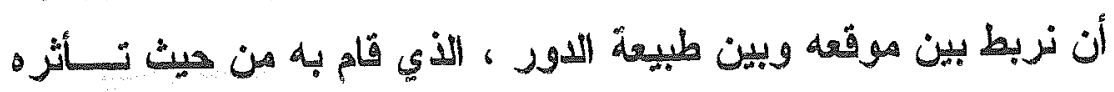

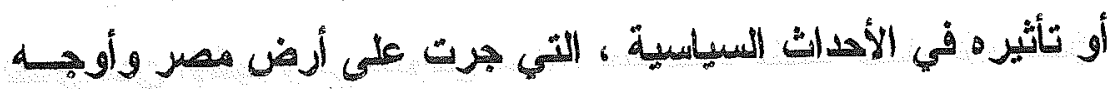

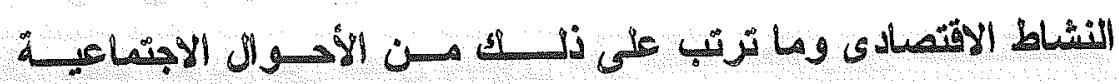

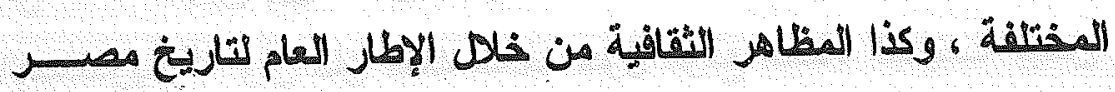

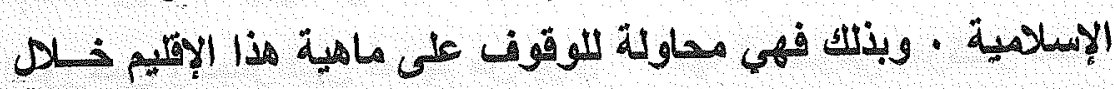

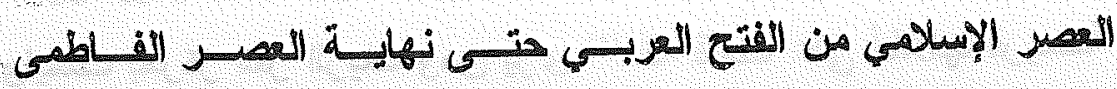

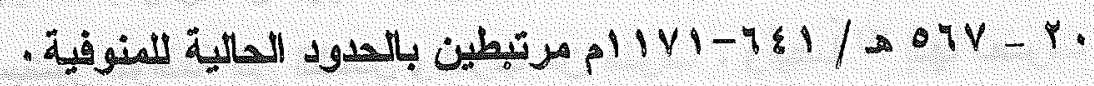




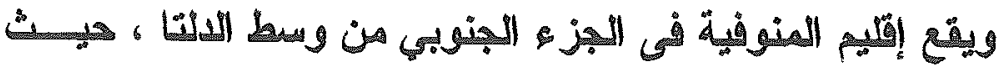

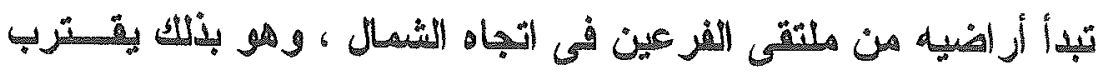

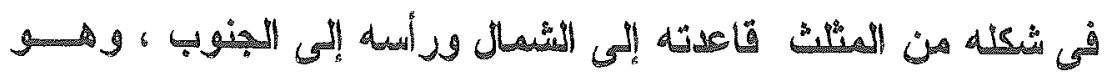

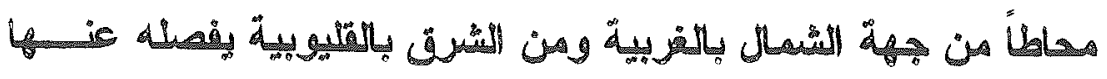

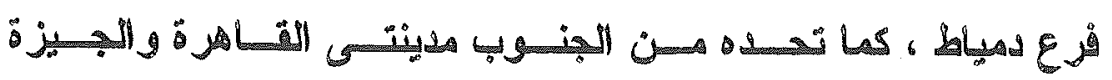

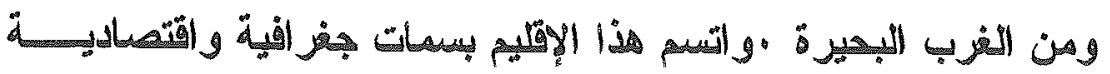

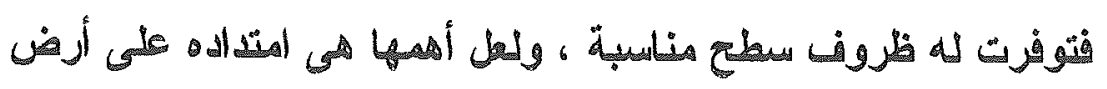

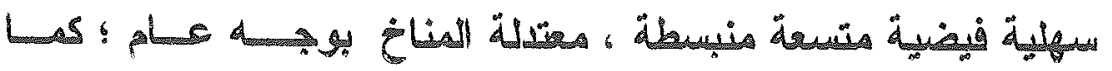

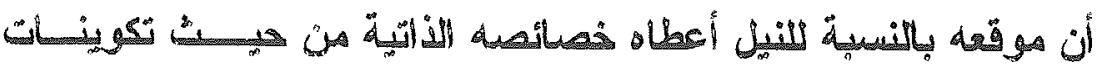

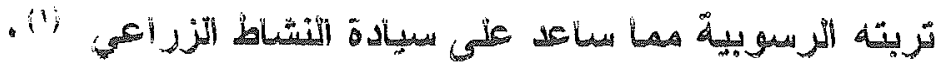

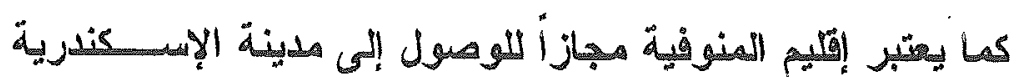

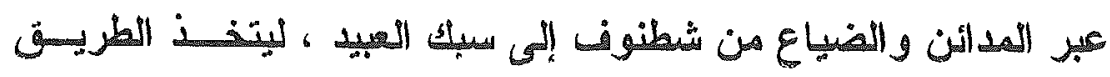

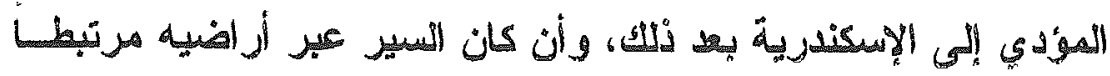

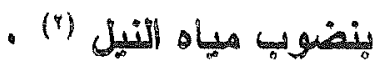

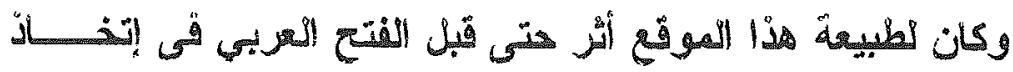

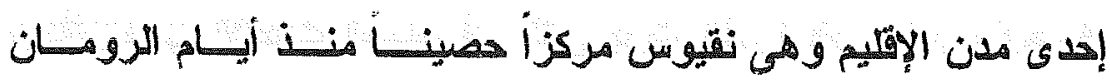
* في هفظ الطريق بين هصن بابليون متر القائد العام وبين عاصن

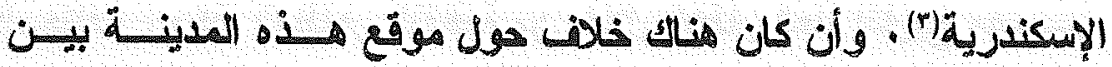

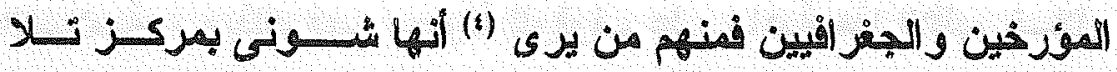

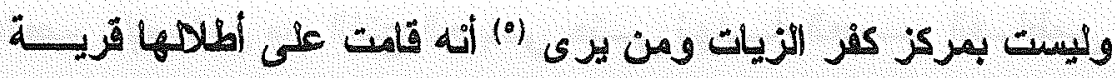

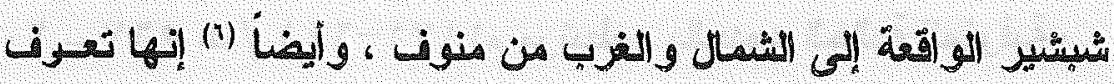

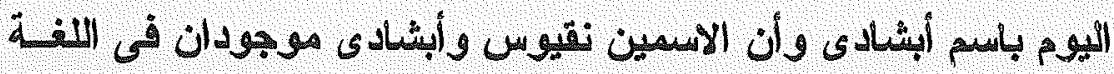

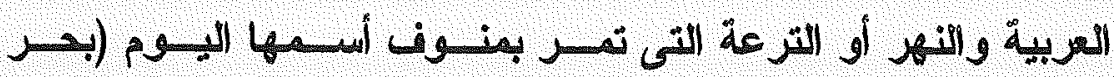

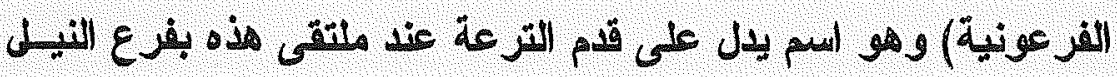




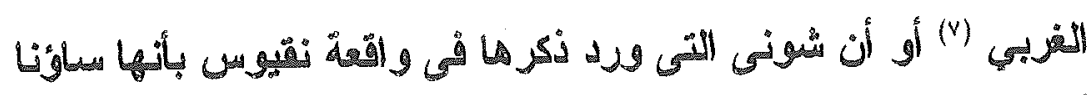

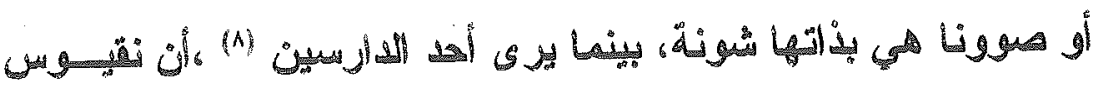

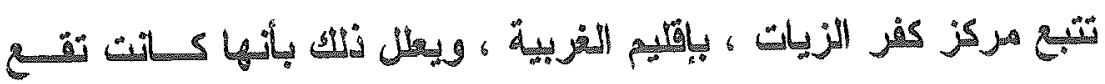

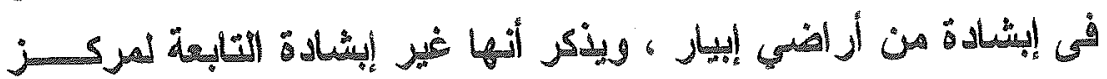

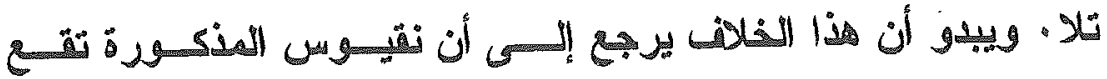

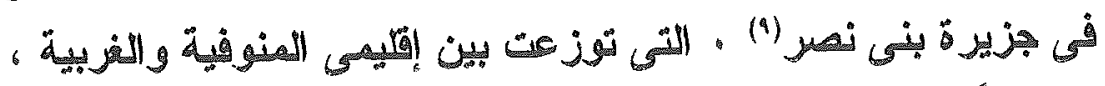

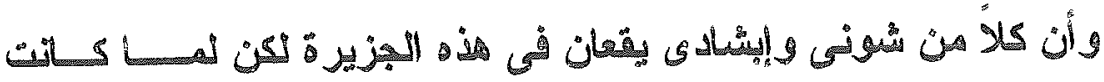

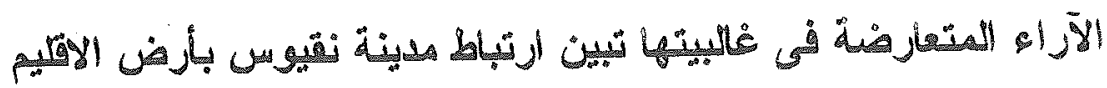

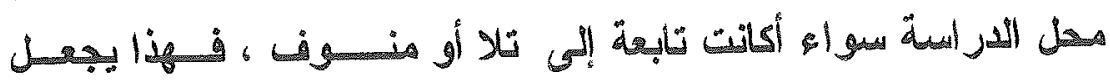

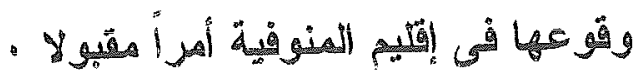

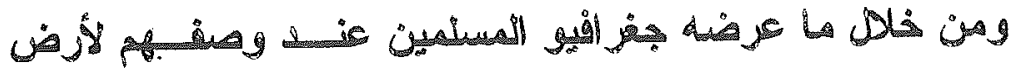

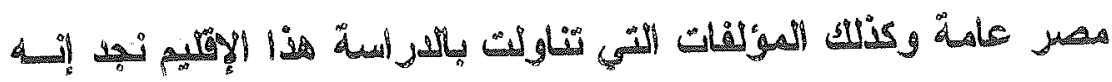

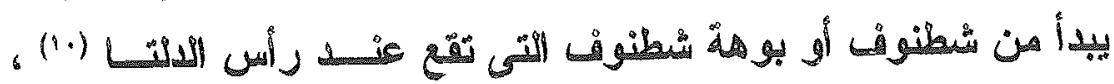

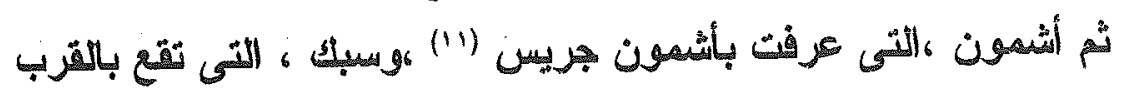

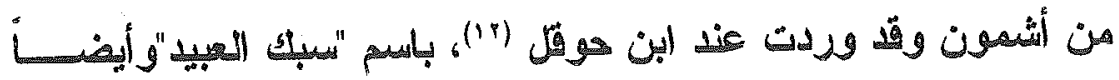

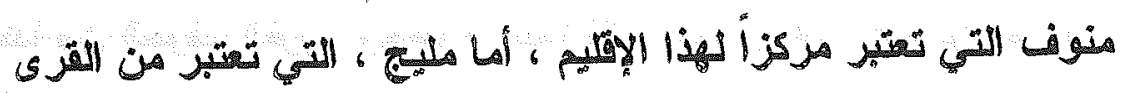

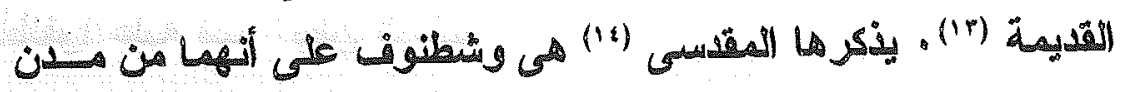

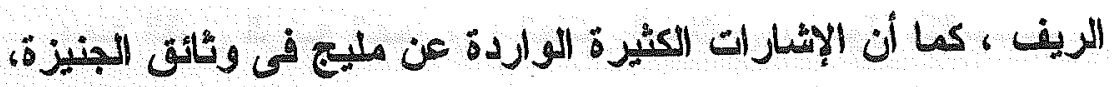

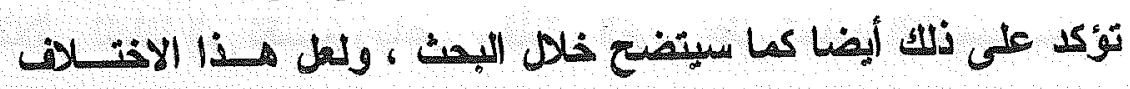

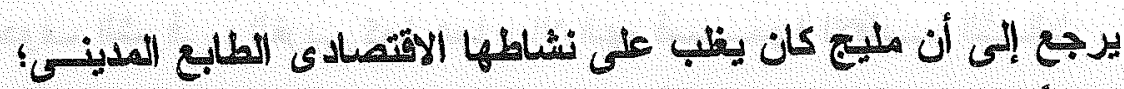

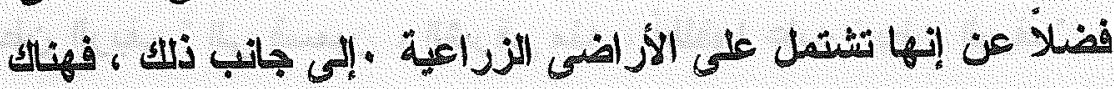

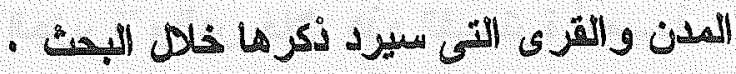

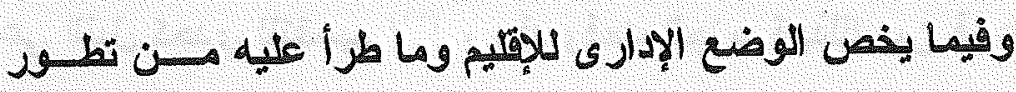

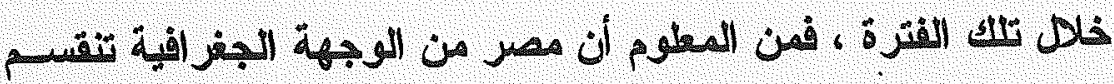




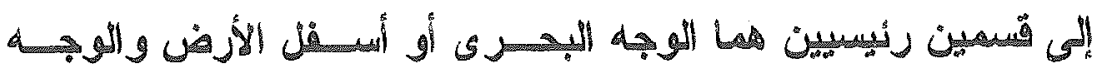

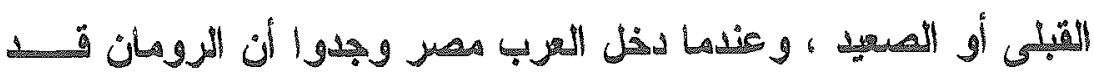

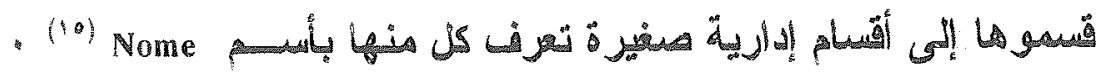

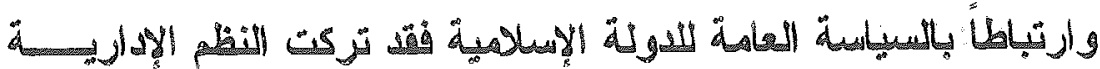

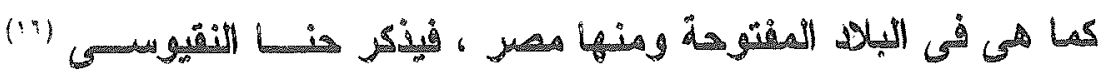

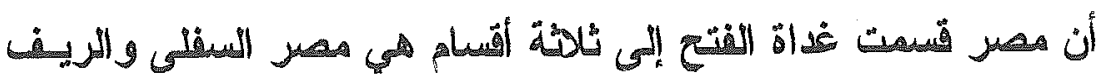

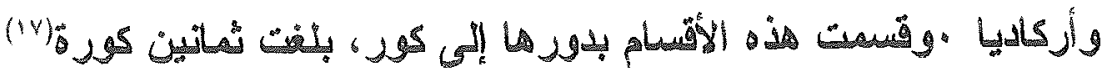

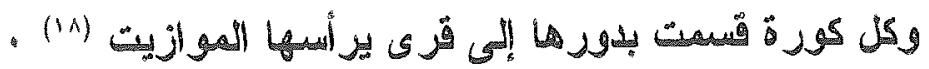

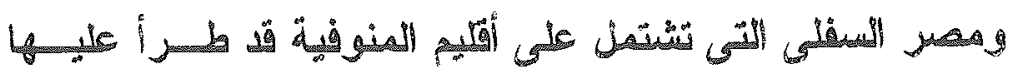

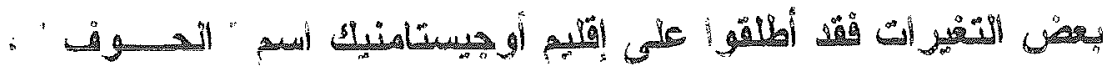

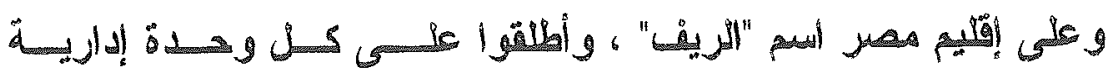

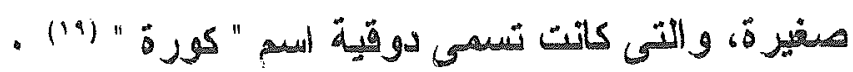

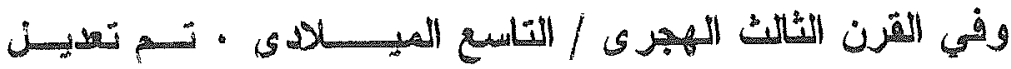

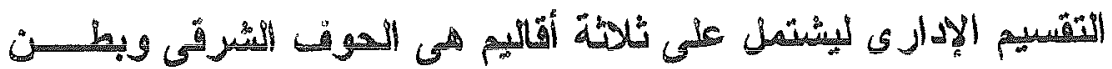

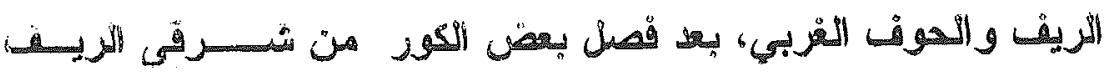

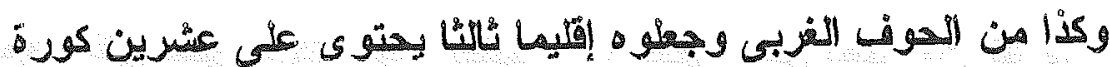

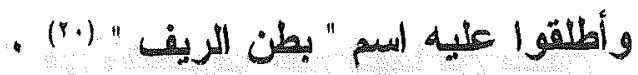

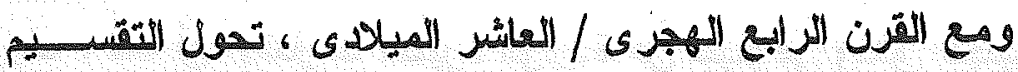

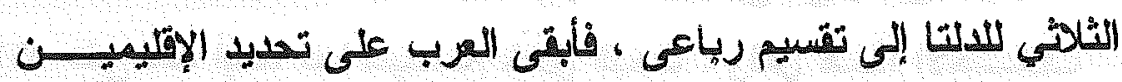

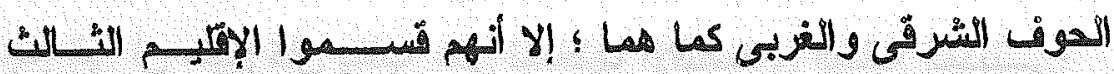

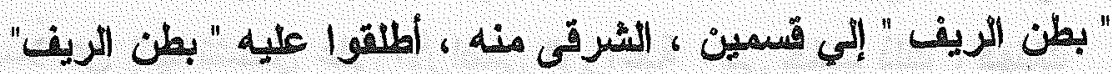

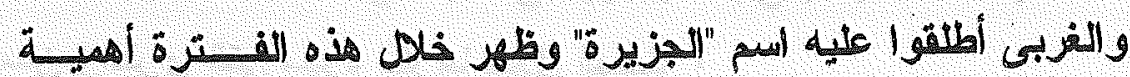

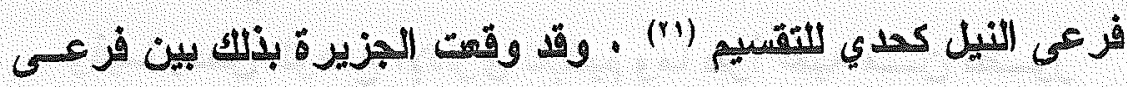




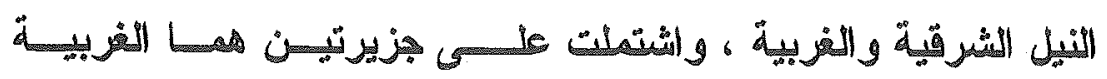
والمئوفئة (194)

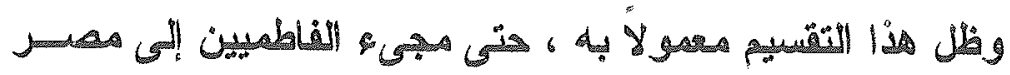

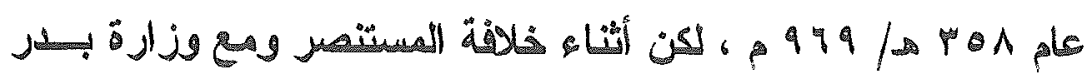

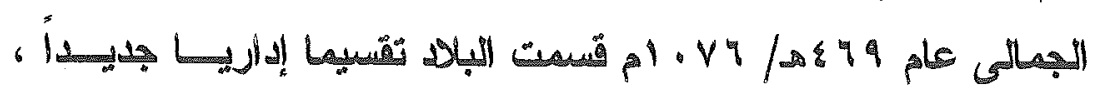

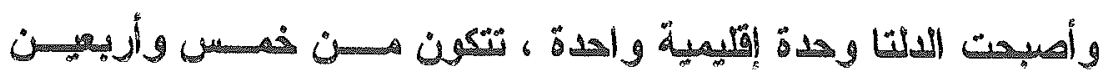

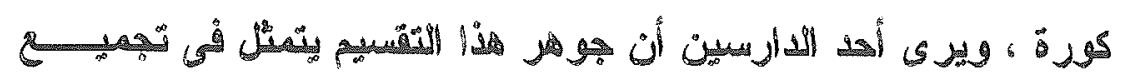

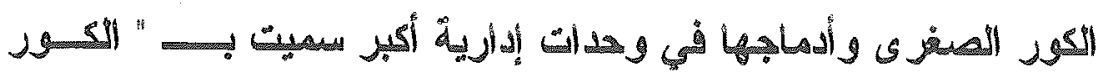

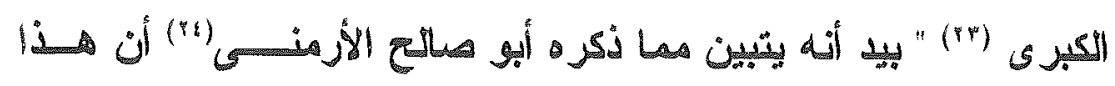

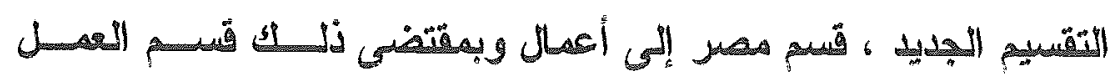

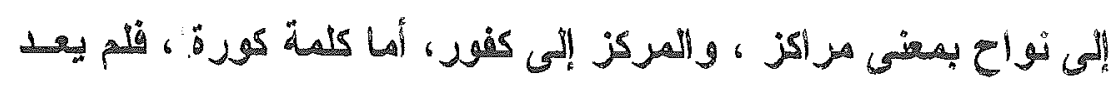
( (")

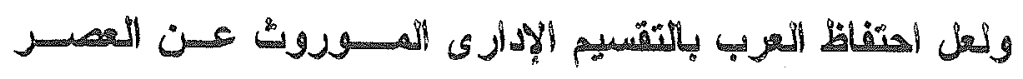

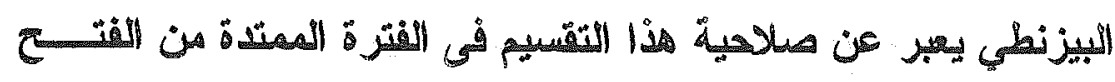

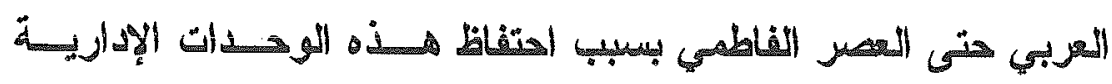

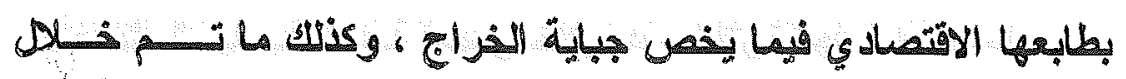

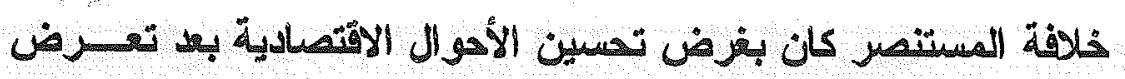

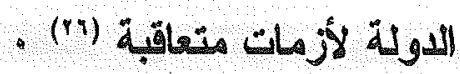

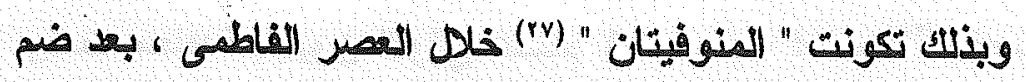

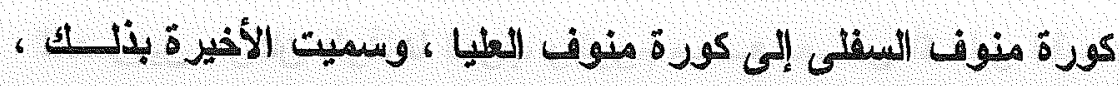

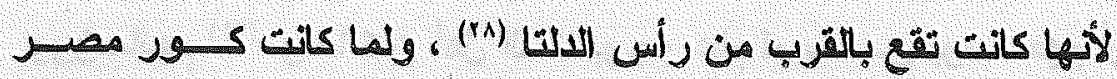

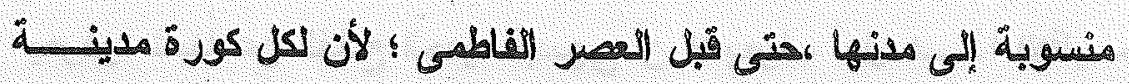

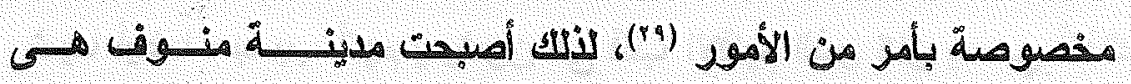




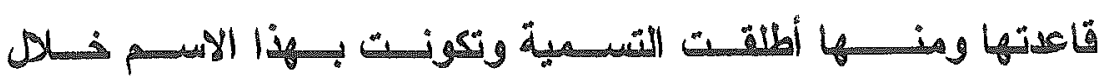

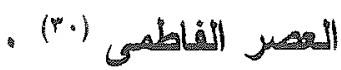

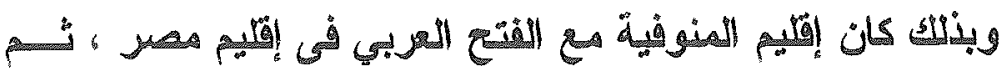

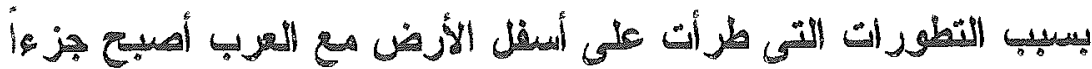

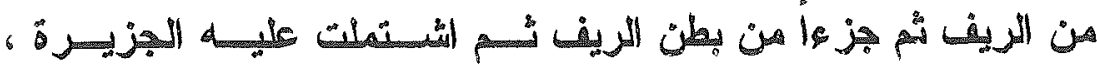

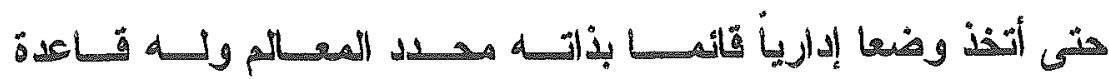
هنسوب إليها

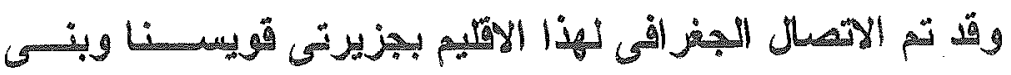

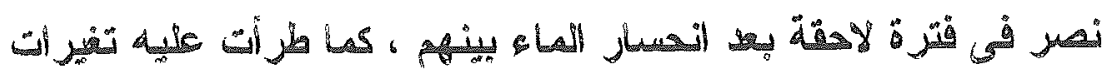

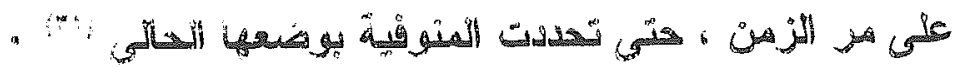

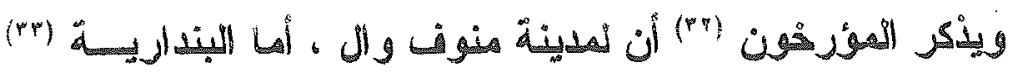

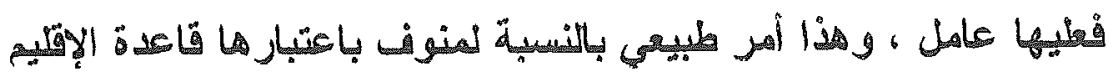

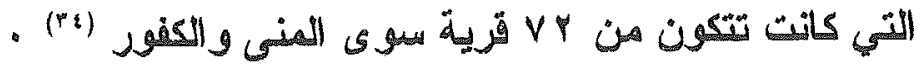

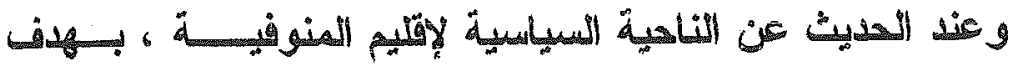

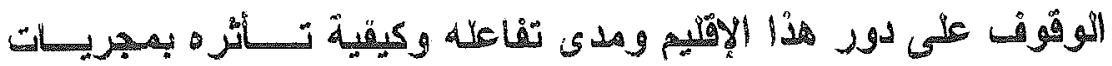

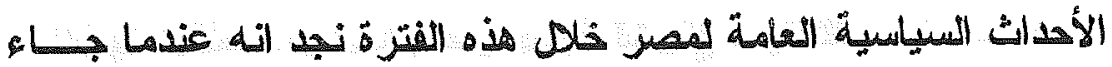

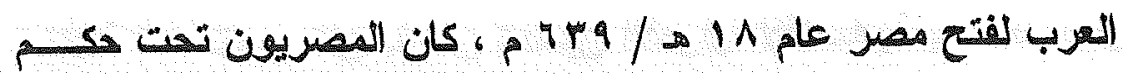

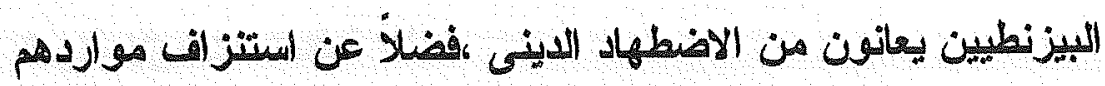

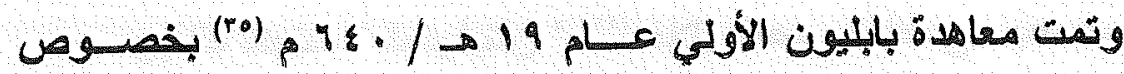

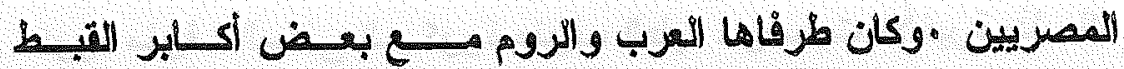

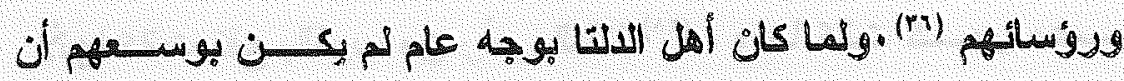

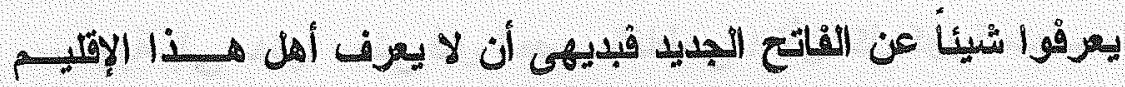

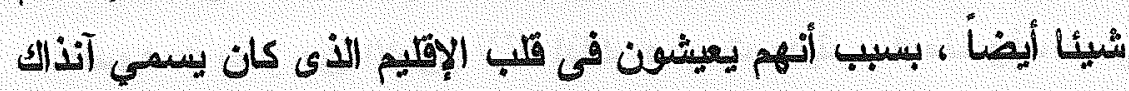

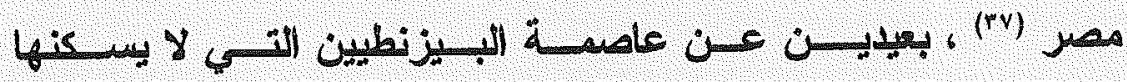




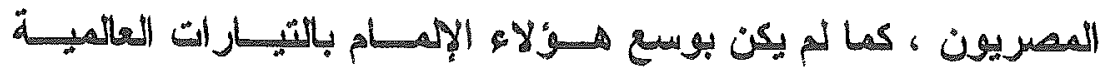

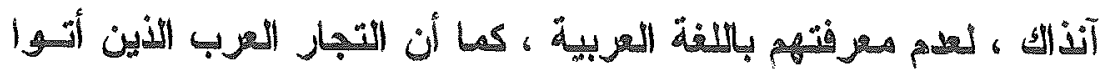

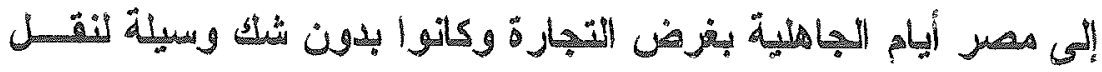

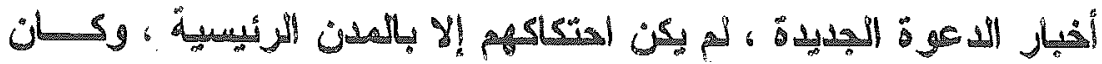

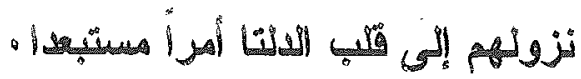

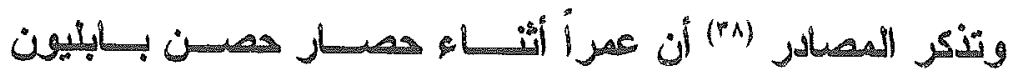

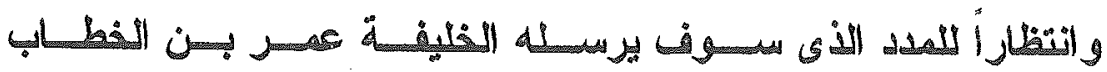

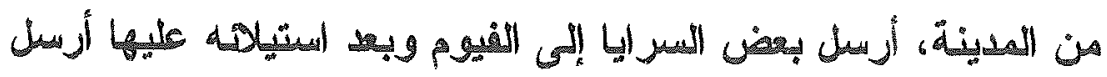

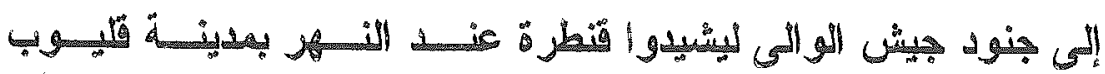

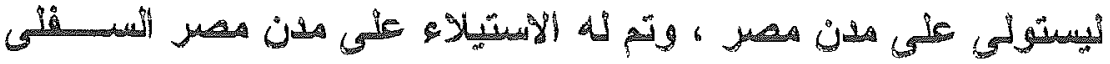

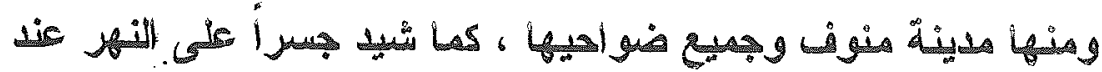

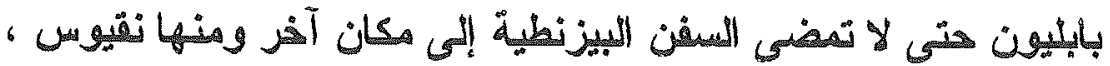

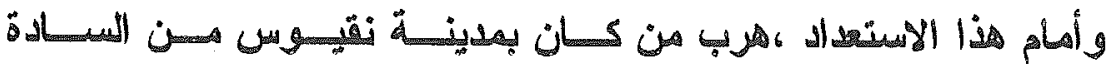

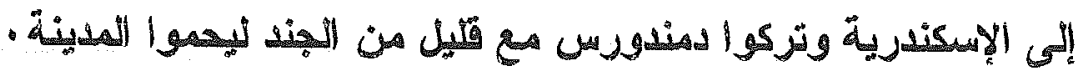

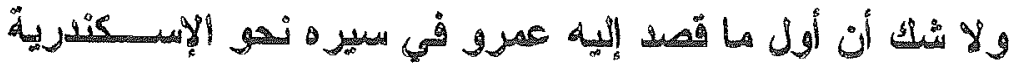

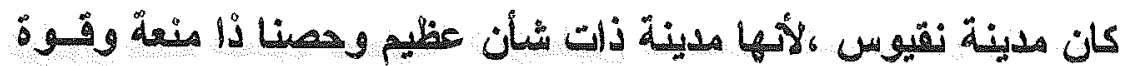

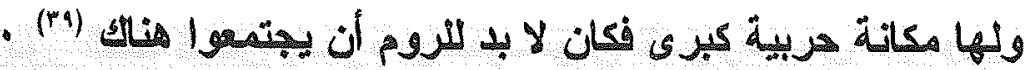
ومع أن هاكم سمنود انضم إلى القائد الثيزنطى لدرب المسكين؛

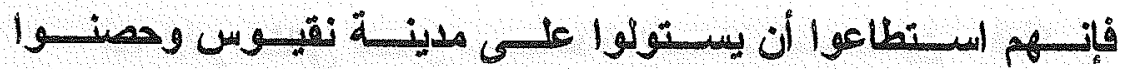

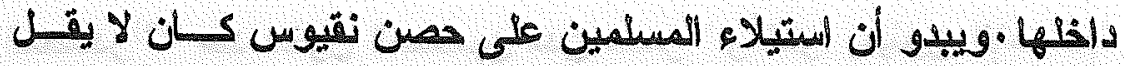

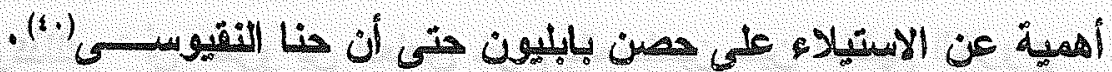

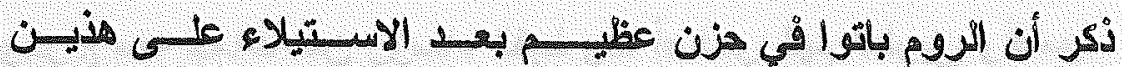





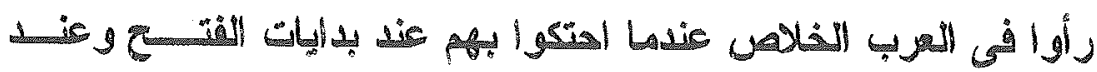

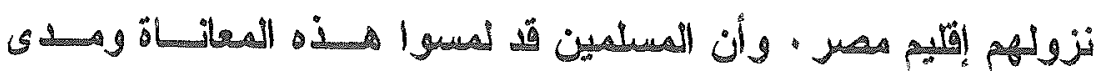

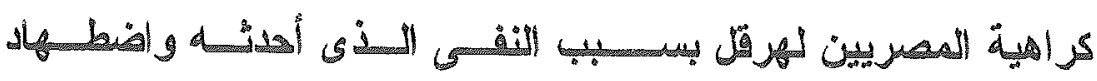

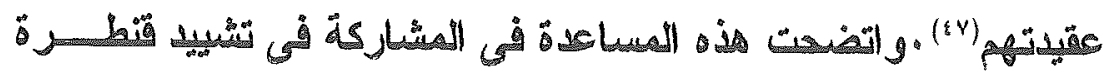

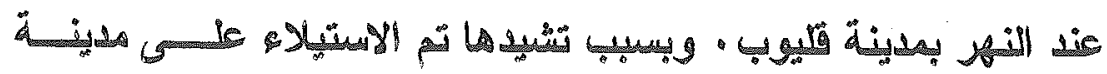

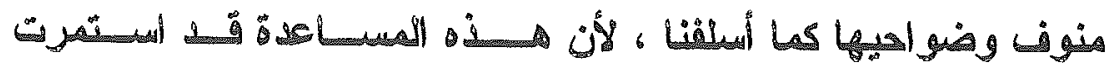

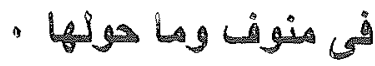

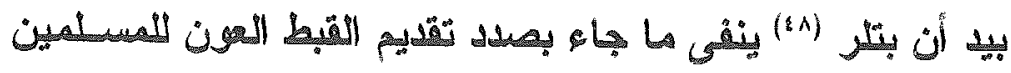

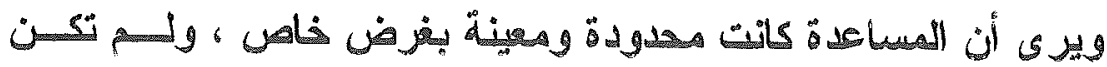

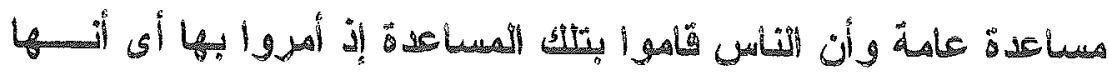

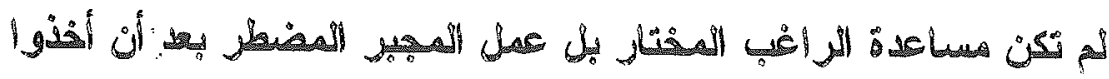

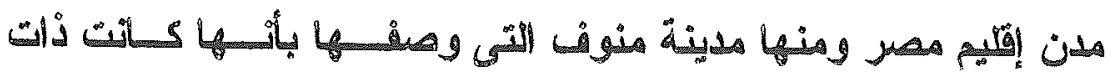

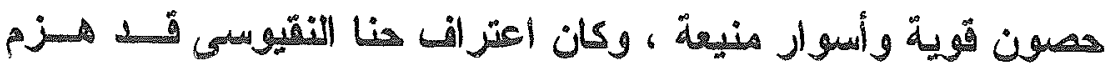

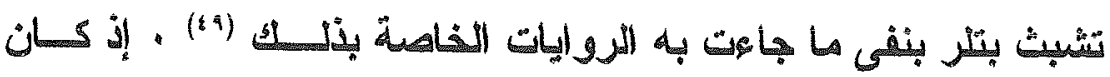

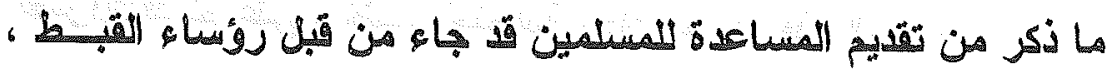

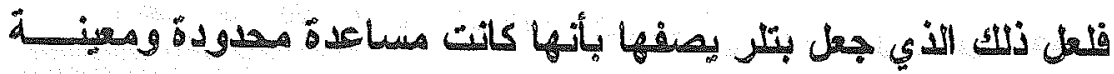

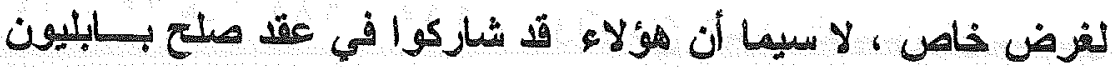

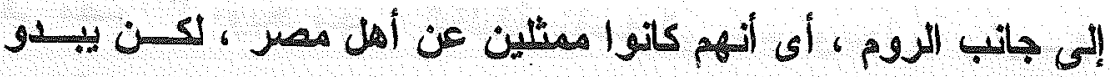

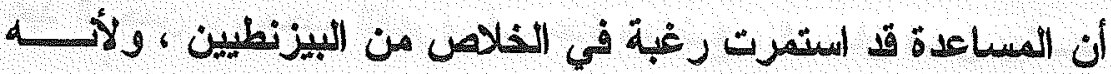

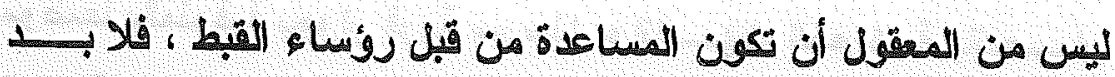

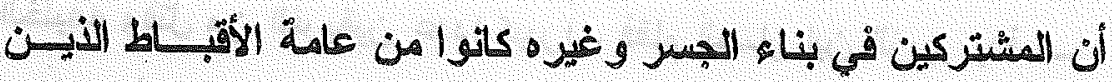
- عانوا أكثر من غير هم من منالم الروم البيزنمينين

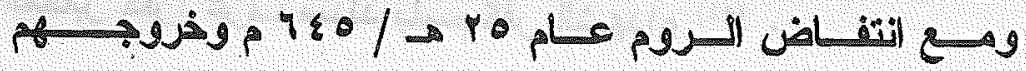

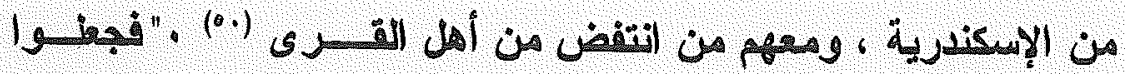




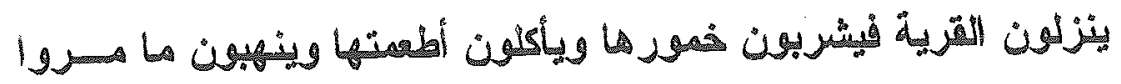

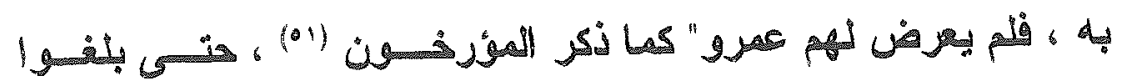

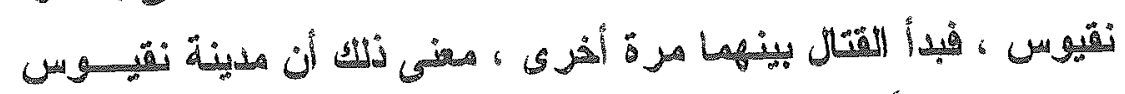

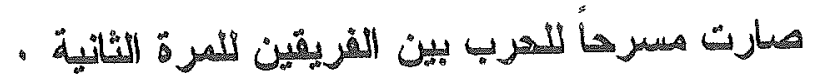

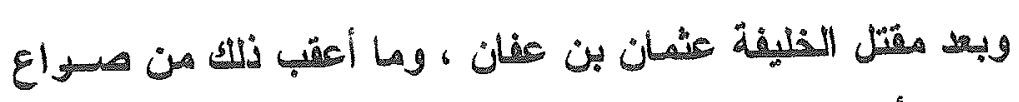

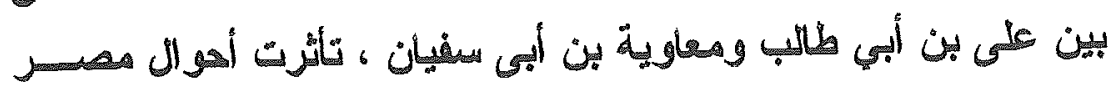

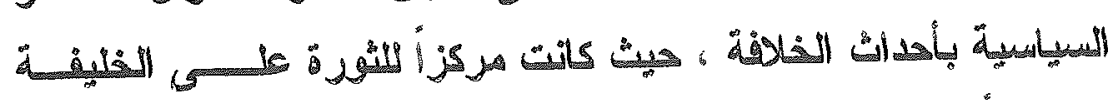

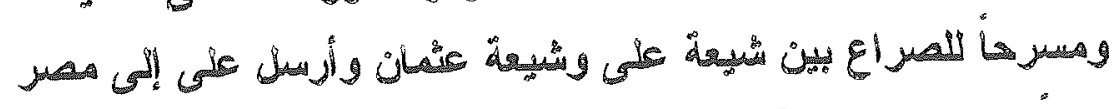

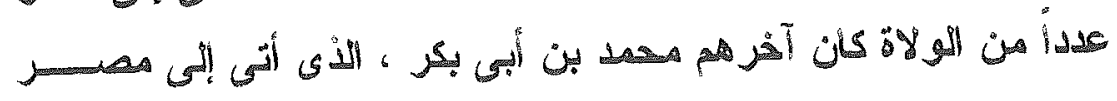

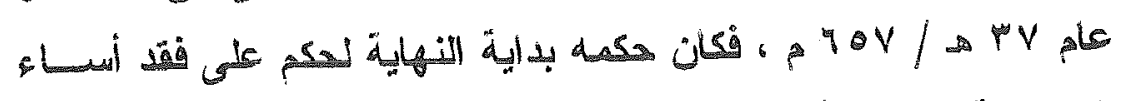

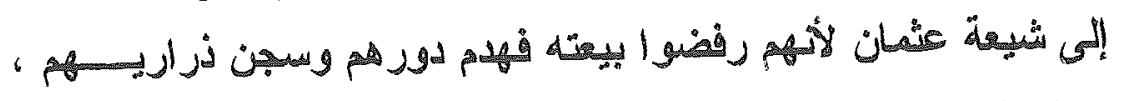

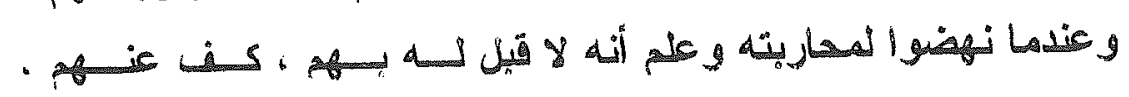

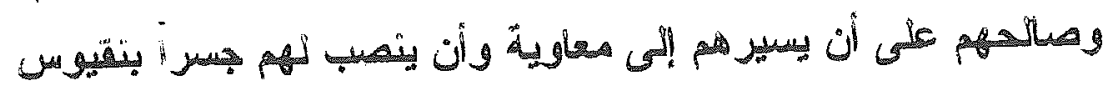

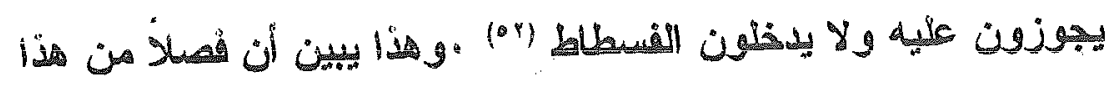

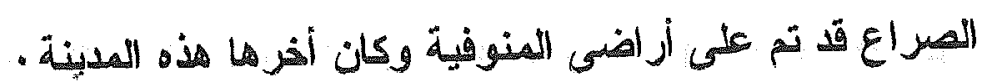

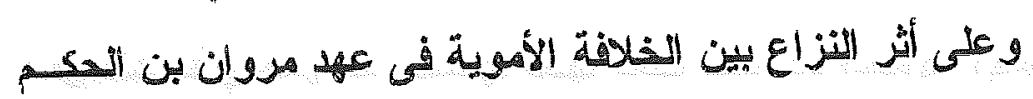
\&

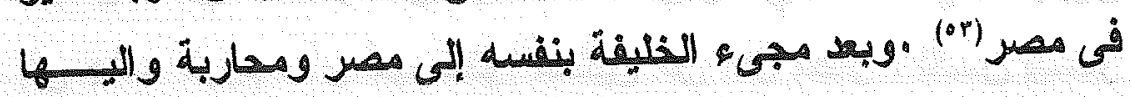

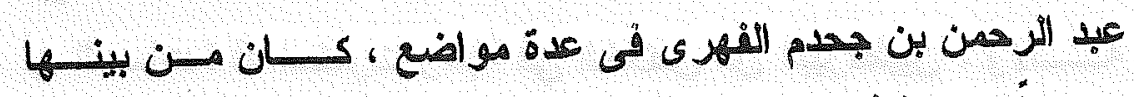

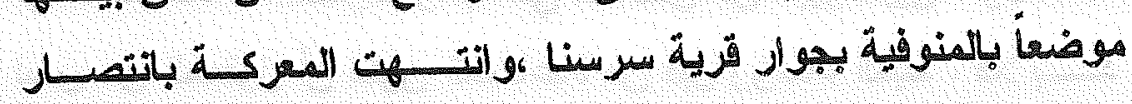

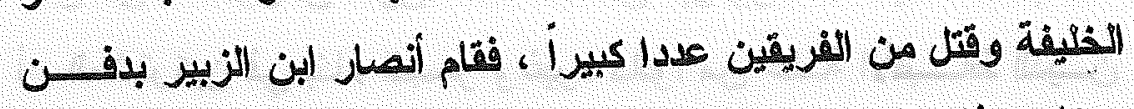

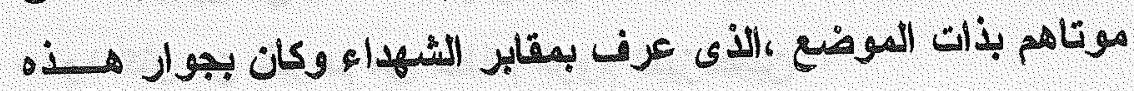

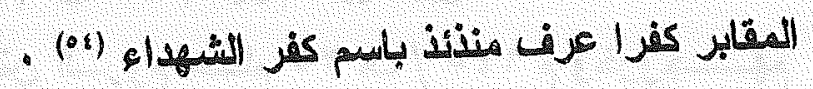




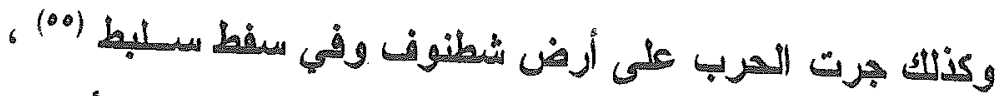

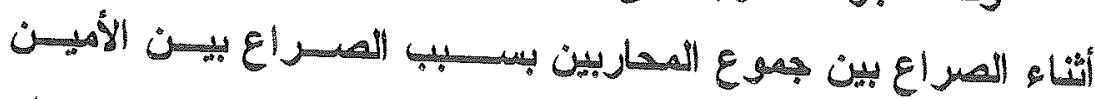

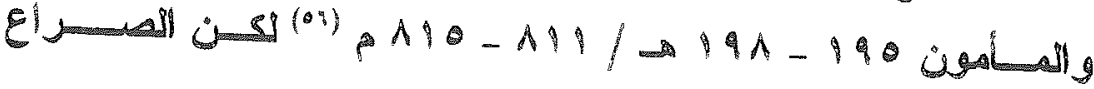

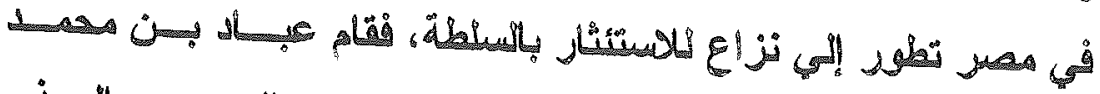

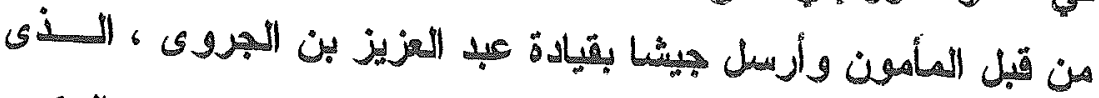

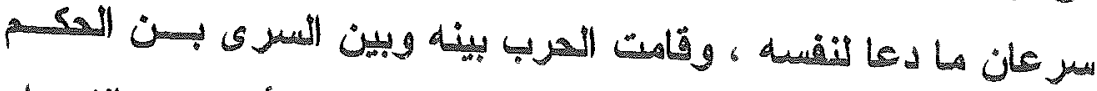

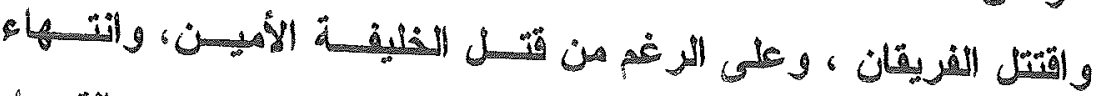

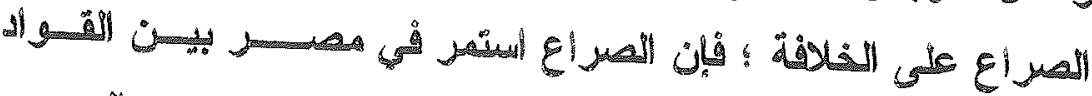

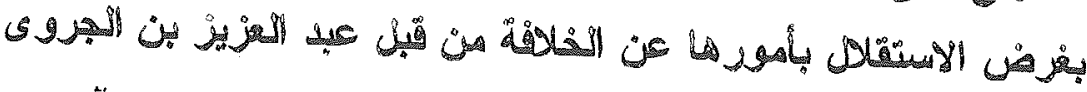

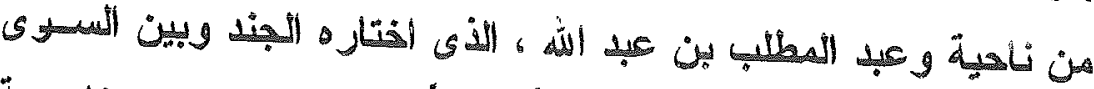

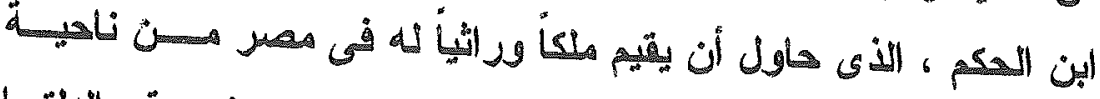

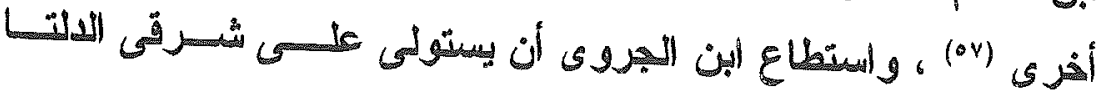

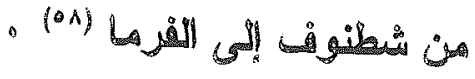

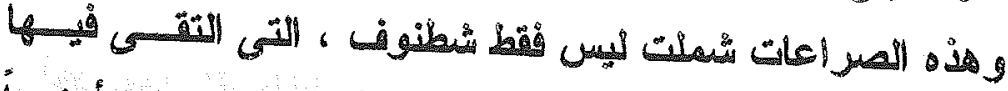

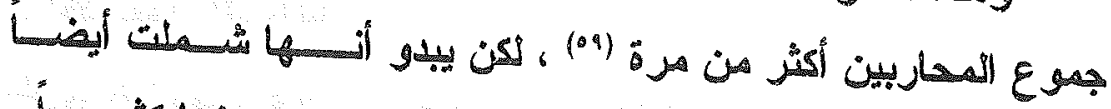

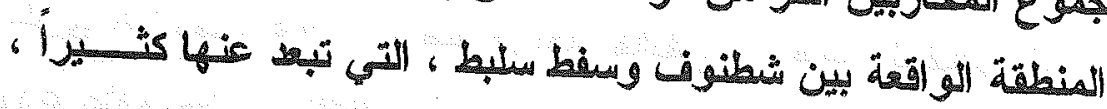

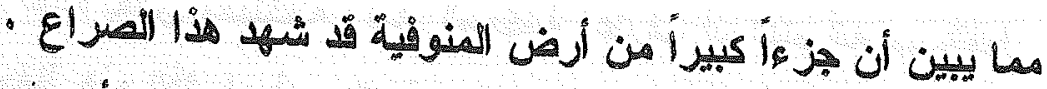

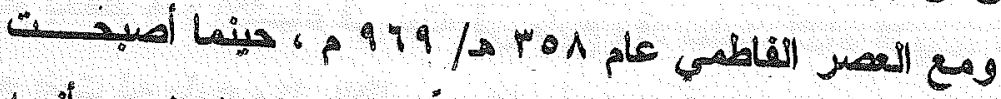

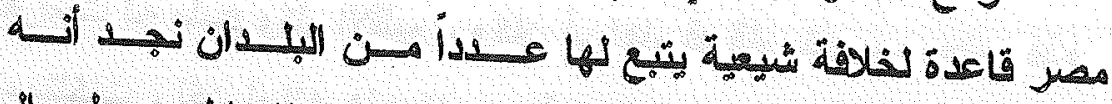

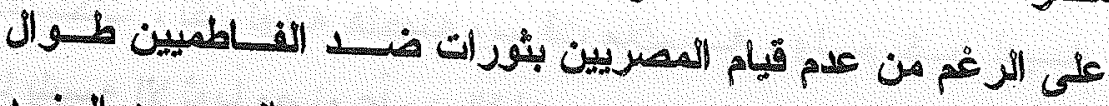

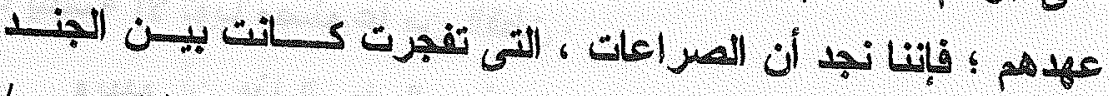

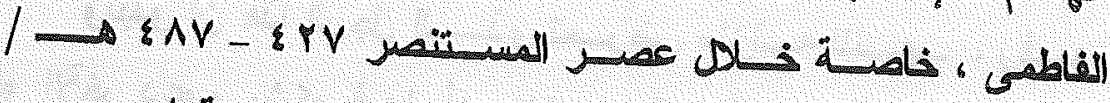

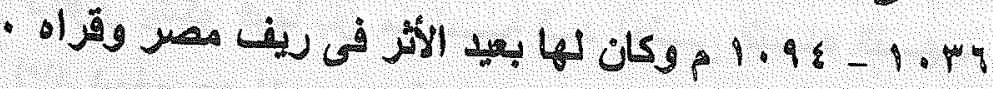




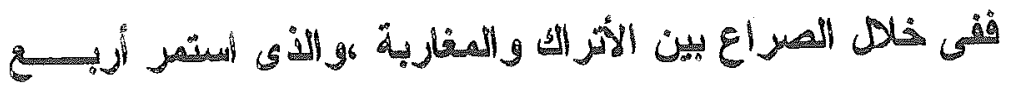

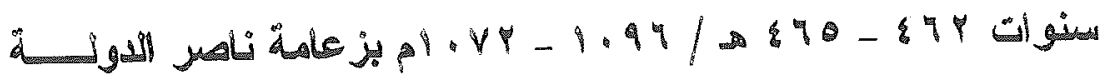

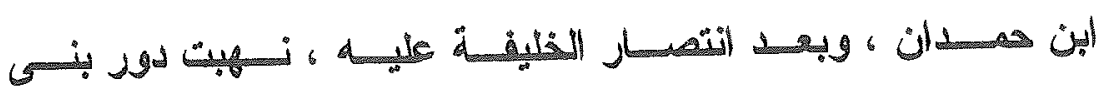

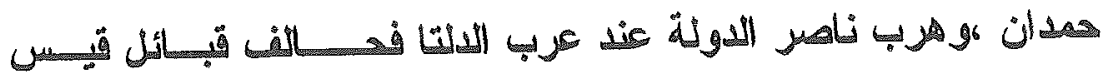

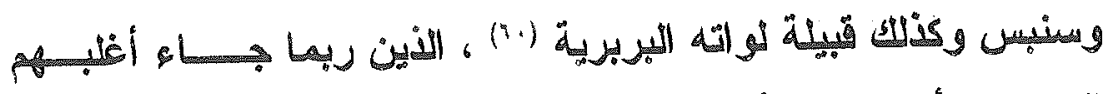

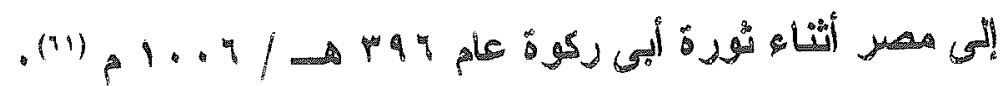

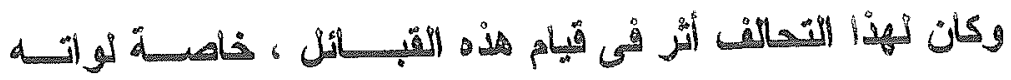

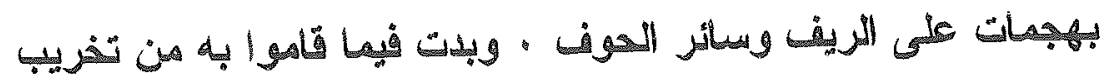

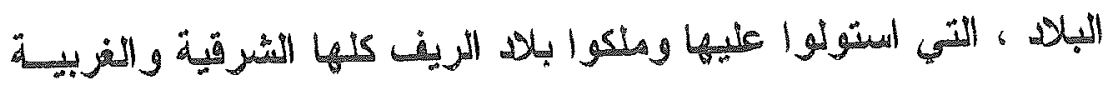

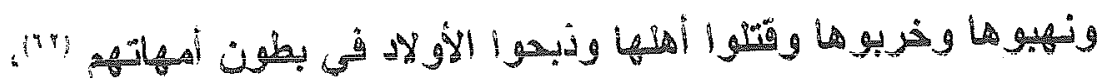

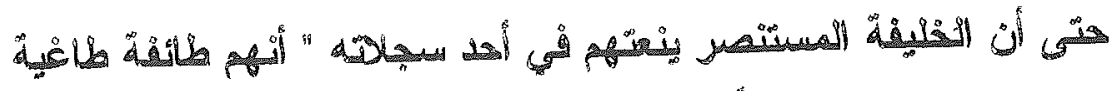

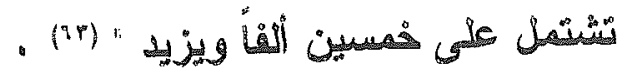

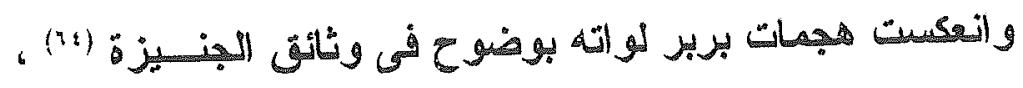

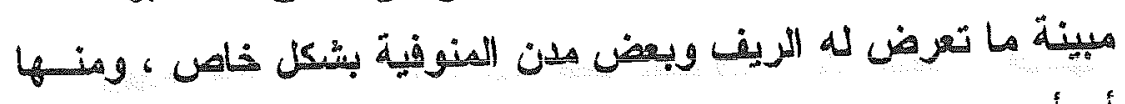

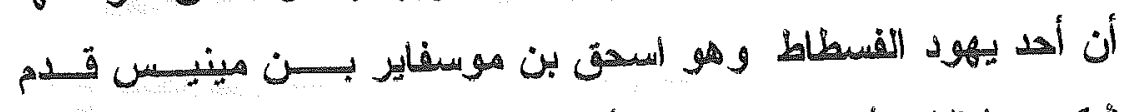

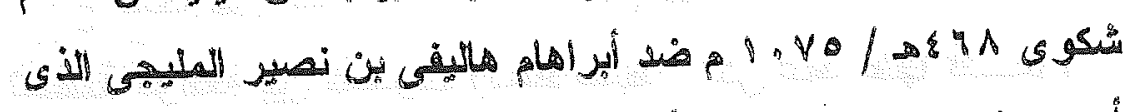

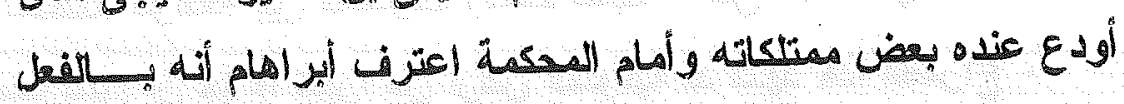

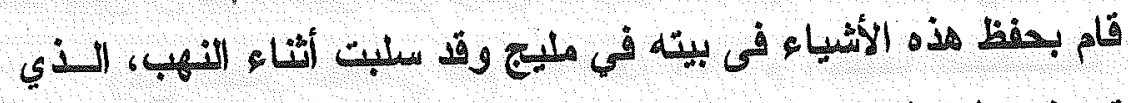

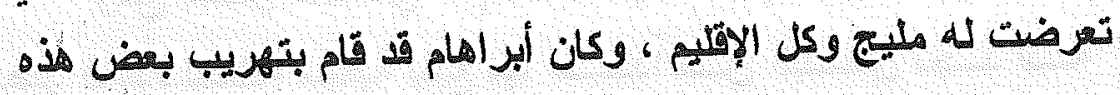

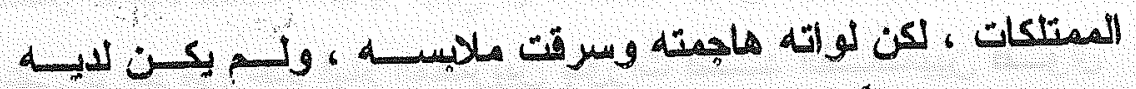

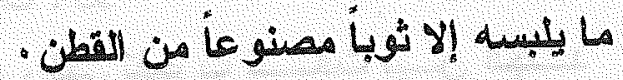

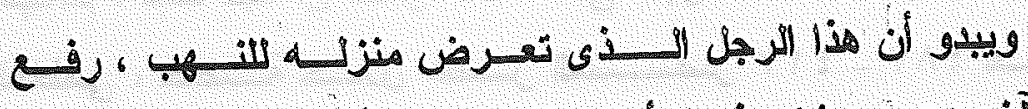

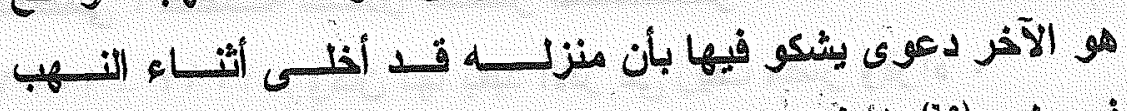

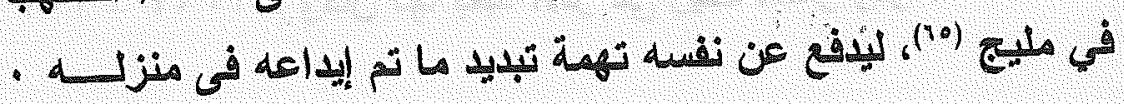




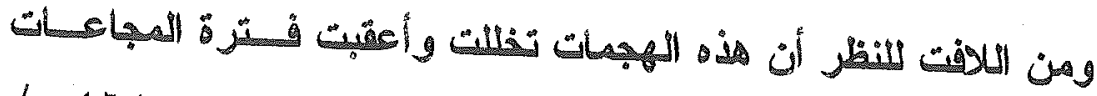

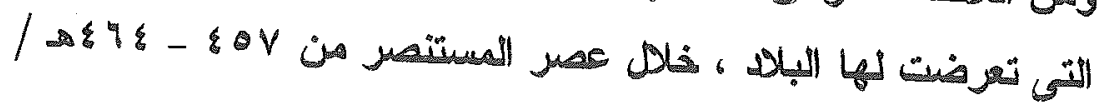

$$
\text { . (iq) } 1 \cdot V_{1}-1.90
$$

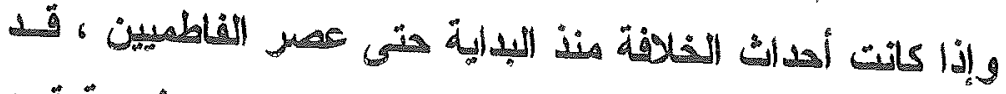

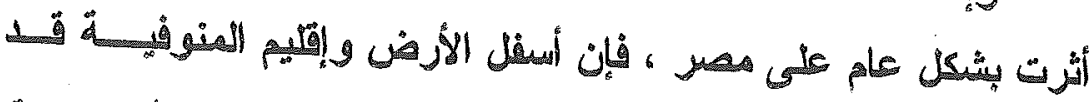

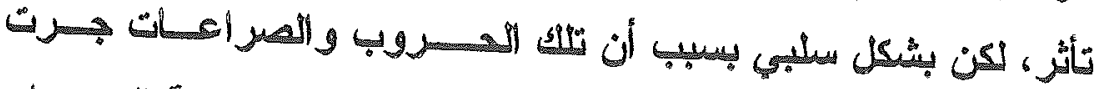

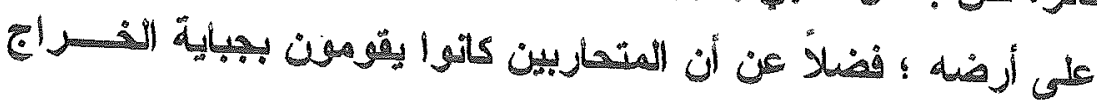

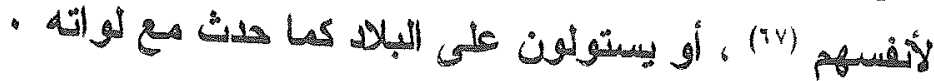

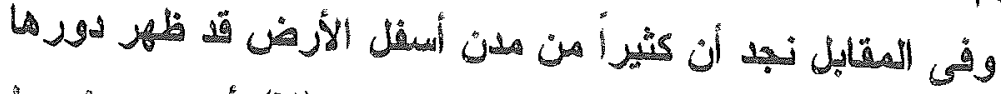

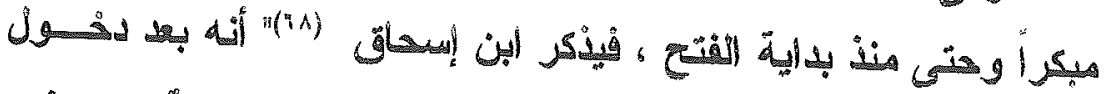

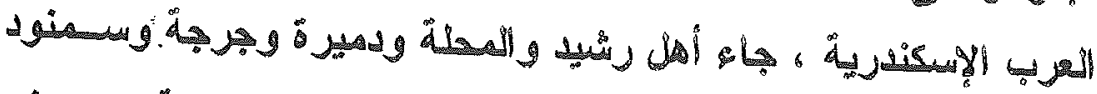

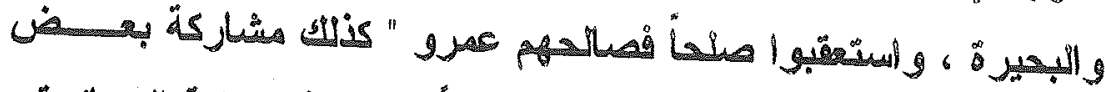

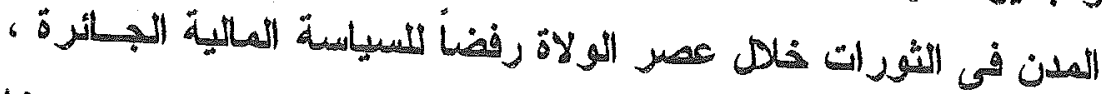

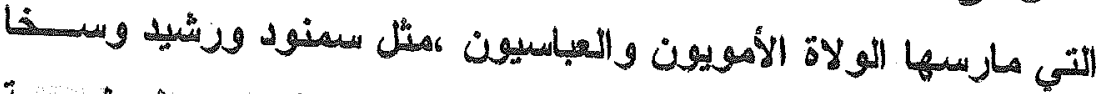

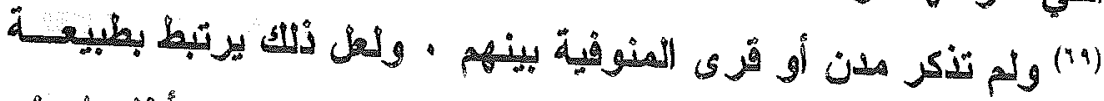

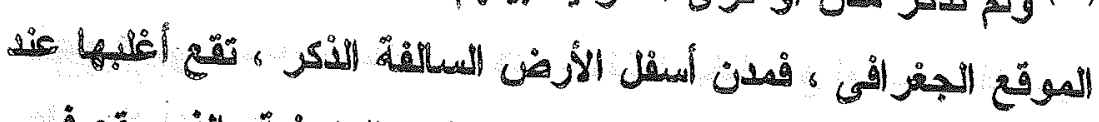

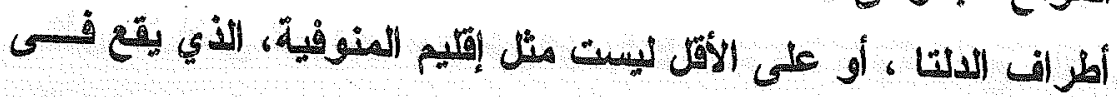

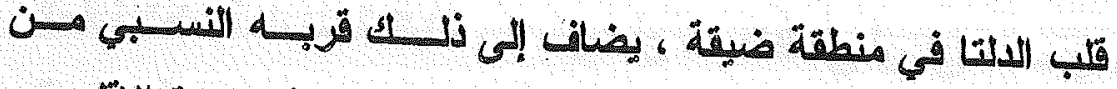

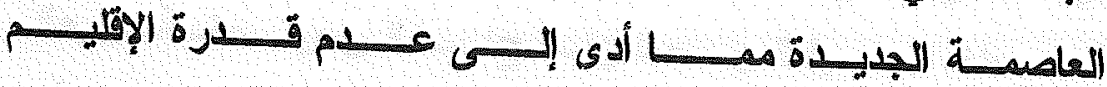

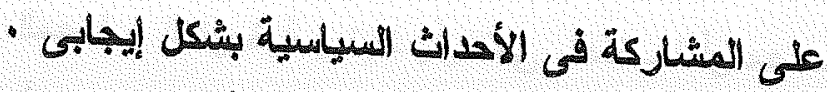

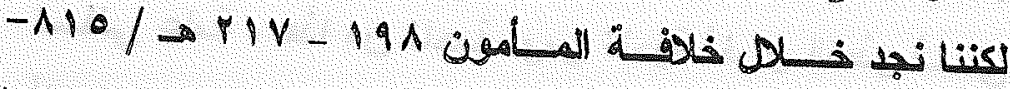

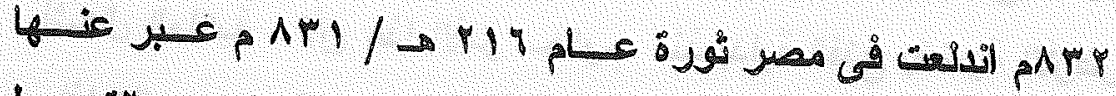

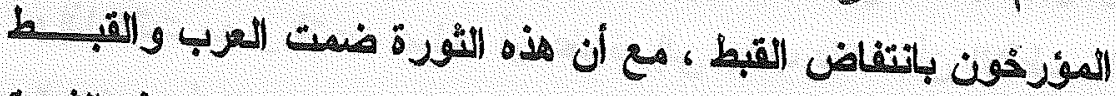

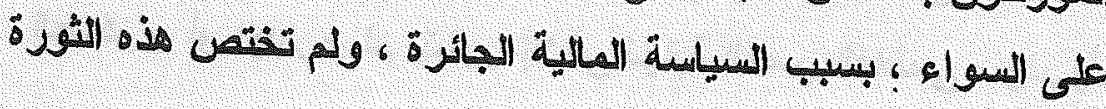




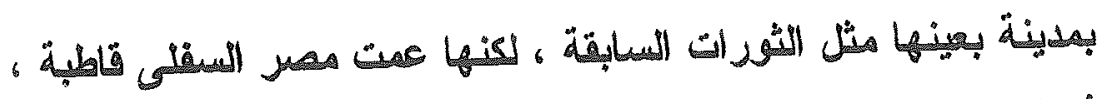

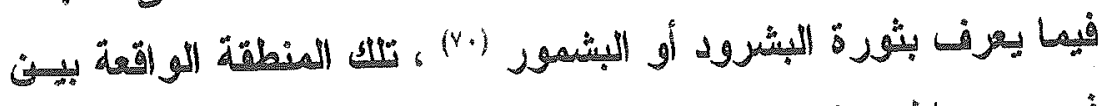

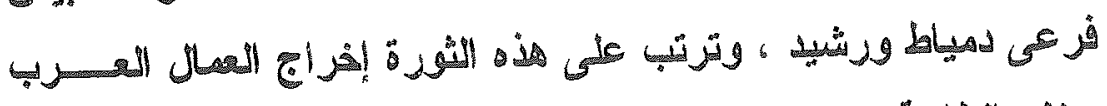

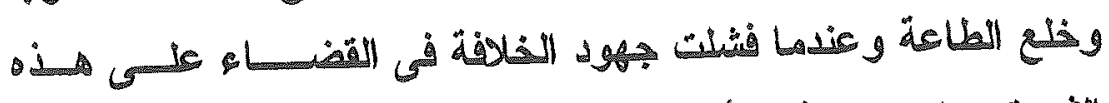

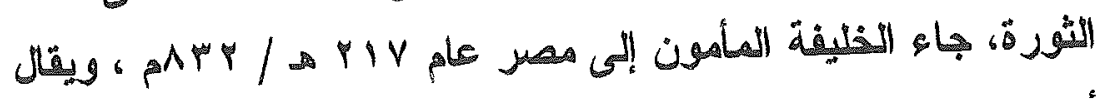

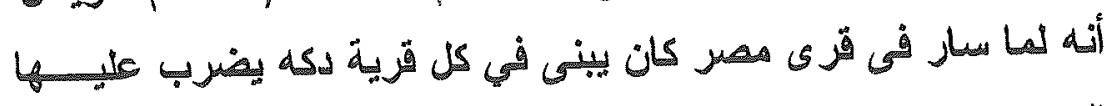

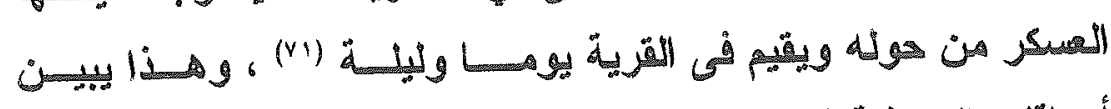

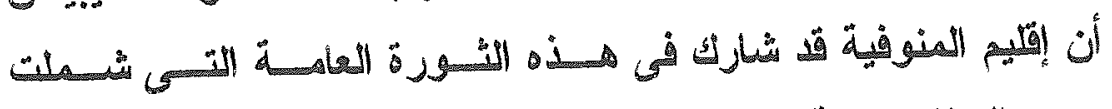
مصر البيفلي عامةلة

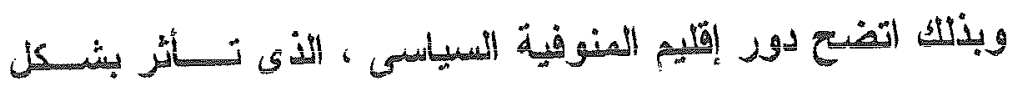

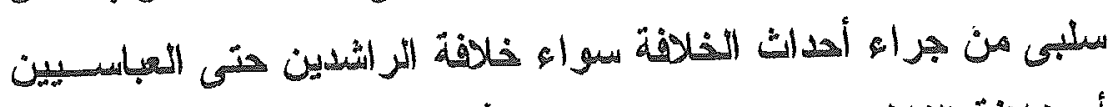

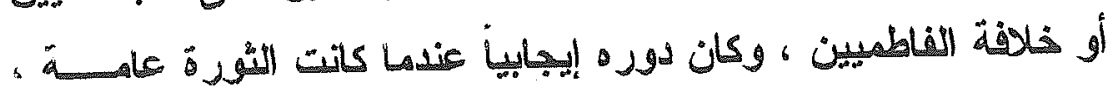

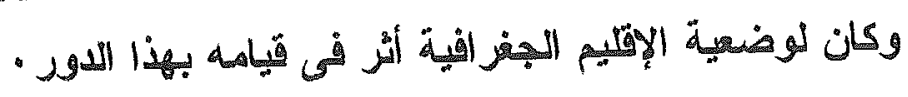

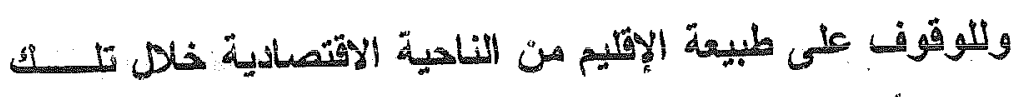

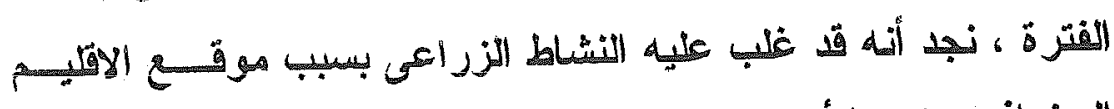

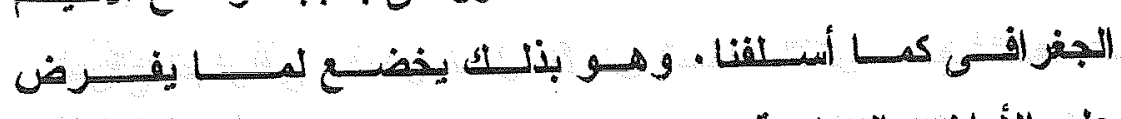

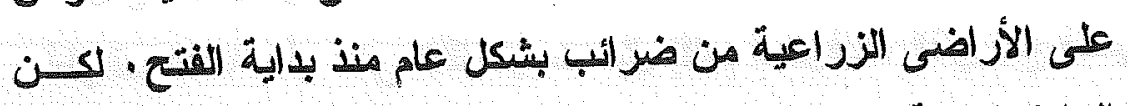

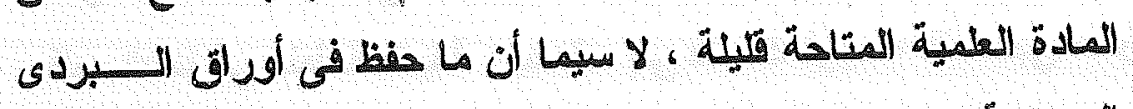

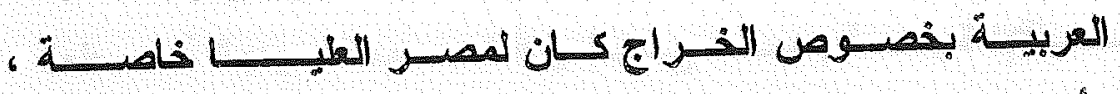

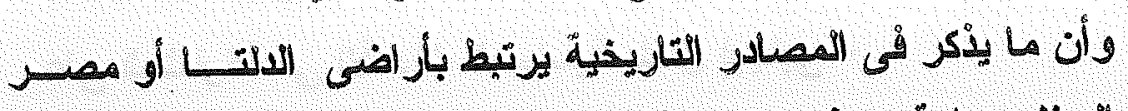

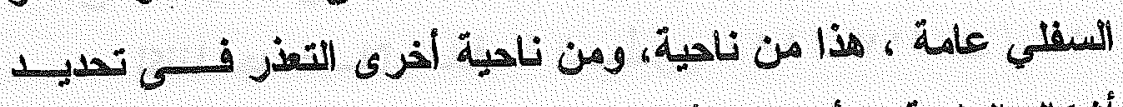

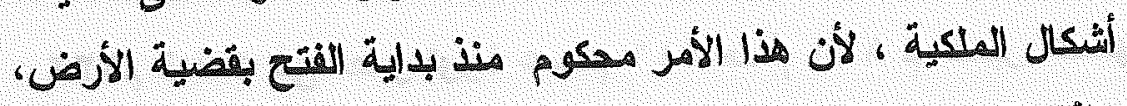

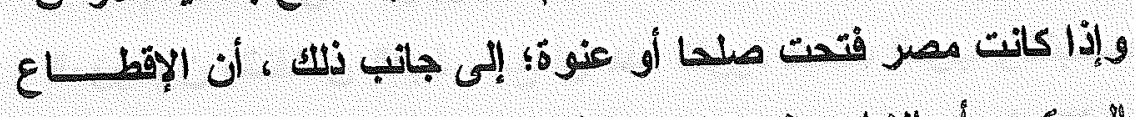

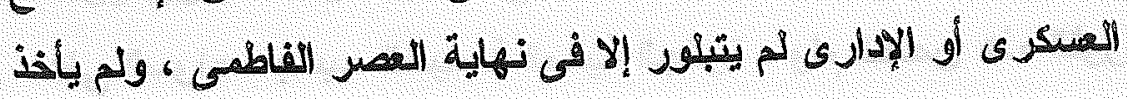




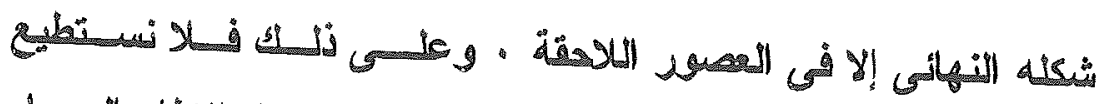

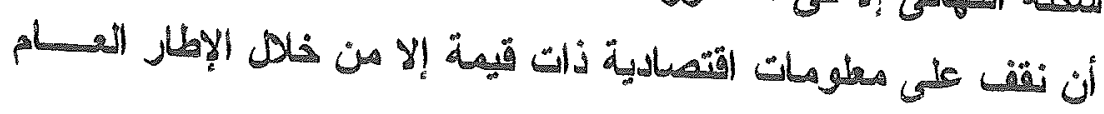

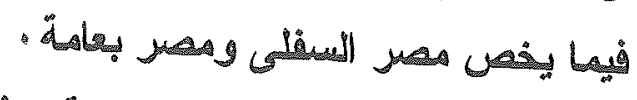

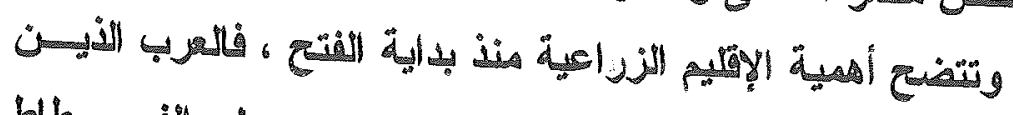

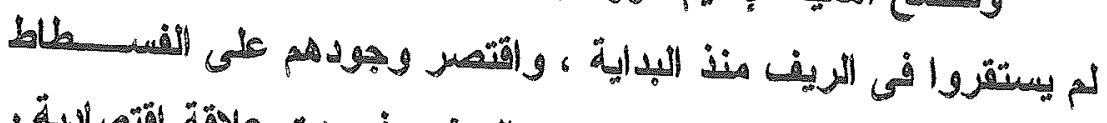

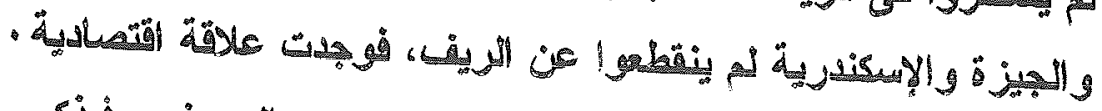

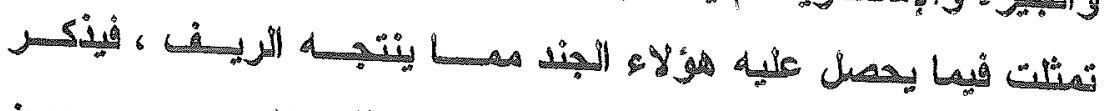

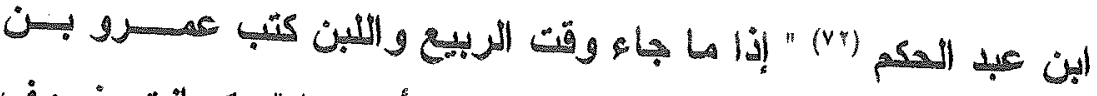

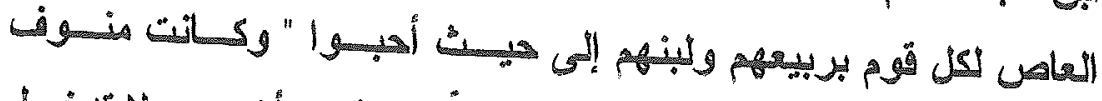

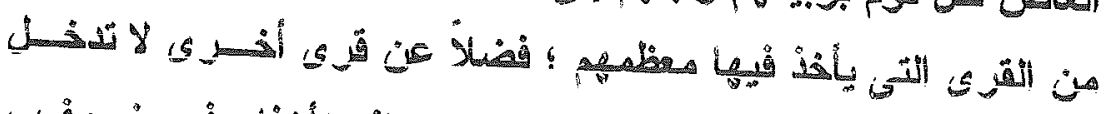

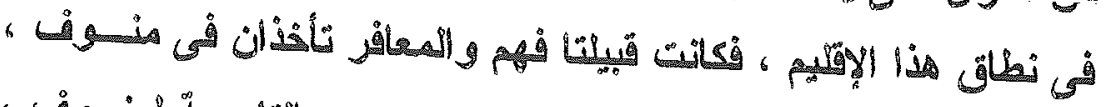

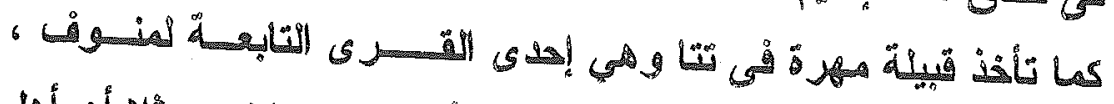

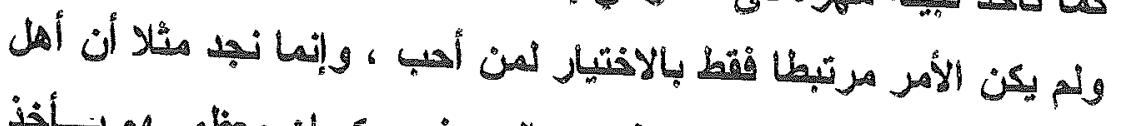

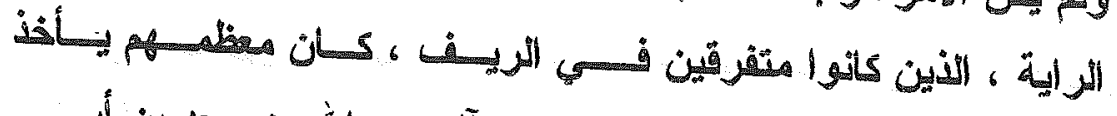

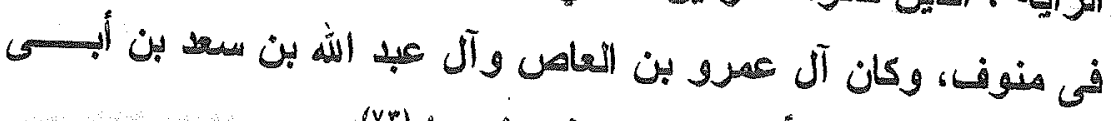

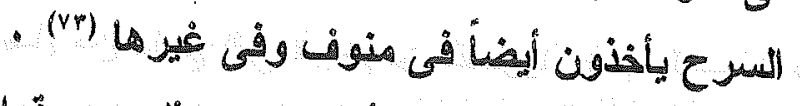

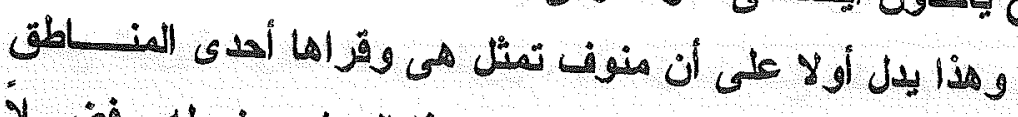

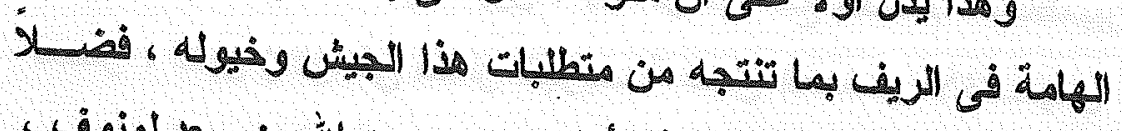

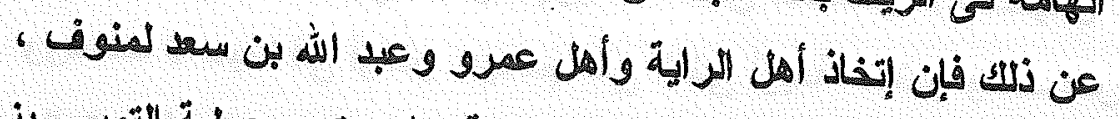

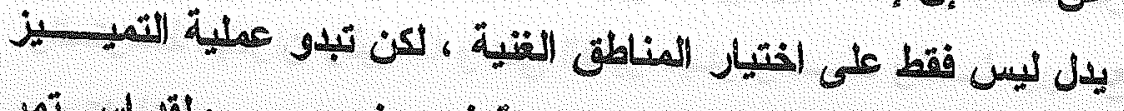

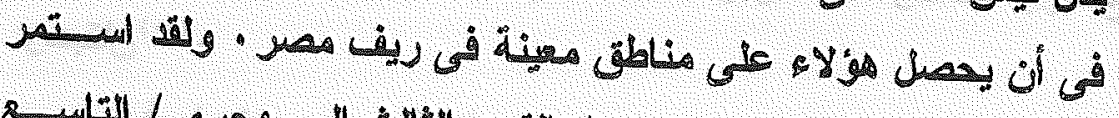

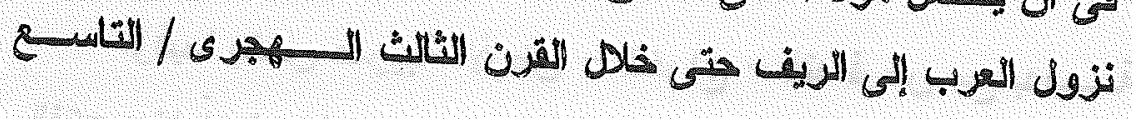

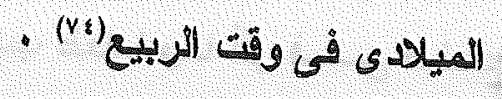




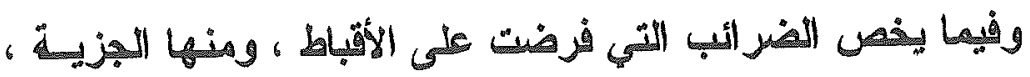

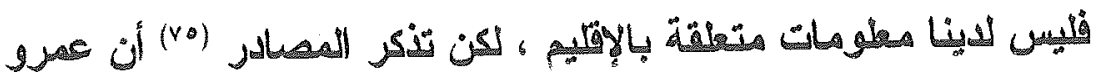

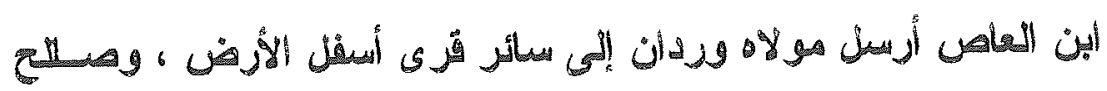

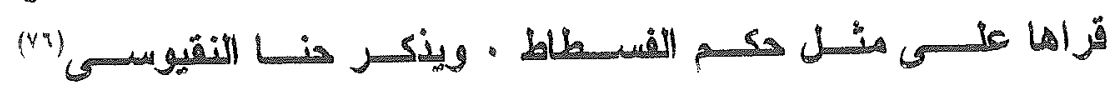

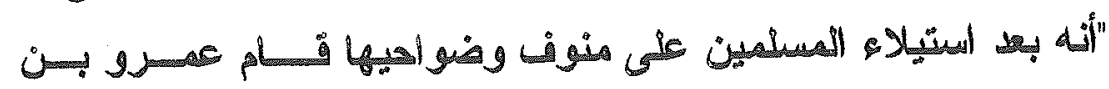

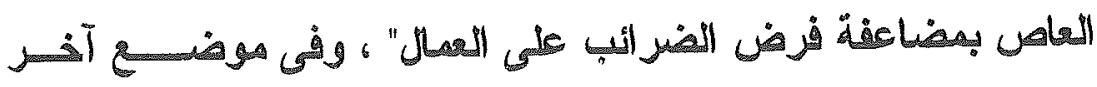

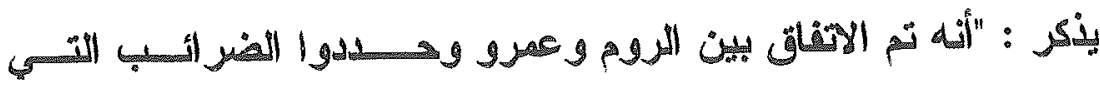

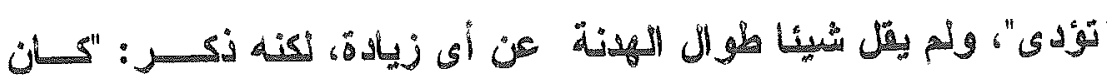

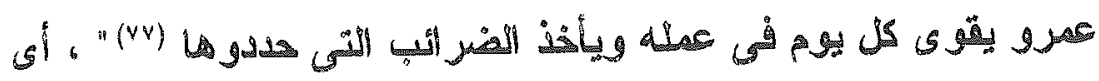

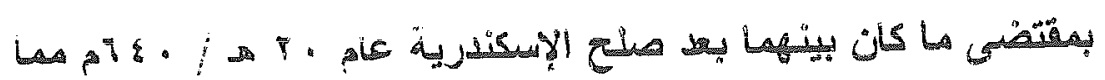

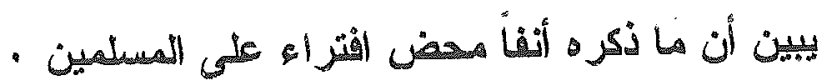

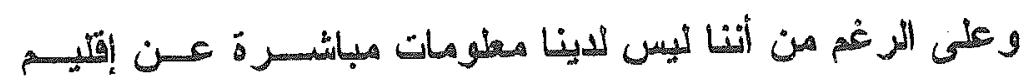

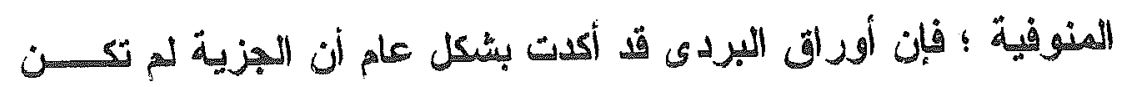

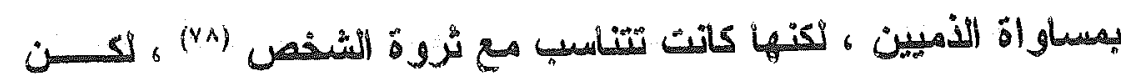

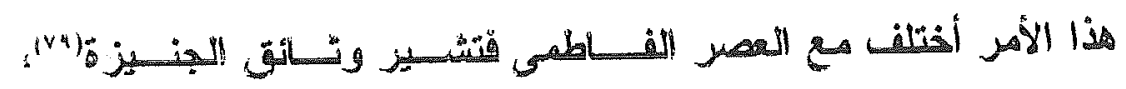

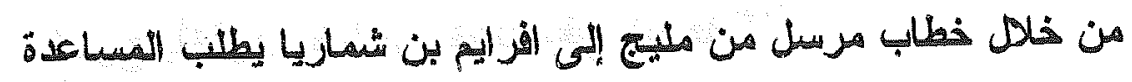

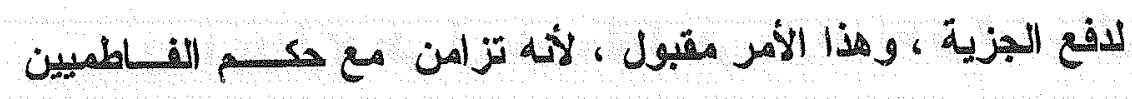

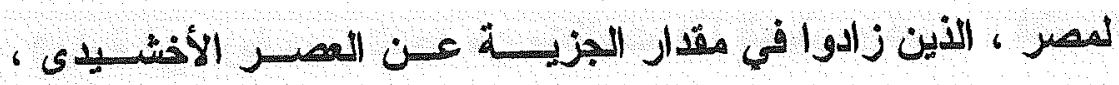

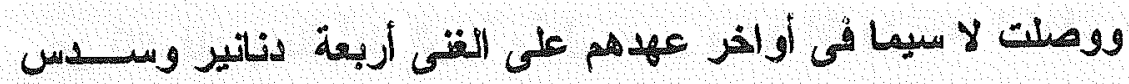

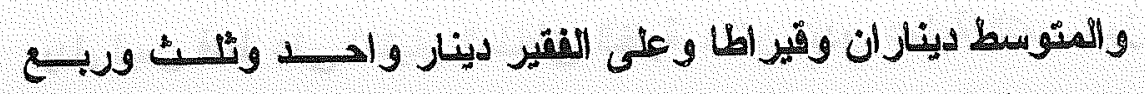

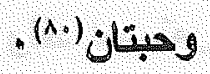

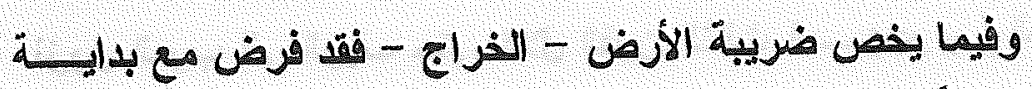

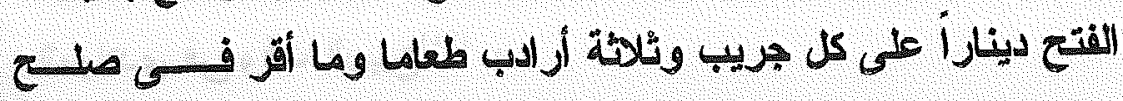

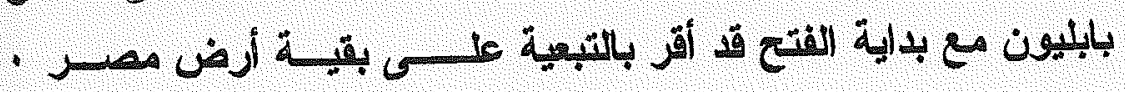




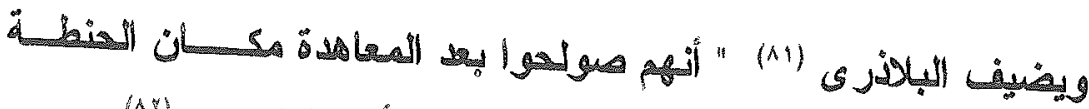

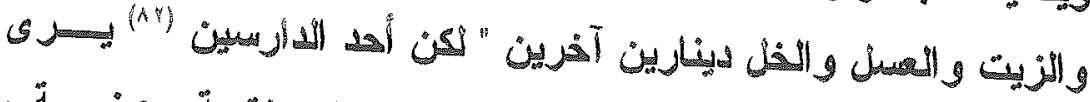

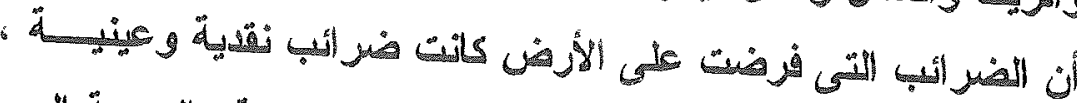

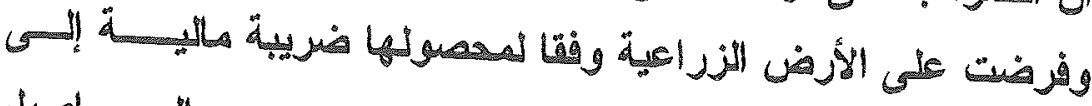

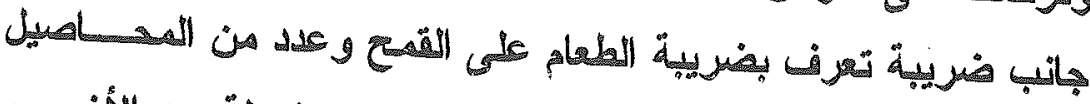

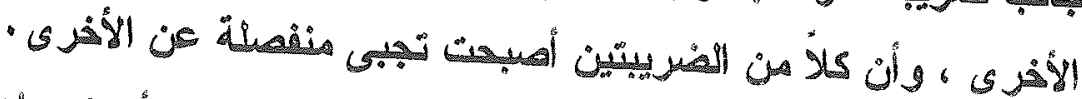

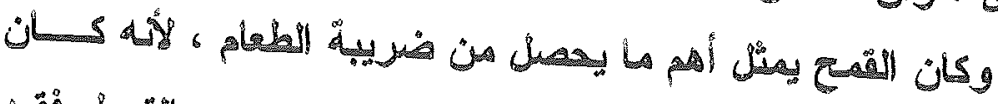

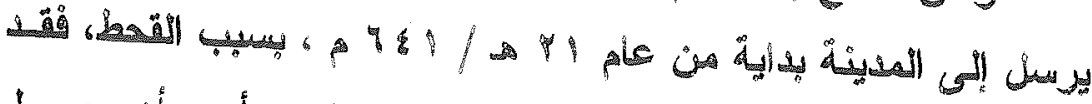

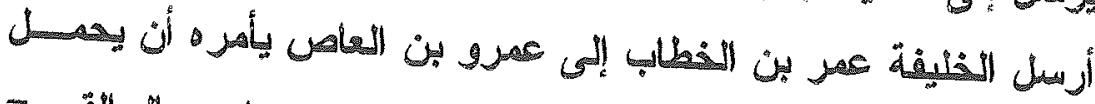

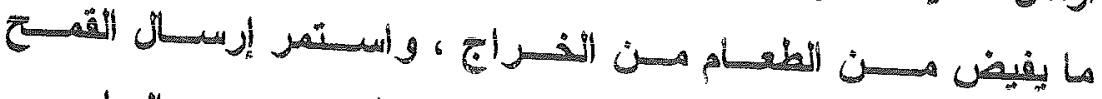

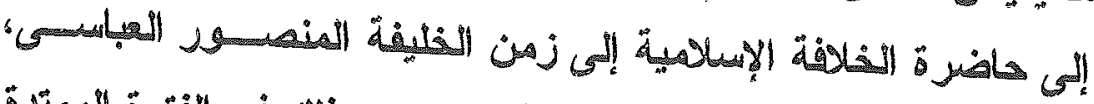

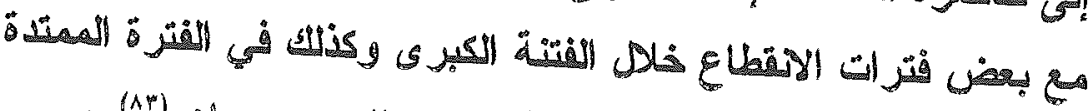

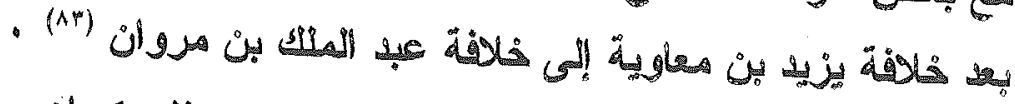

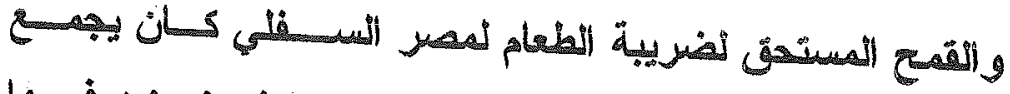

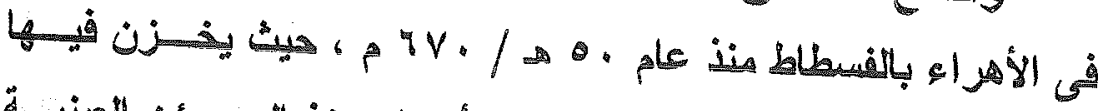

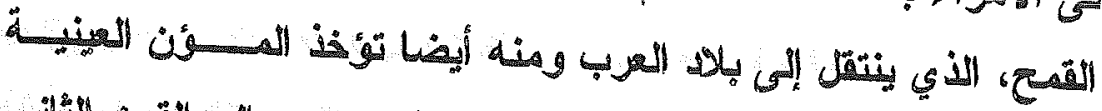

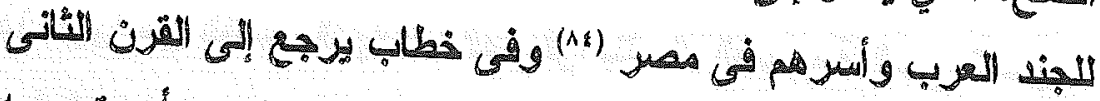

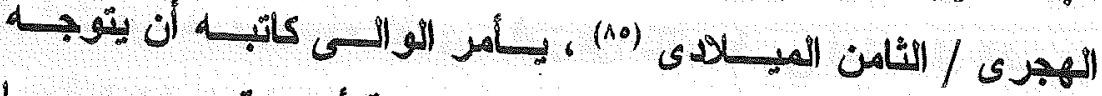

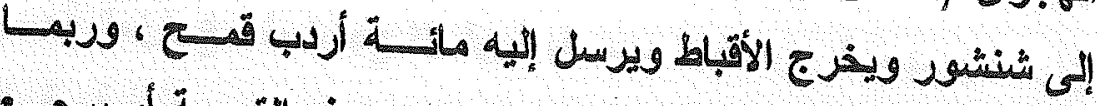

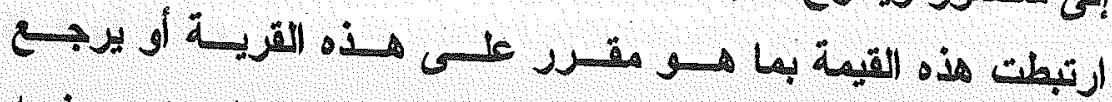

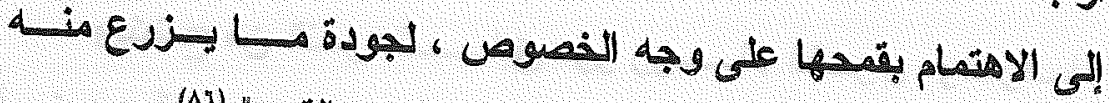

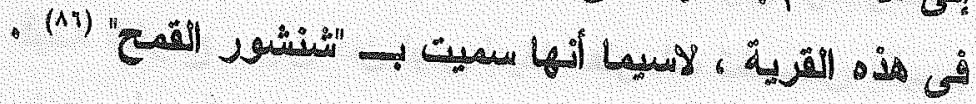




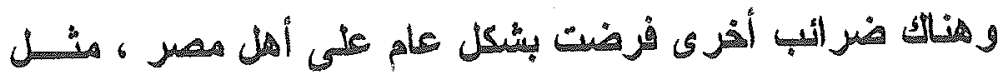

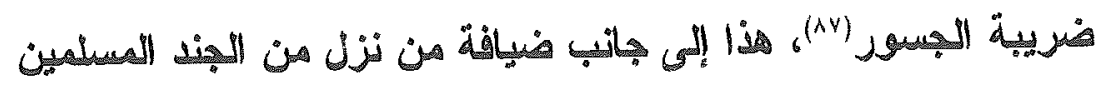
مثلاث ليال

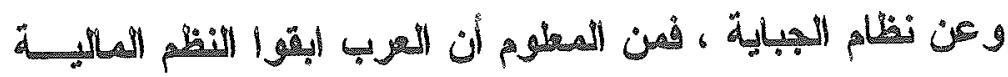

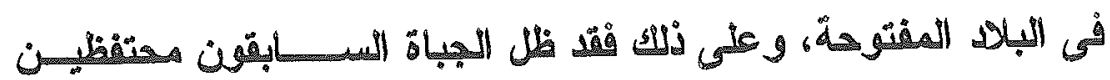

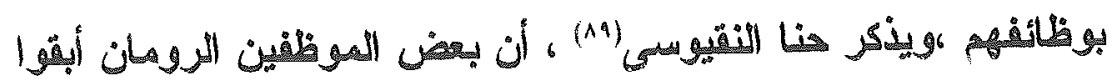

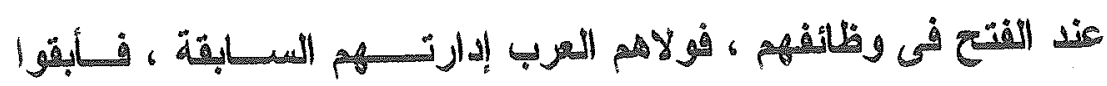

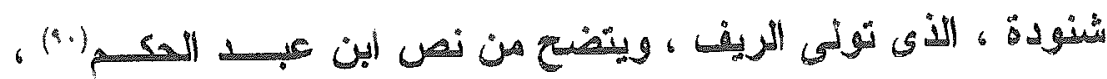

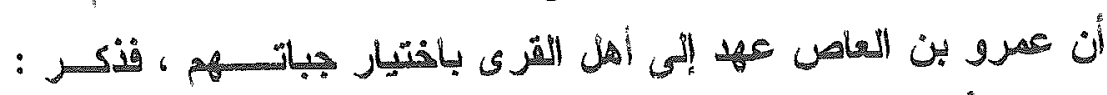

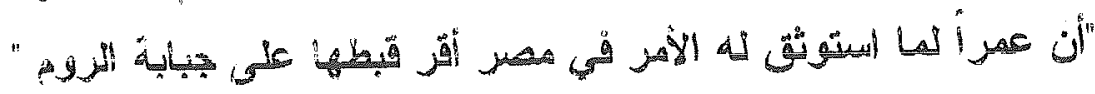

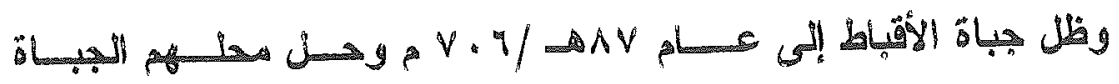

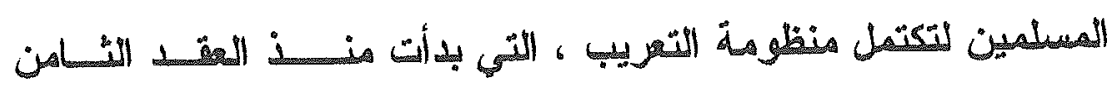

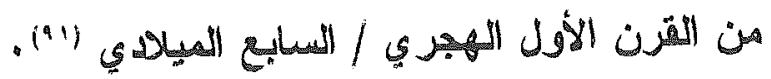

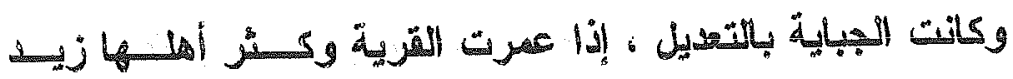

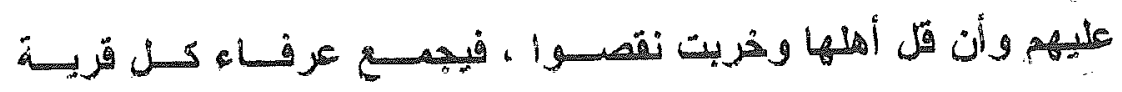

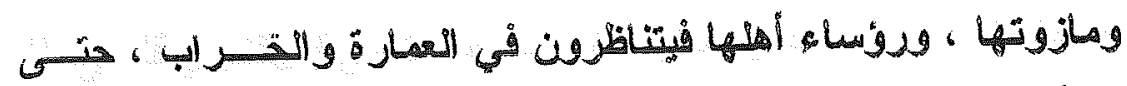

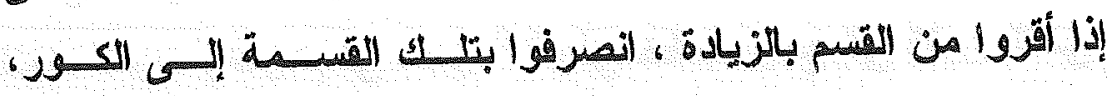

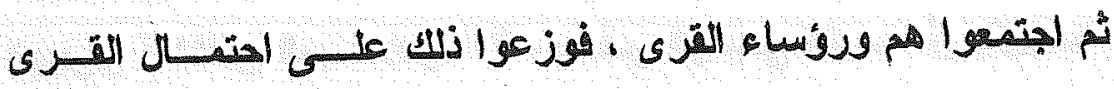

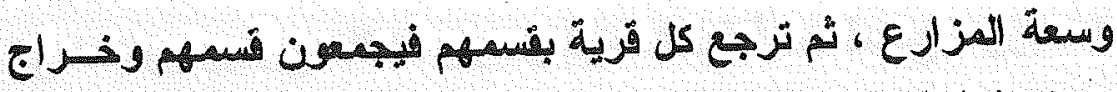
كل قرية (9)

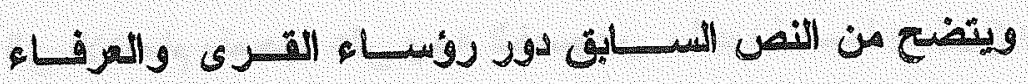

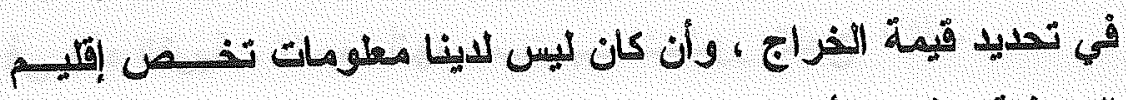

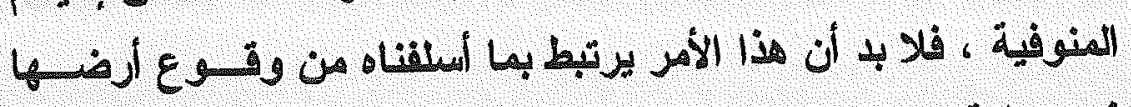

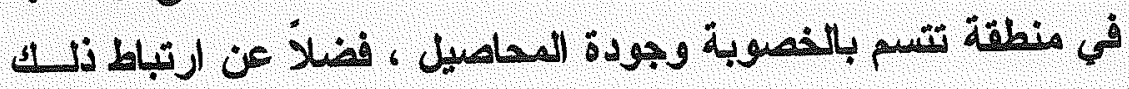




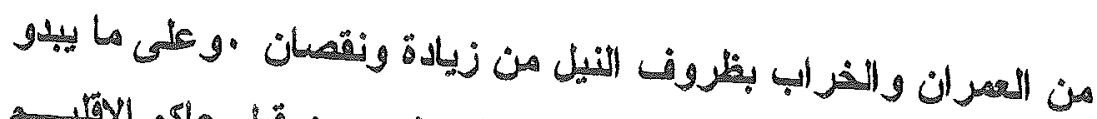

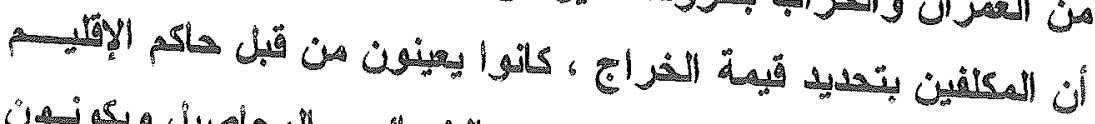

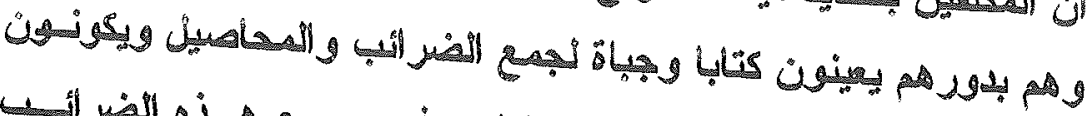

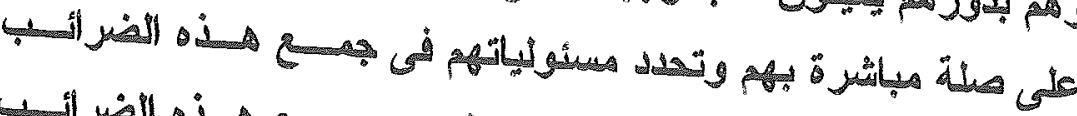

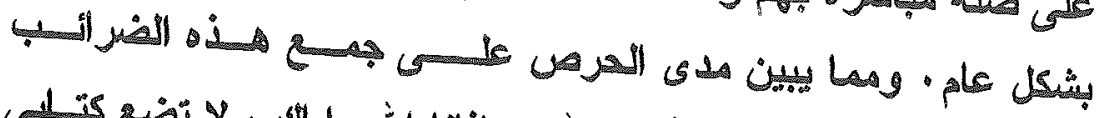

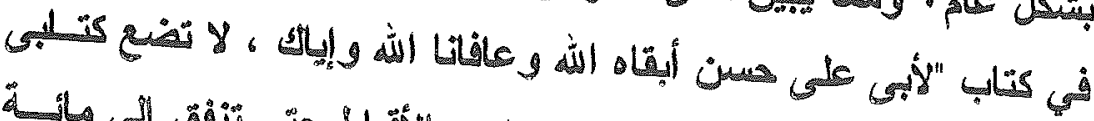

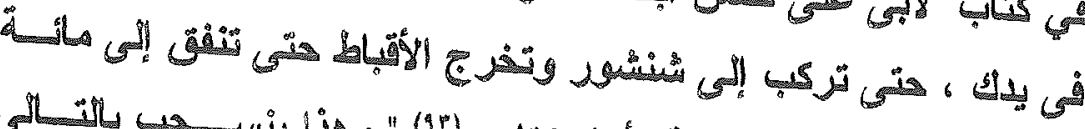

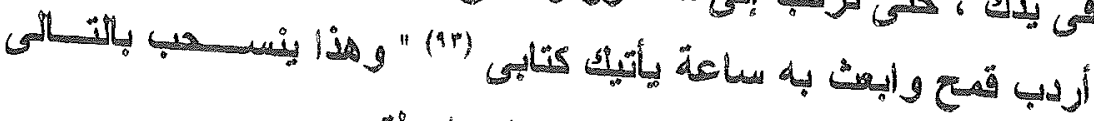

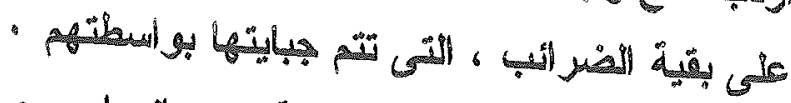

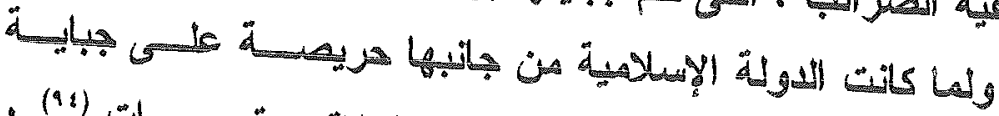

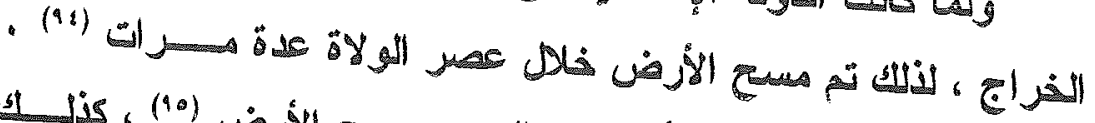

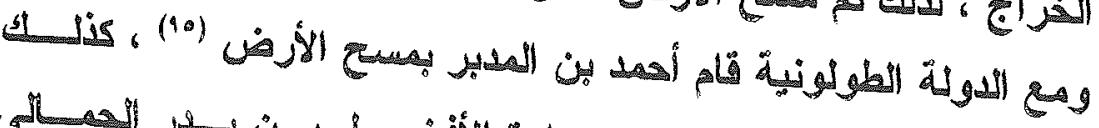

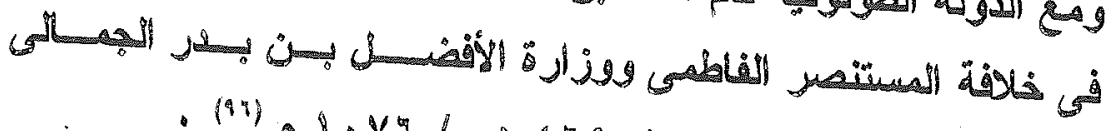

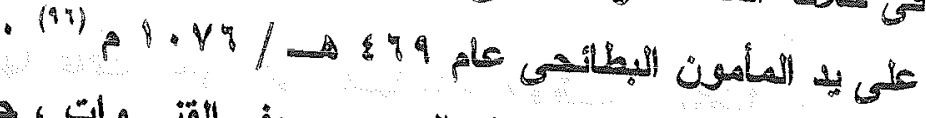

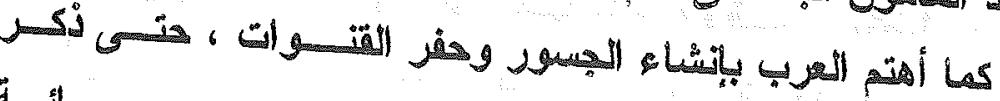

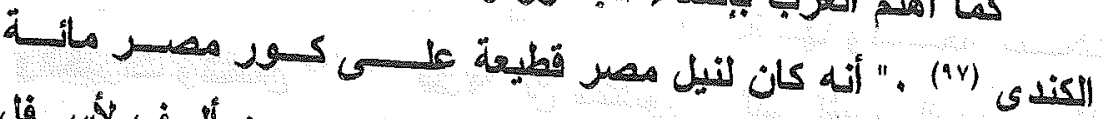

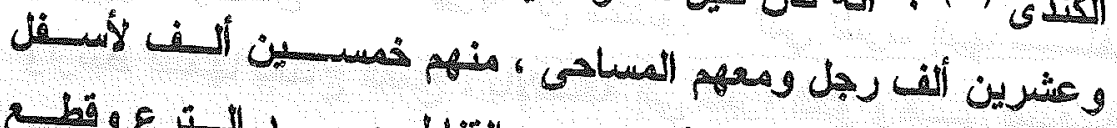

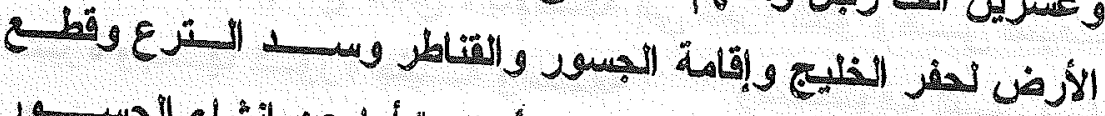

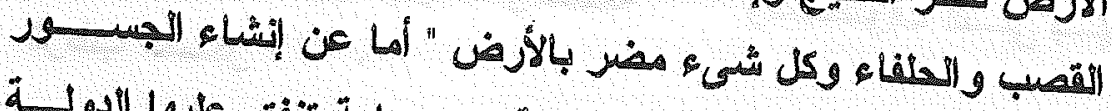

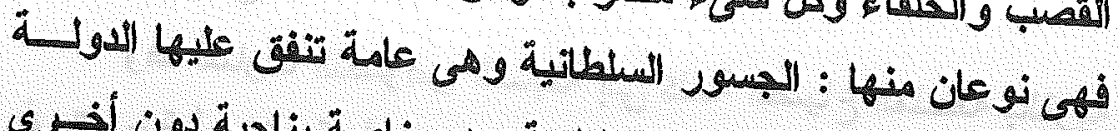

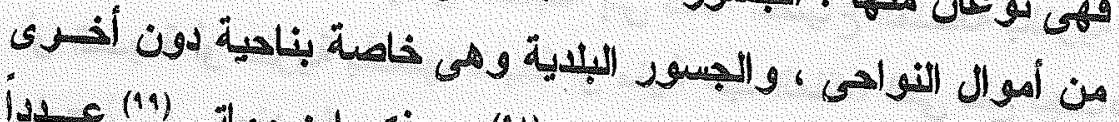

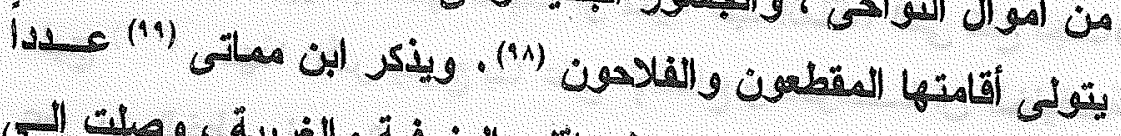

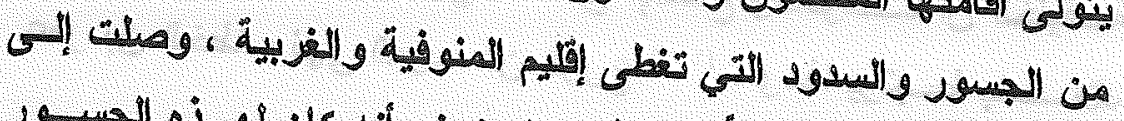

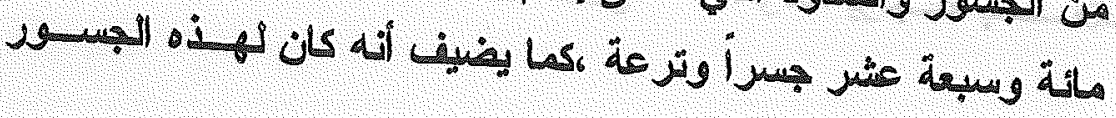




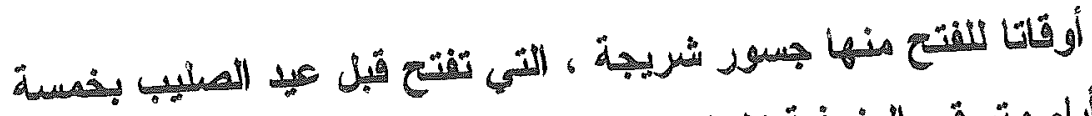

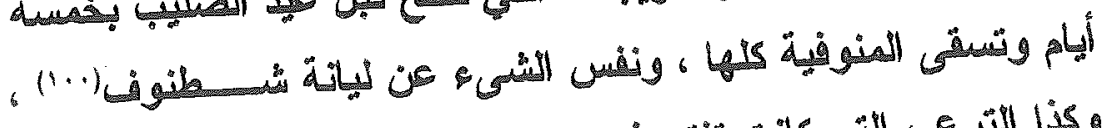

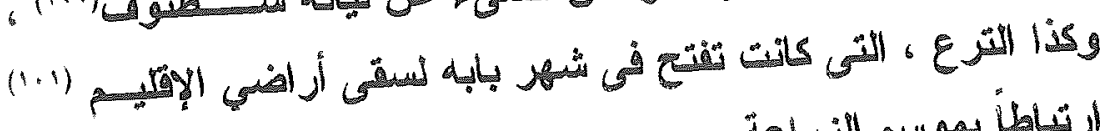

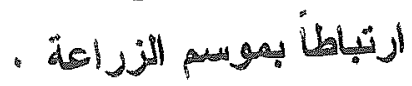

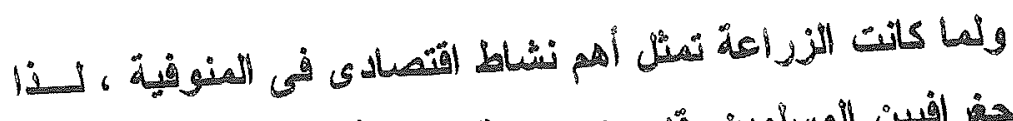

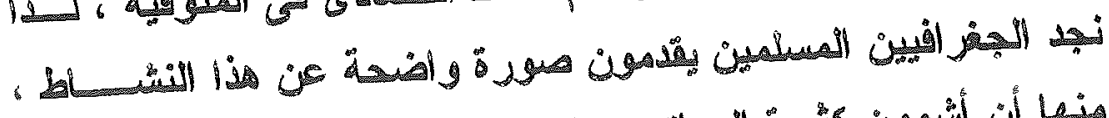

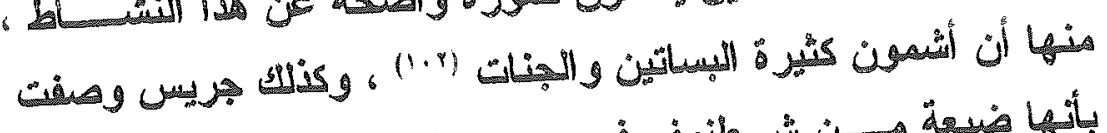

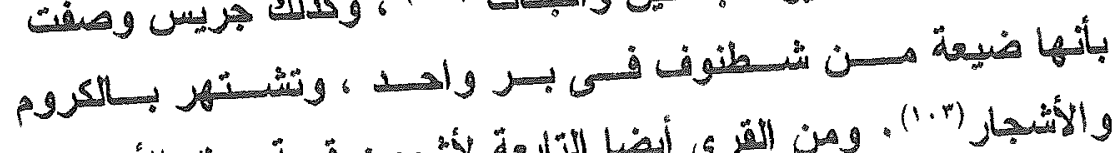

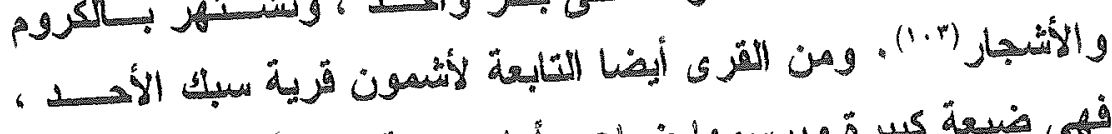

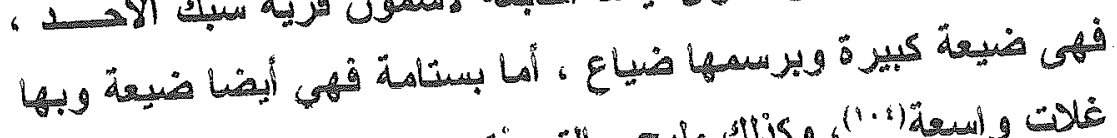

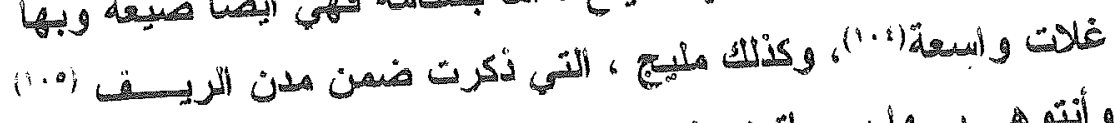

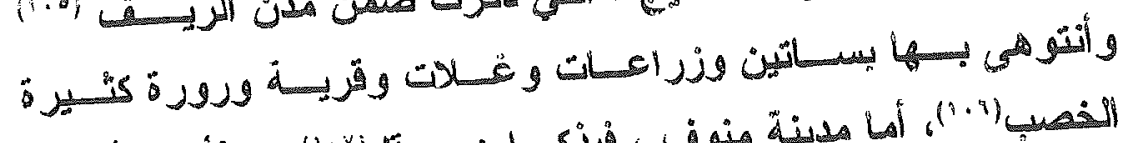

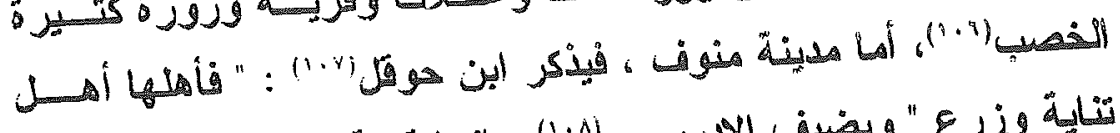

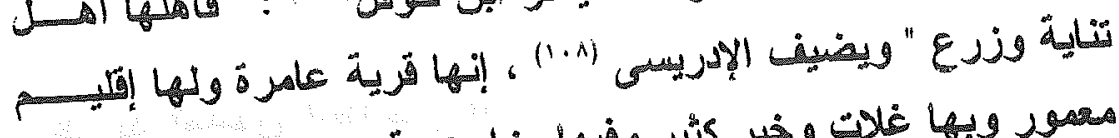

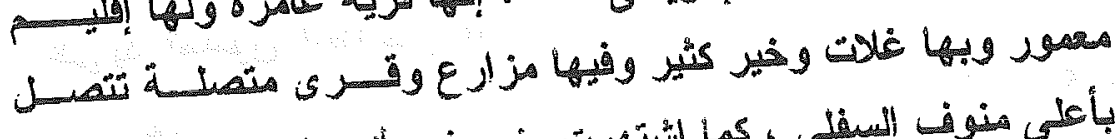

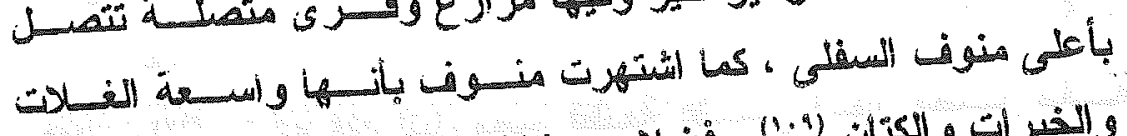

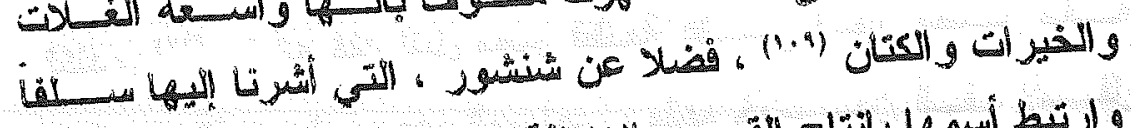

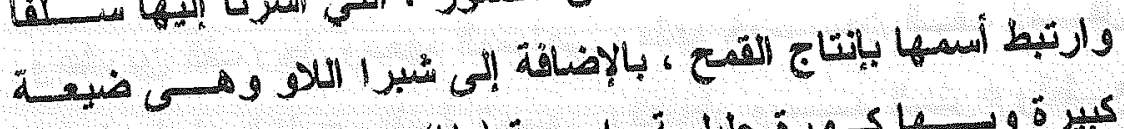

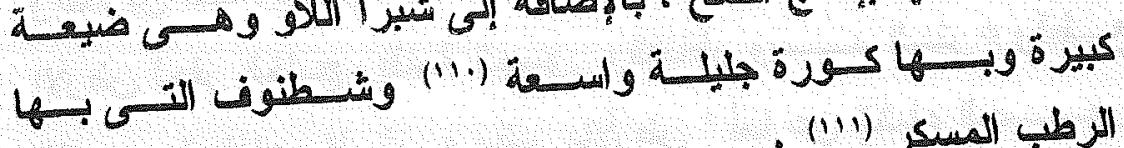

وقد أثنارت النصوص السابقة إلى كلمة الضياع الشلحقة بالقرية

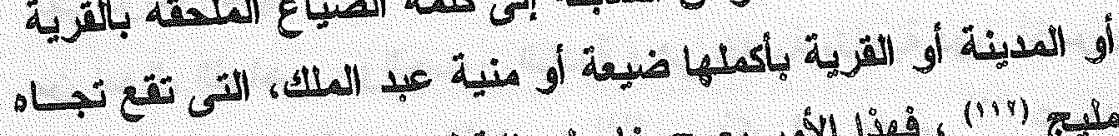

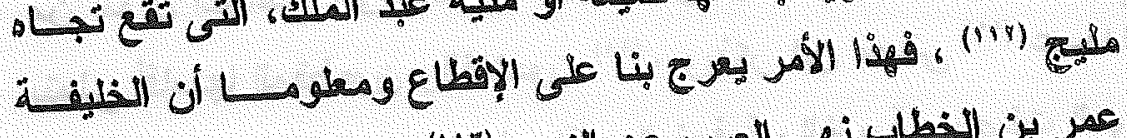

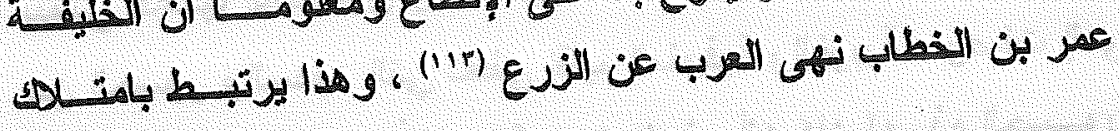




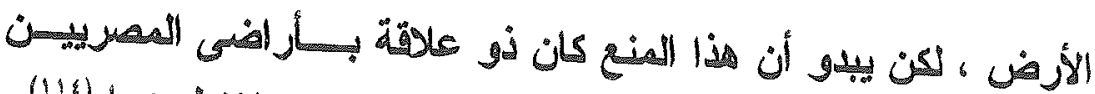

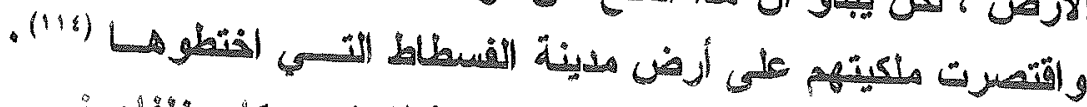

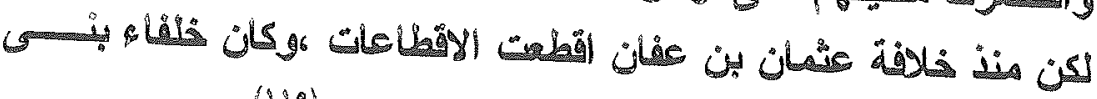

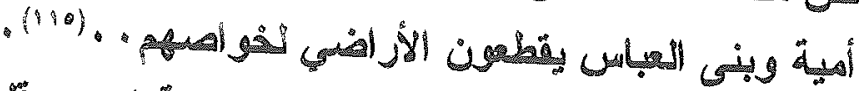

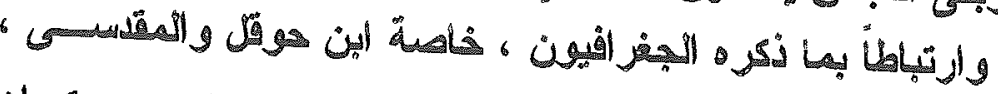

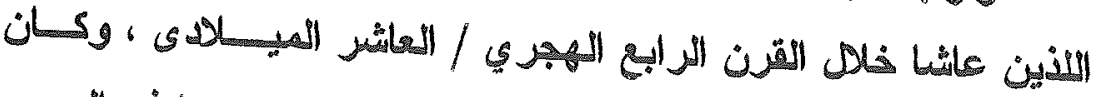

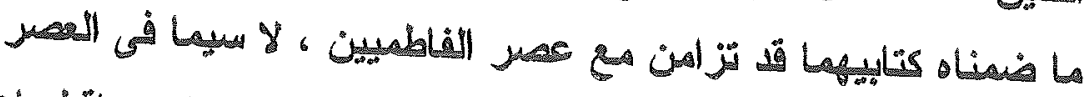

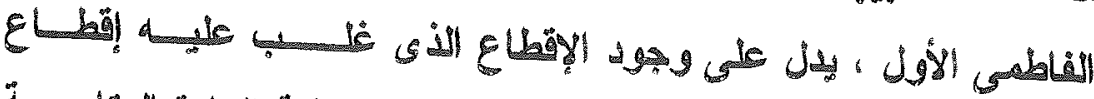

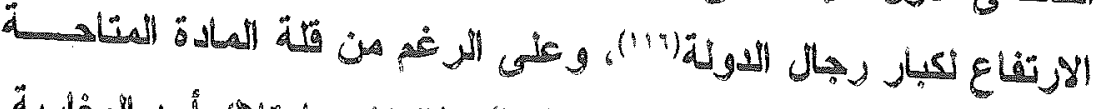

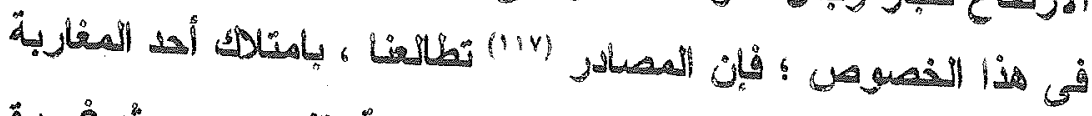

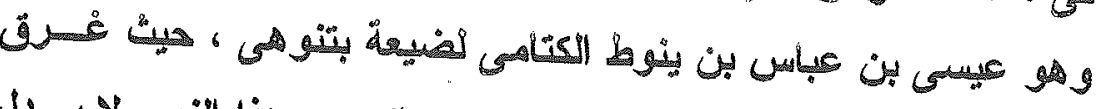

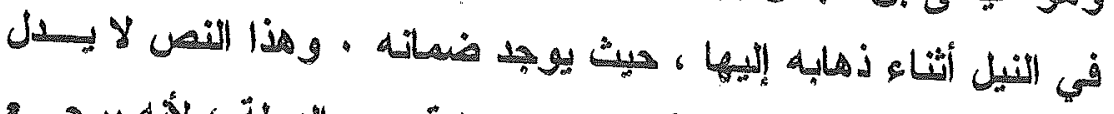

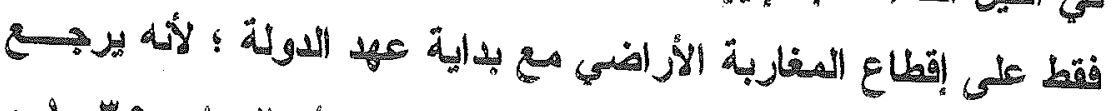

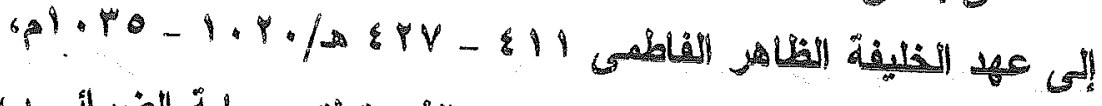

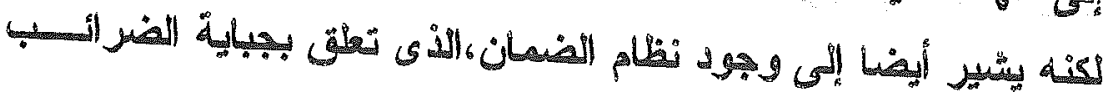

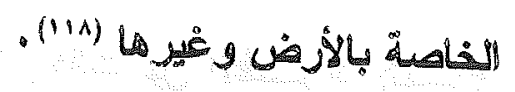

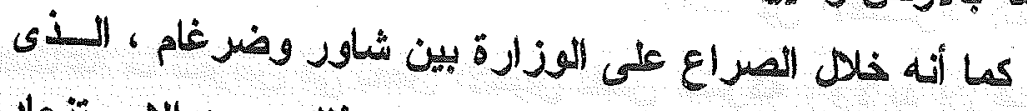

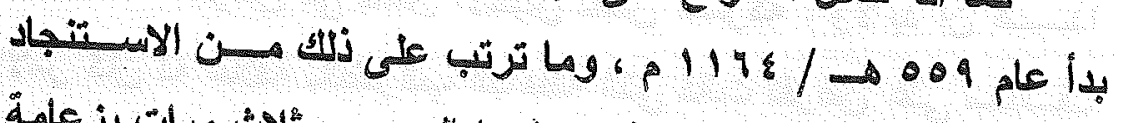

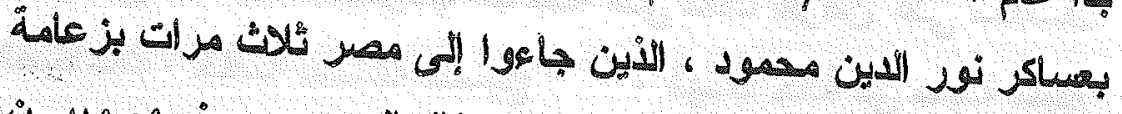

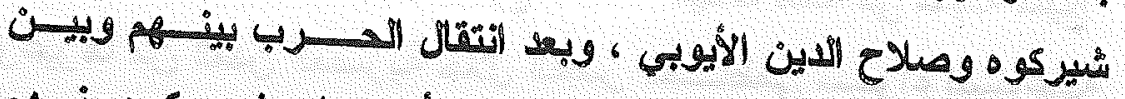

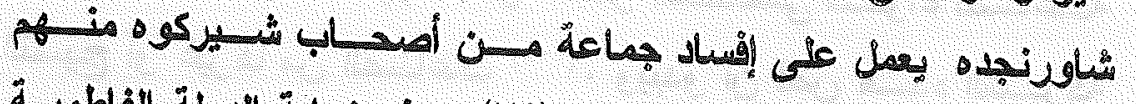

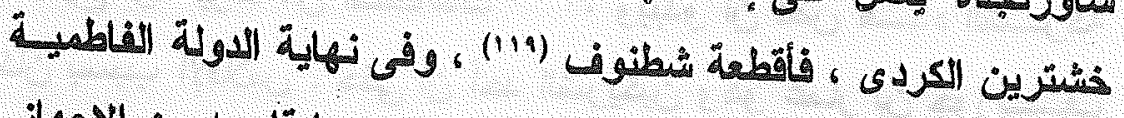

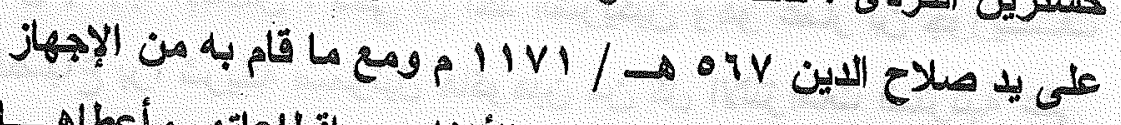

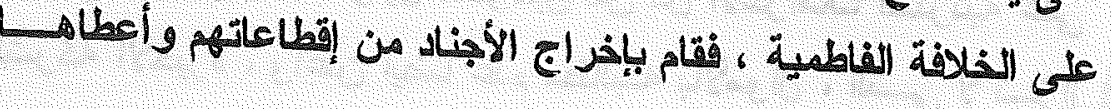




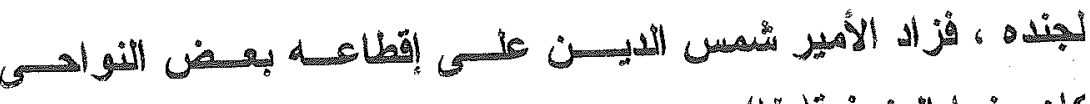

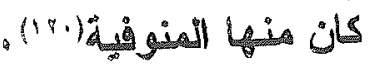

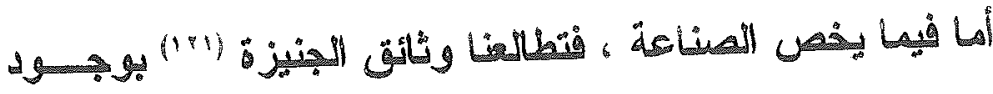

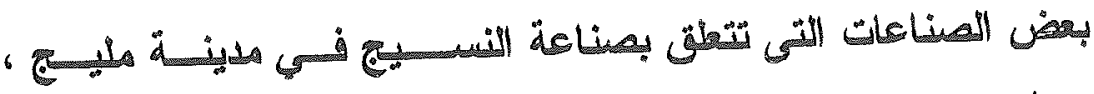

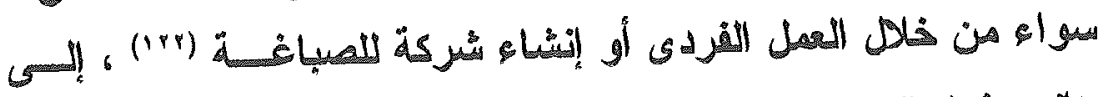

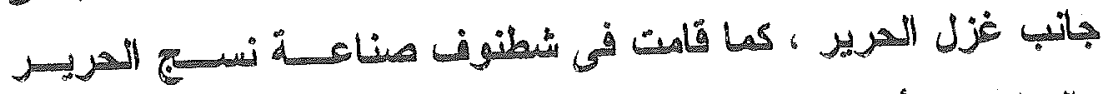

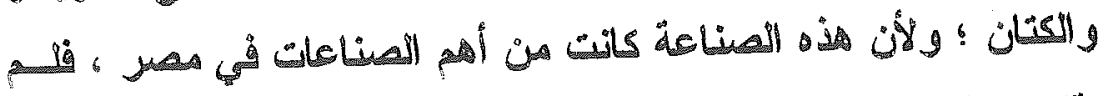

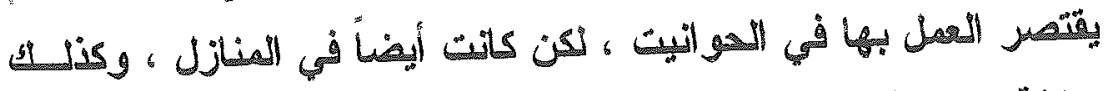

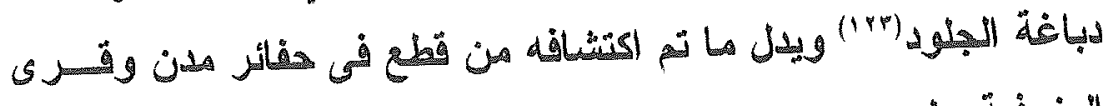

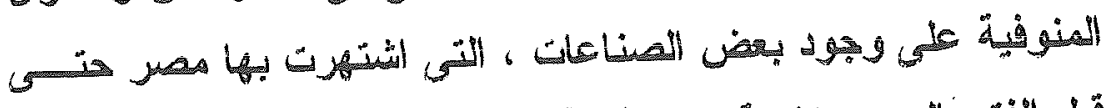

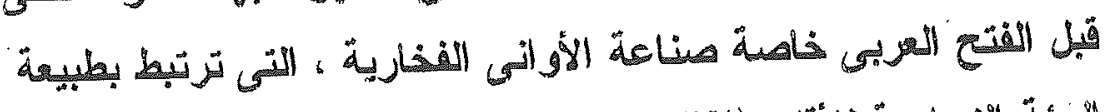

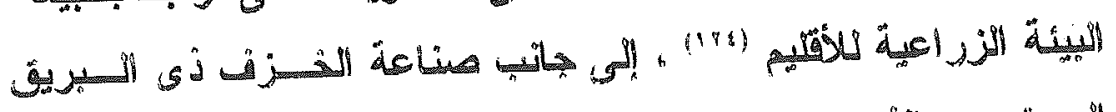

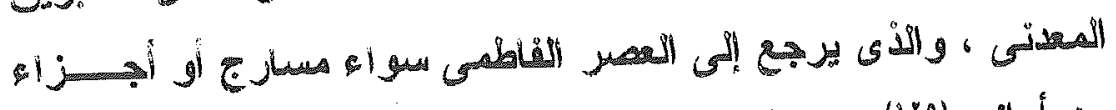

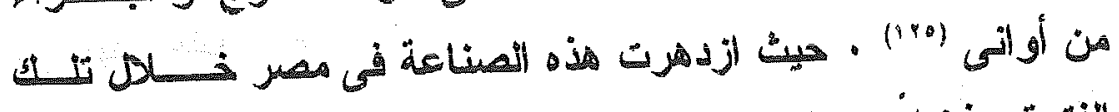

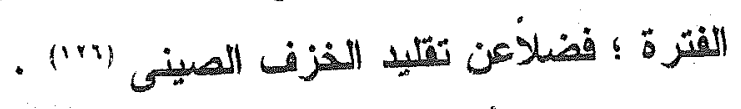

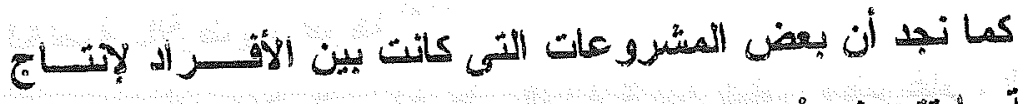

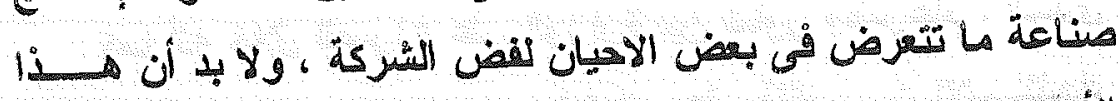

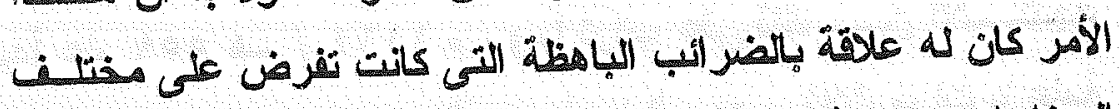

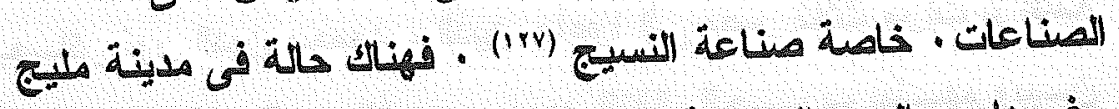

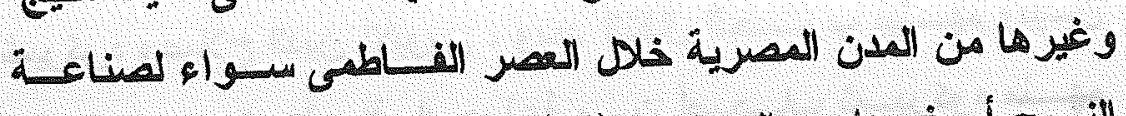

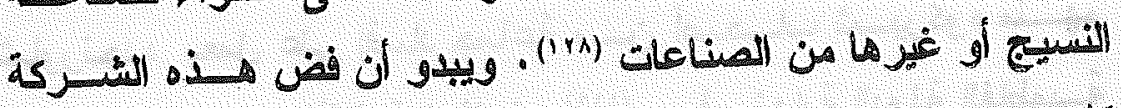

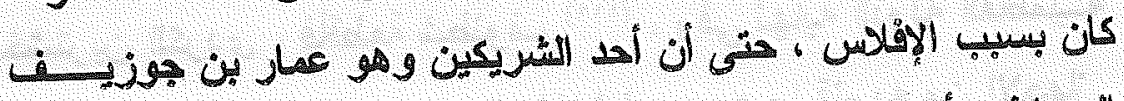

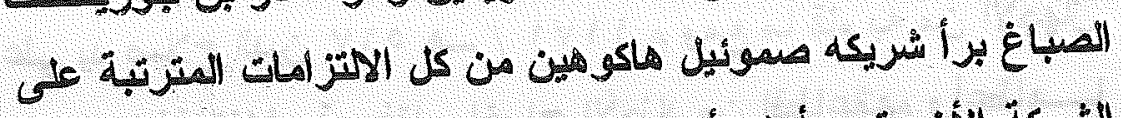

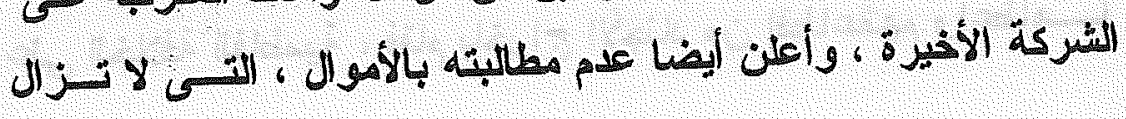




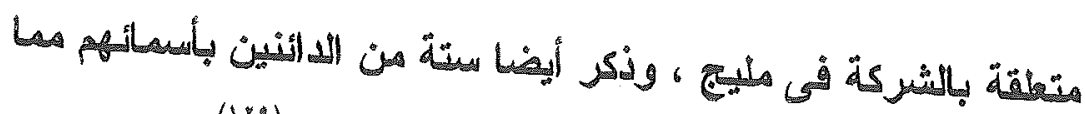

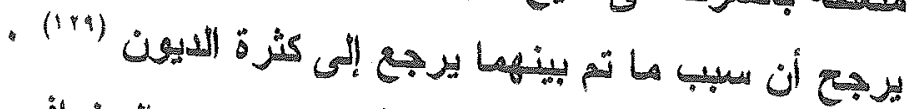

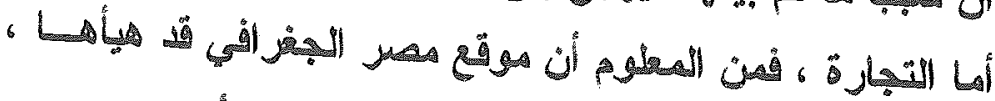

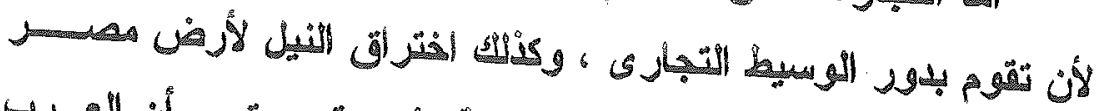

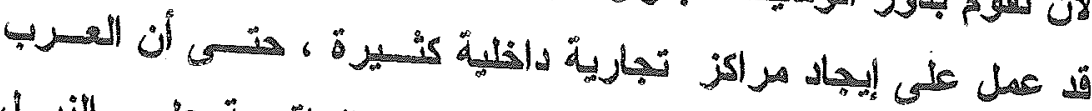

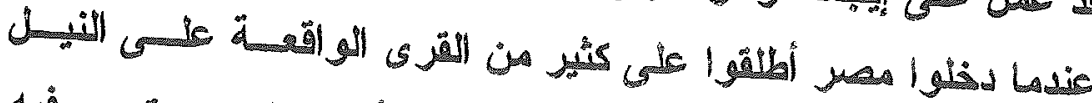

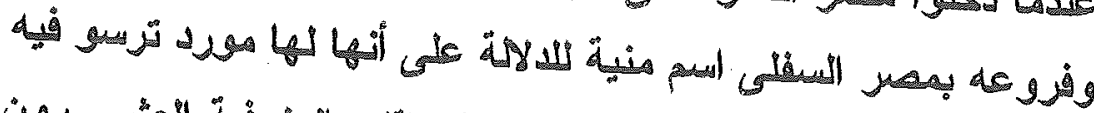

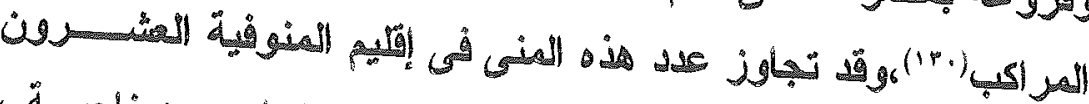

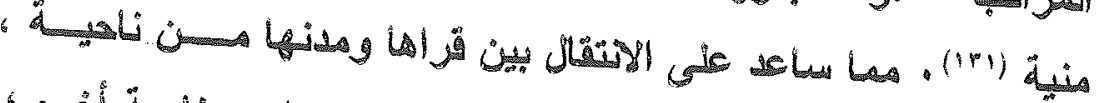

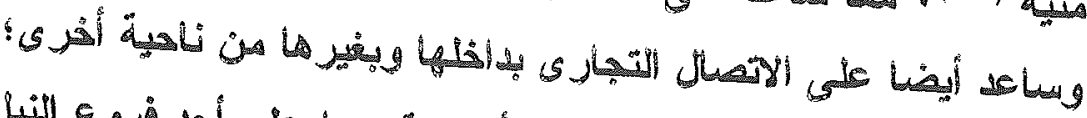

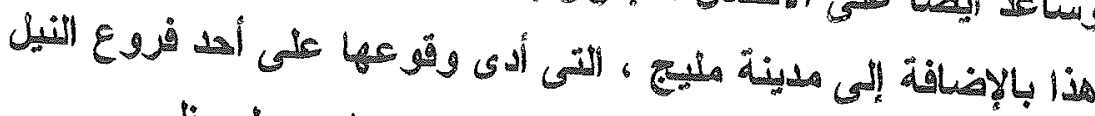

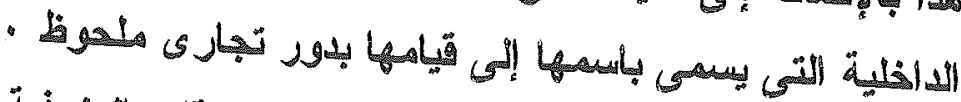

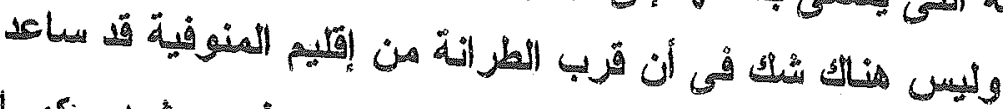

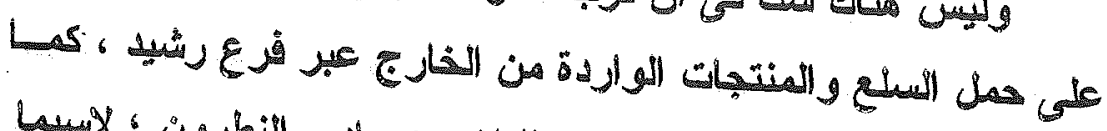

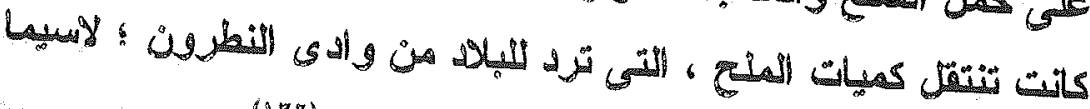

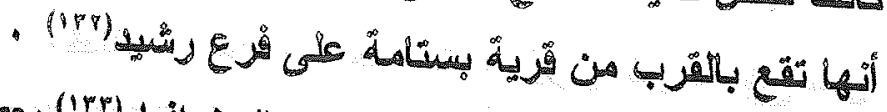

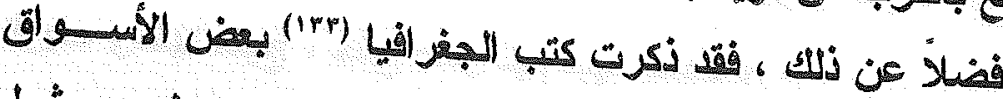

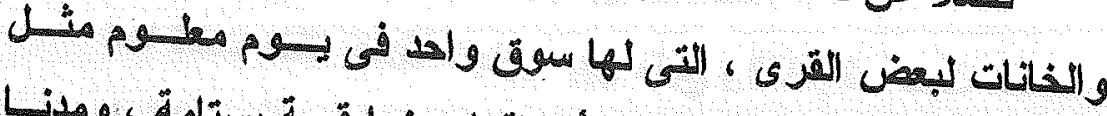

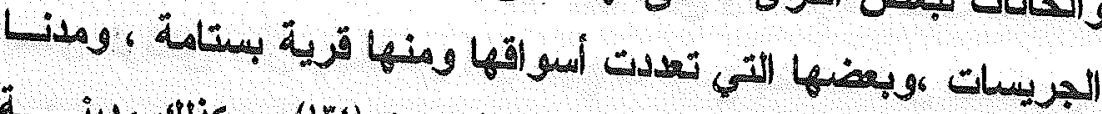

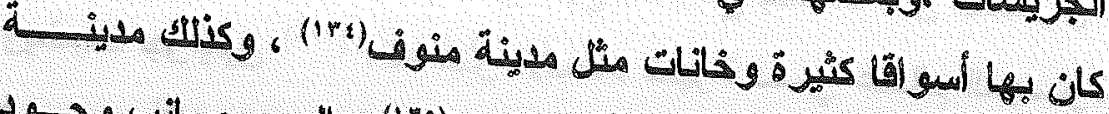

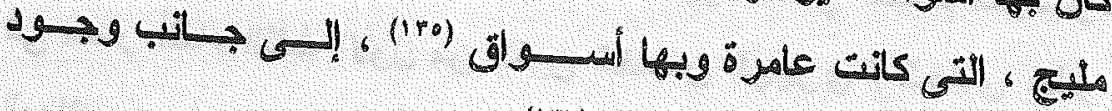

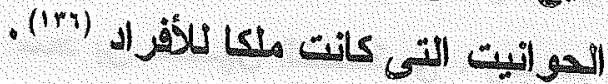

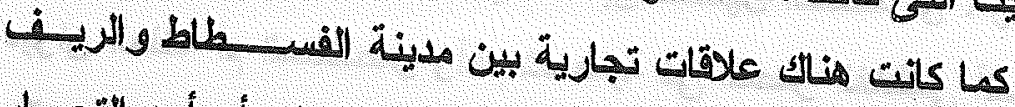

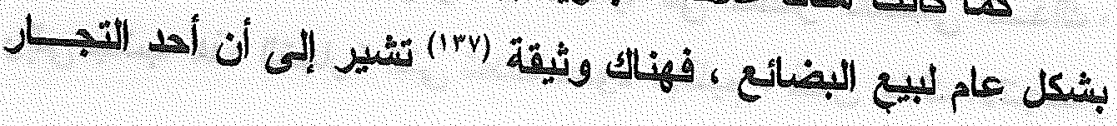




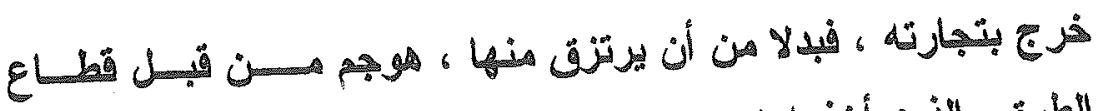

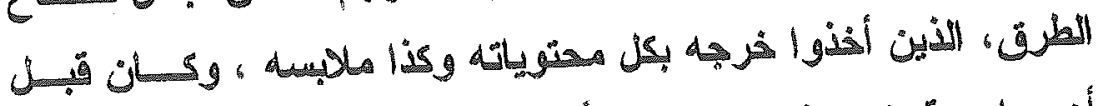

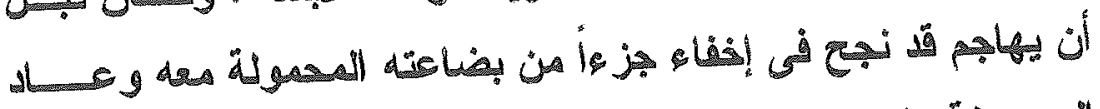

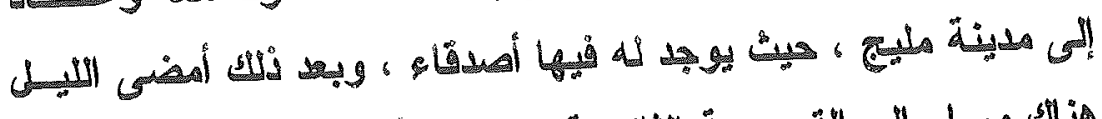

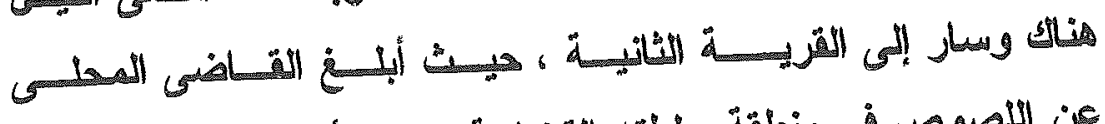

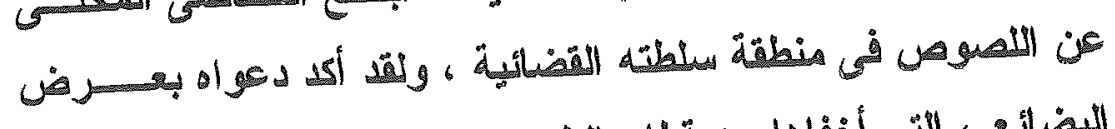

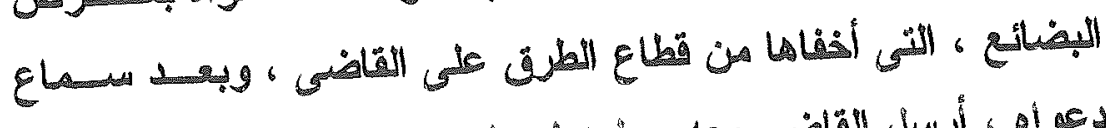

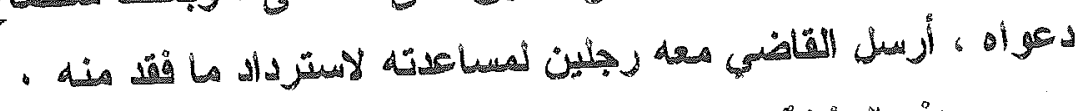

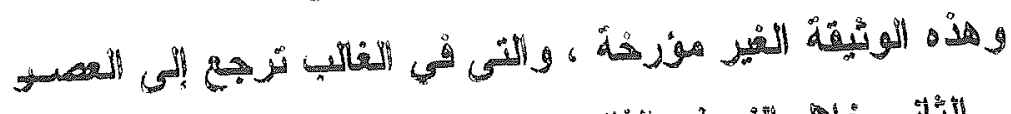

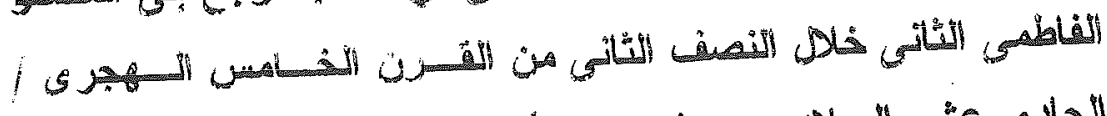

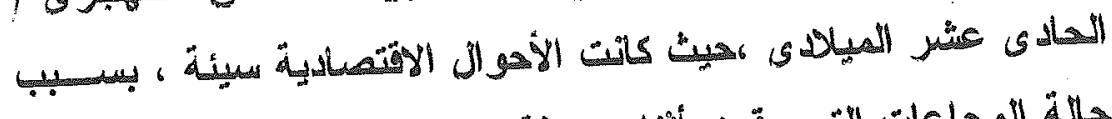

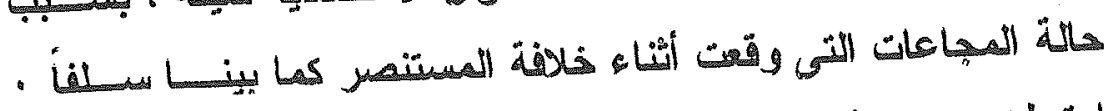

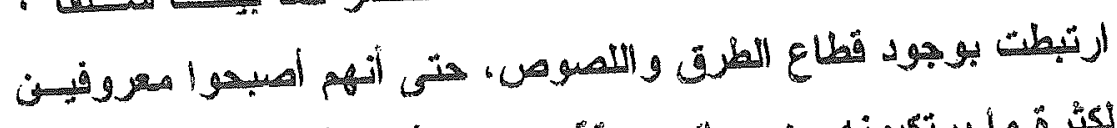

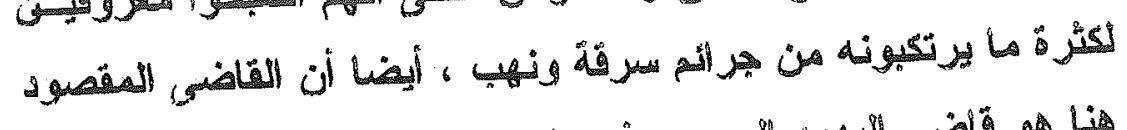

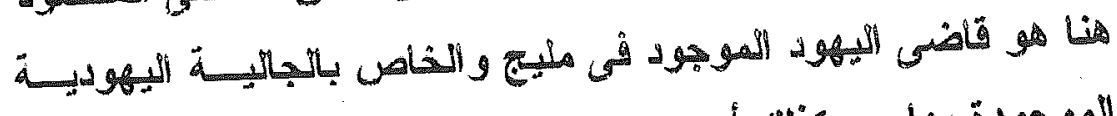

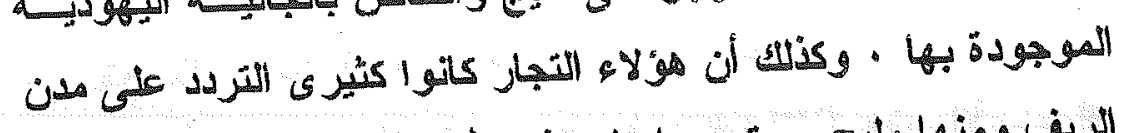

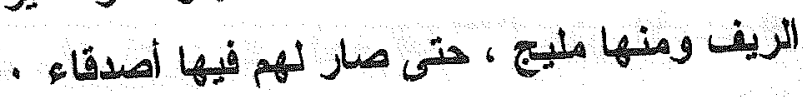

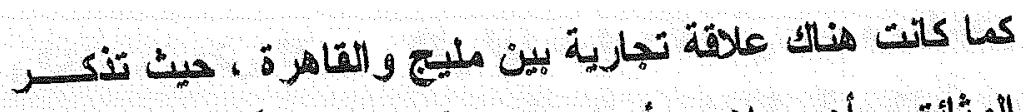

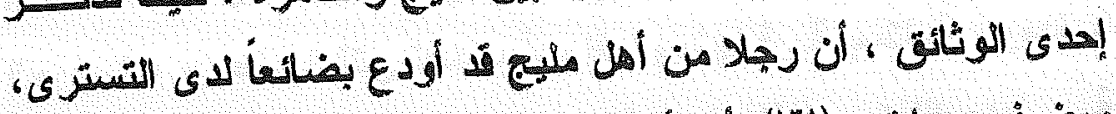

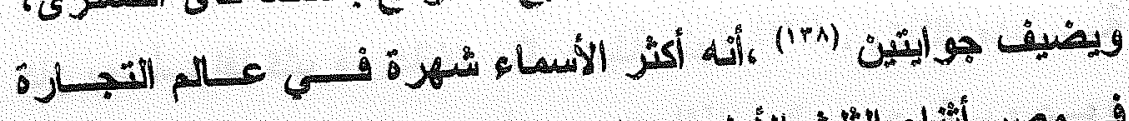

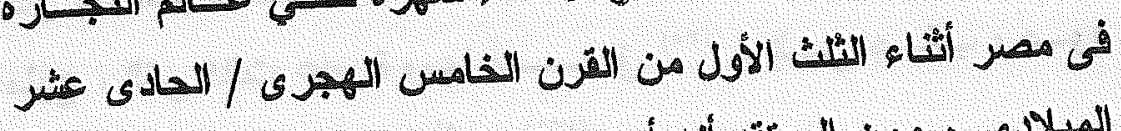

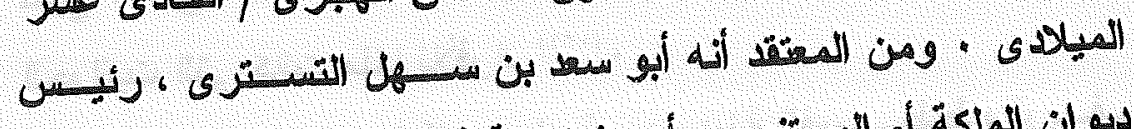

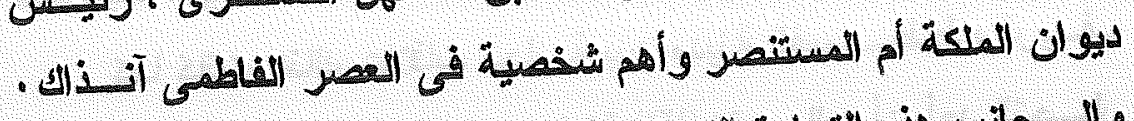

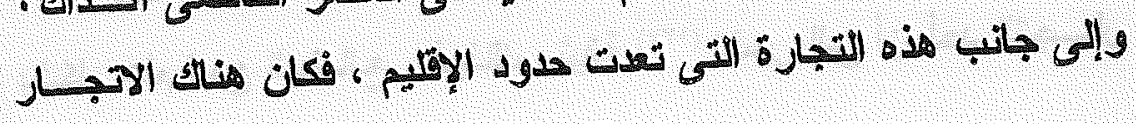




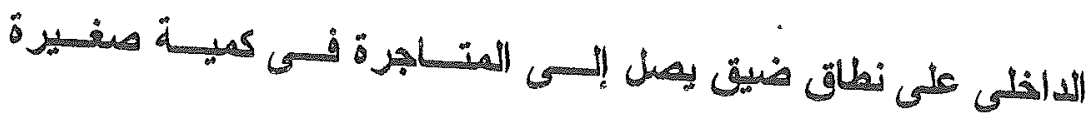

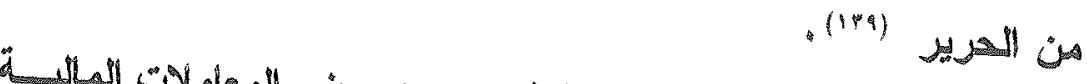

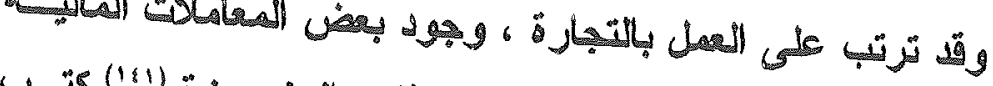

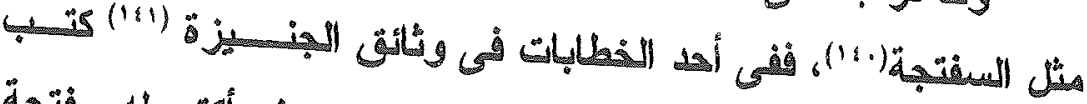

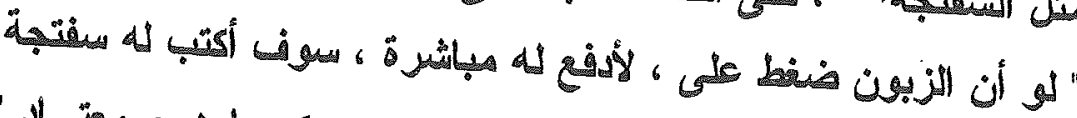

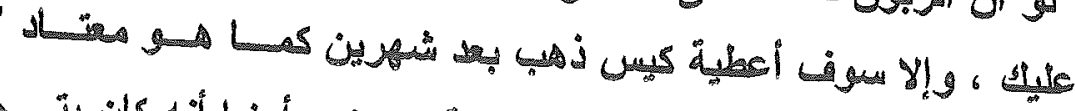

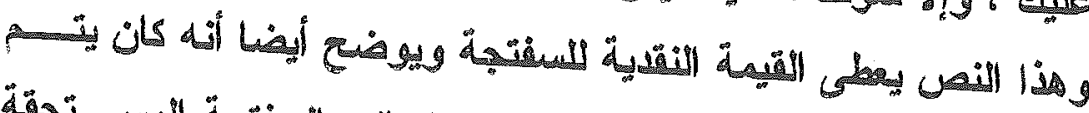

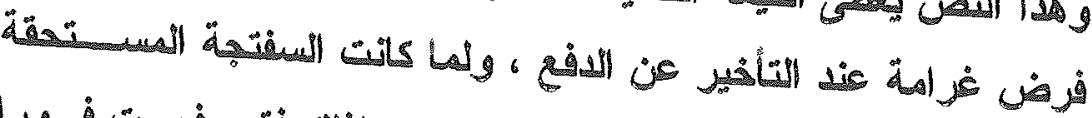

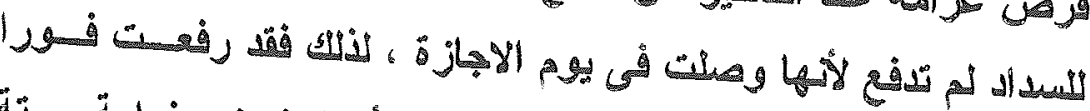

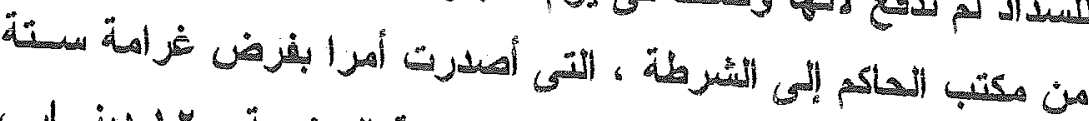

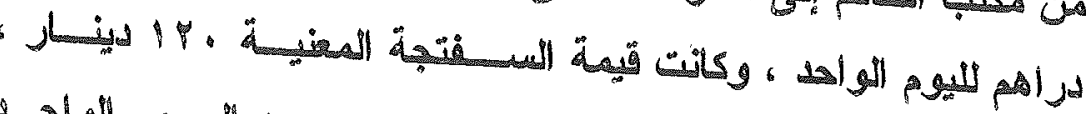

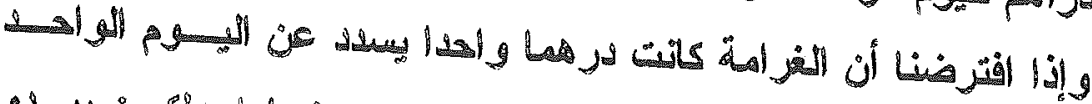

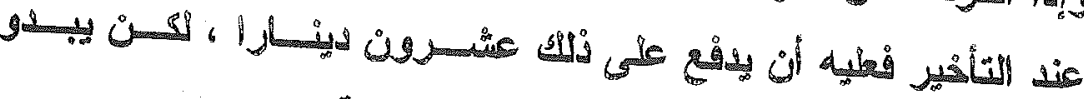

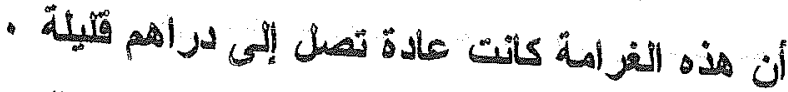

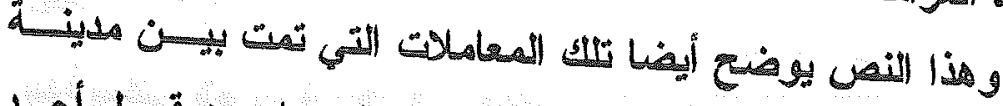

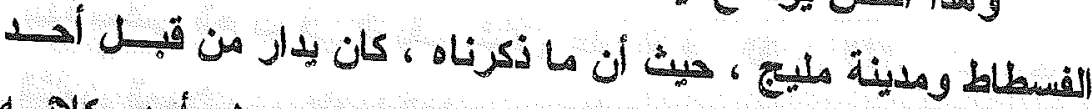

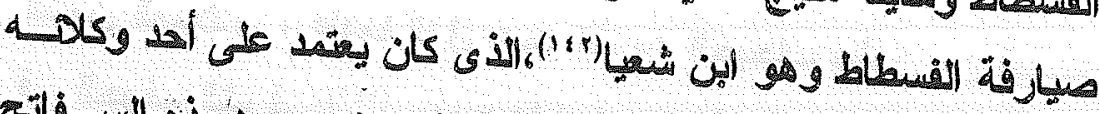

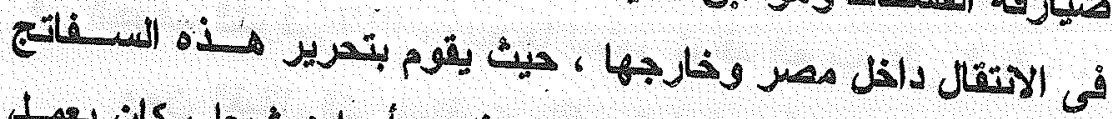

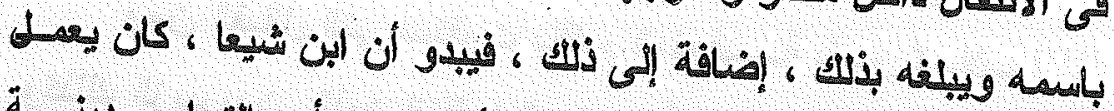

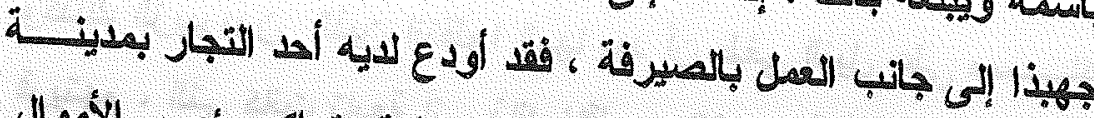

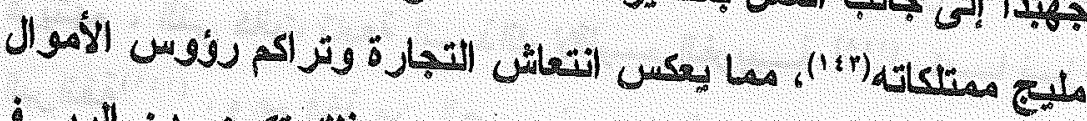

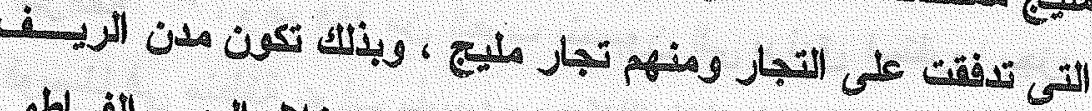

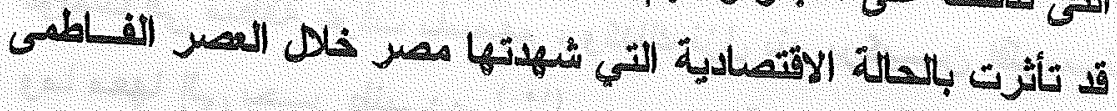




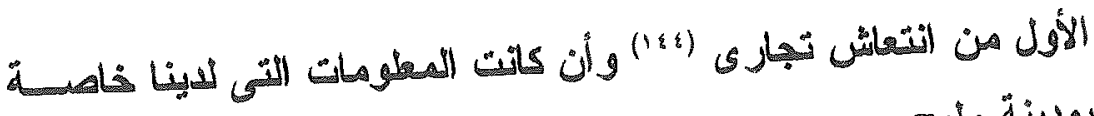

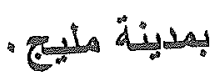

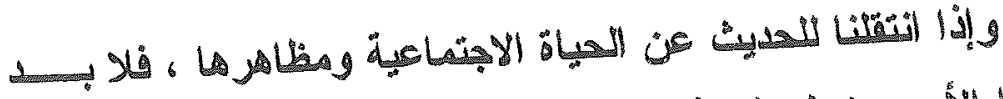

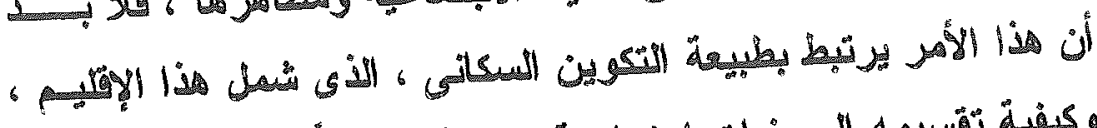

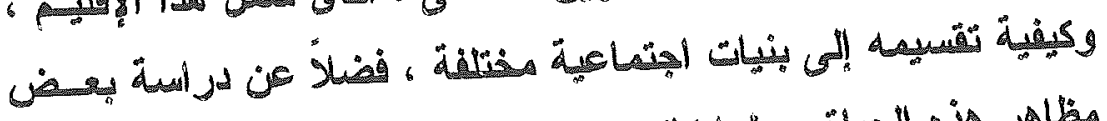

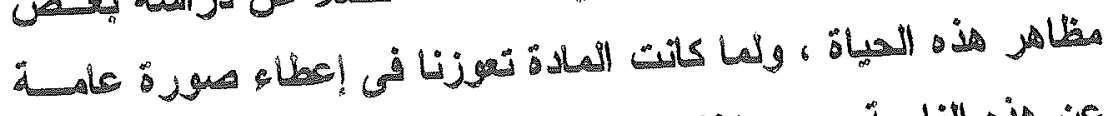

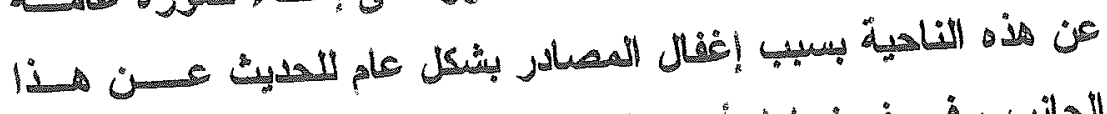

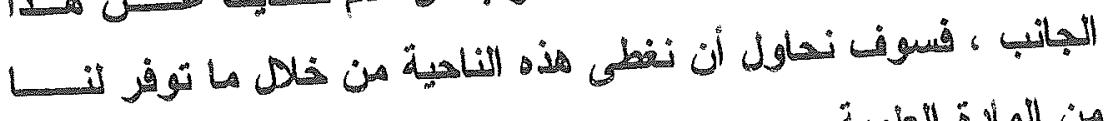

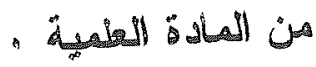

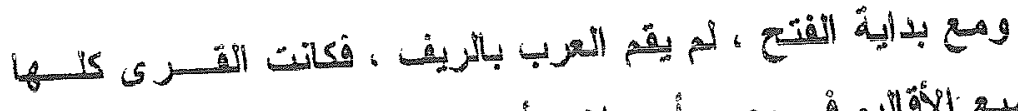
و

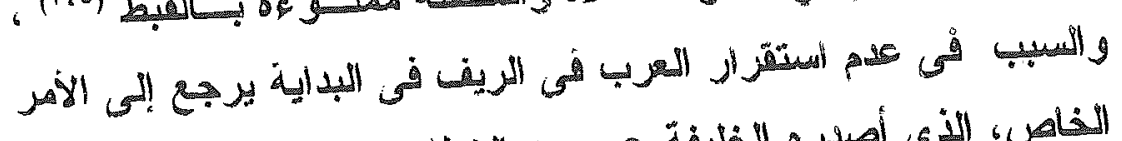

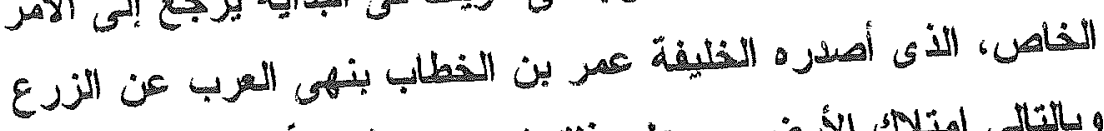

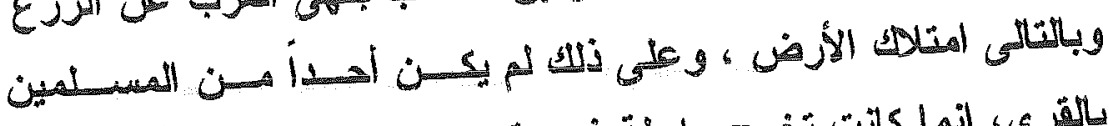

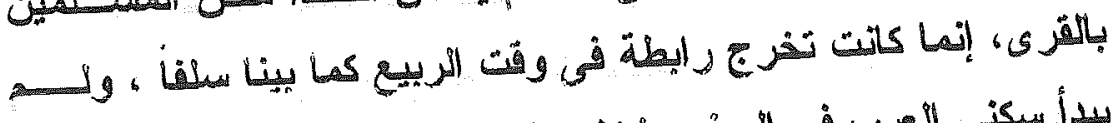

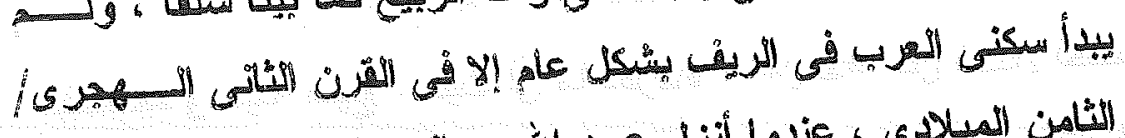

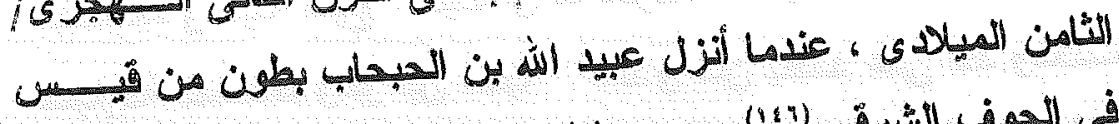

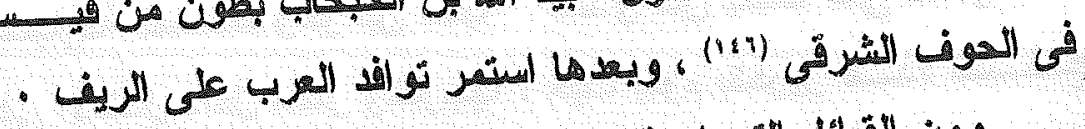

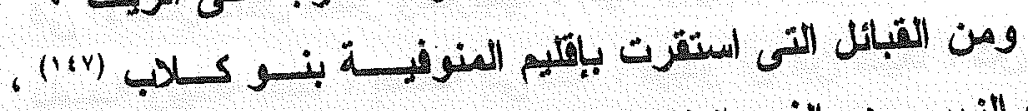

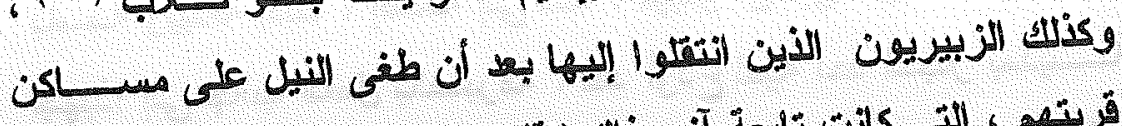

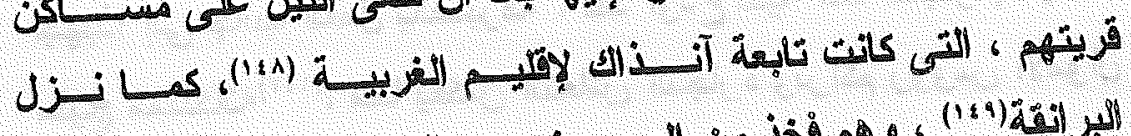

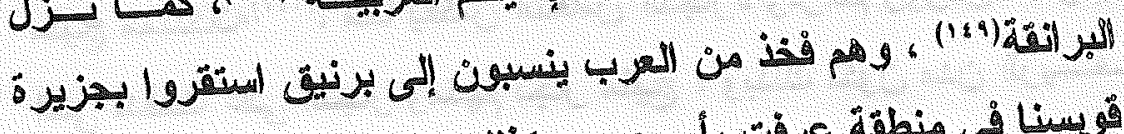

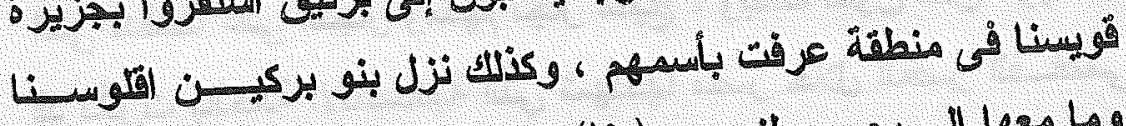

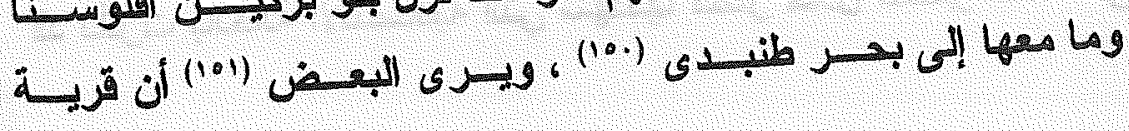




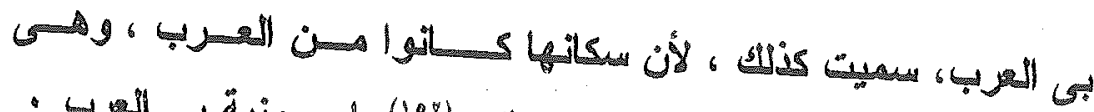

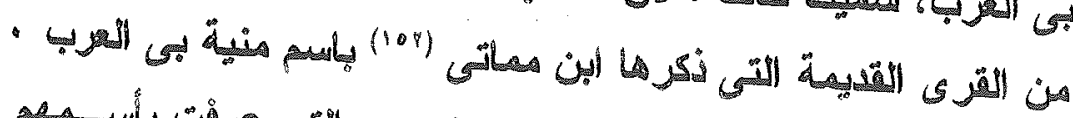

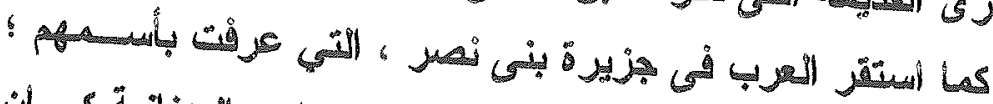

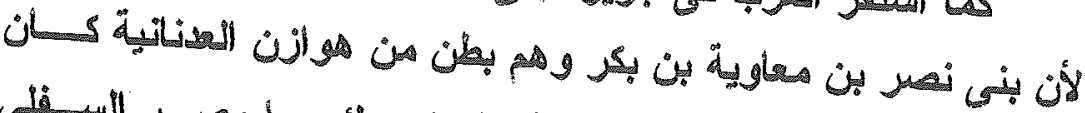

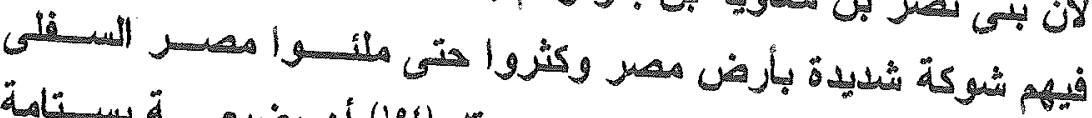

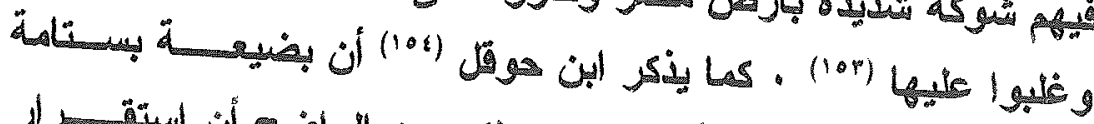

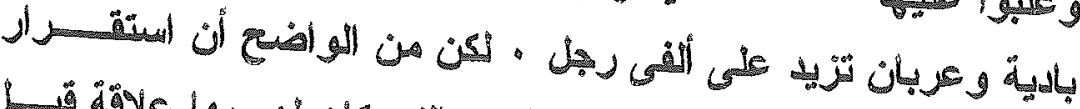

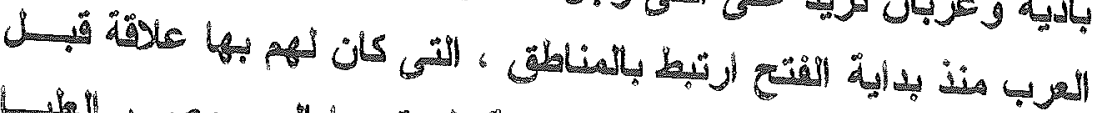

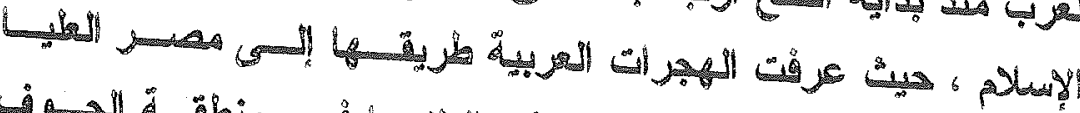

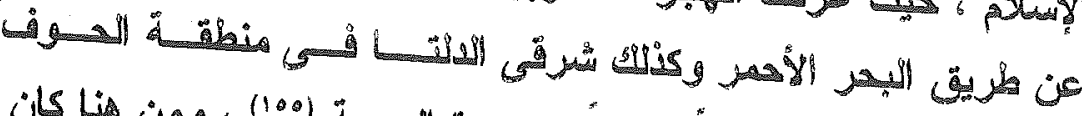

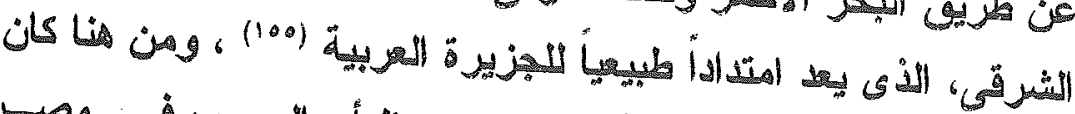

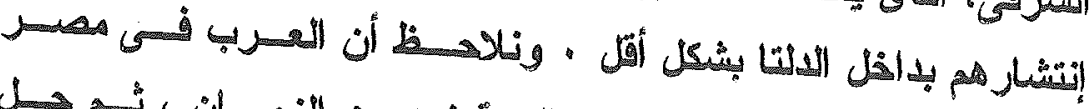

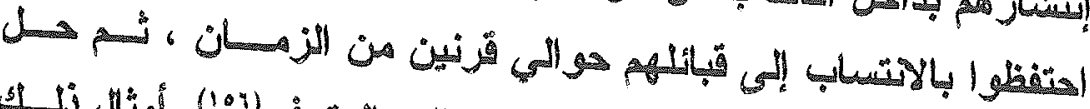

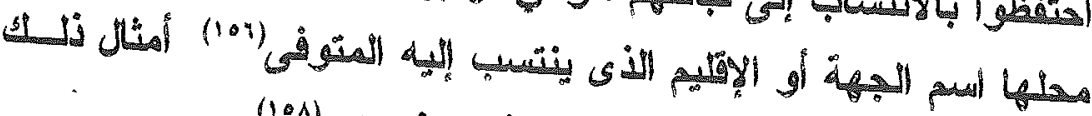

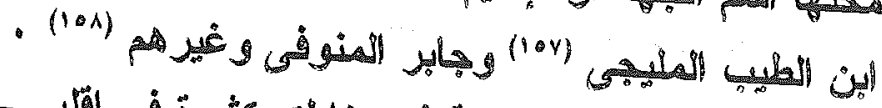

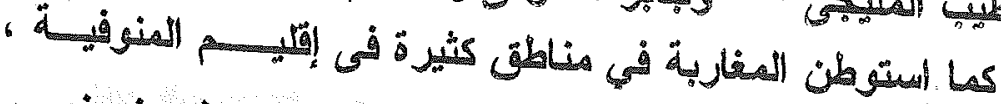

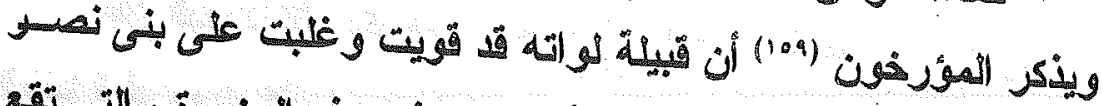

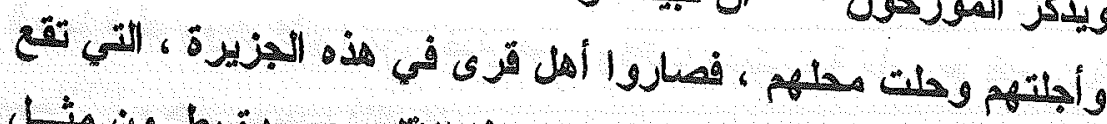

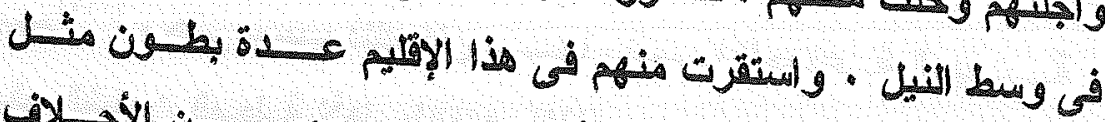

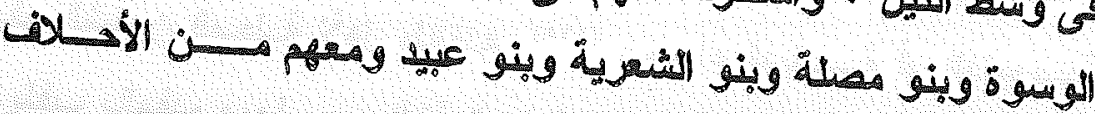

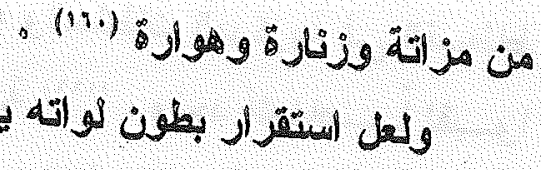

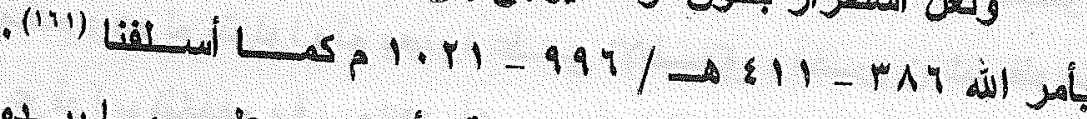

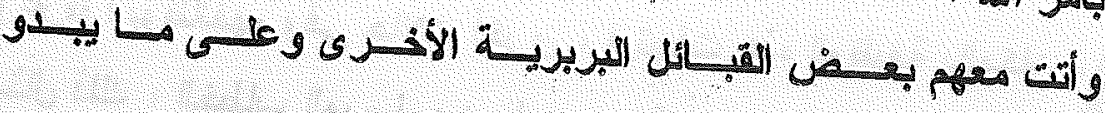




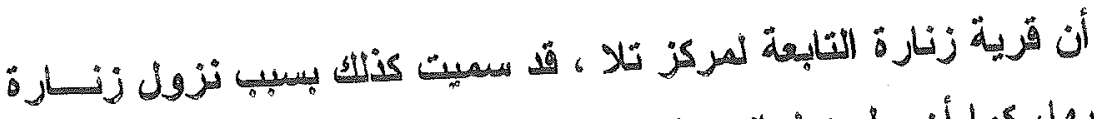

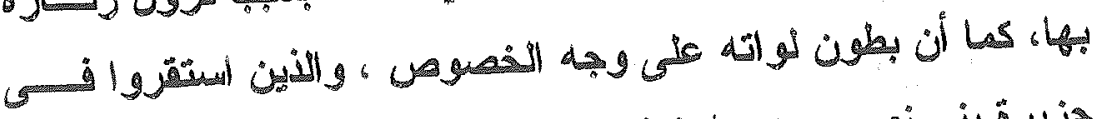

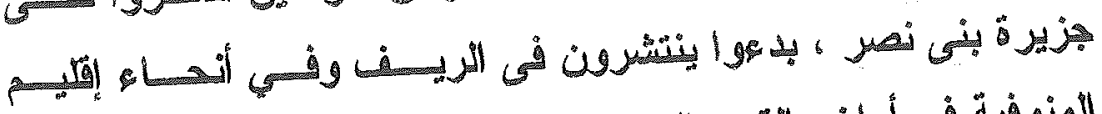

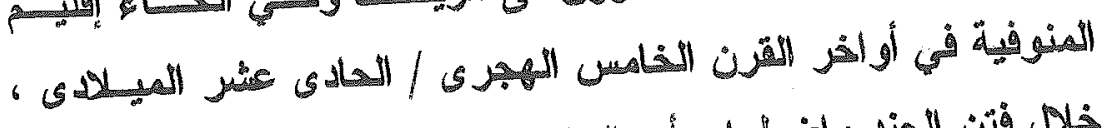

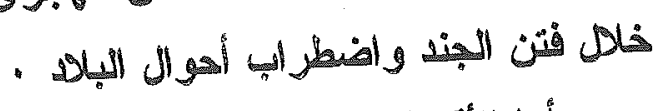

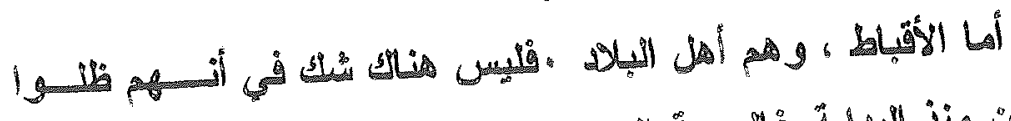

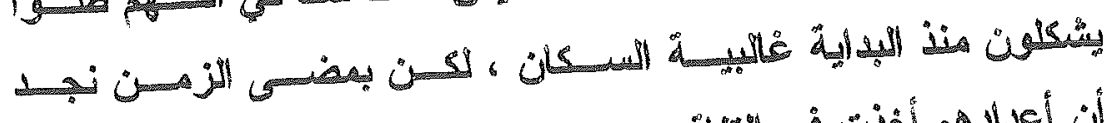

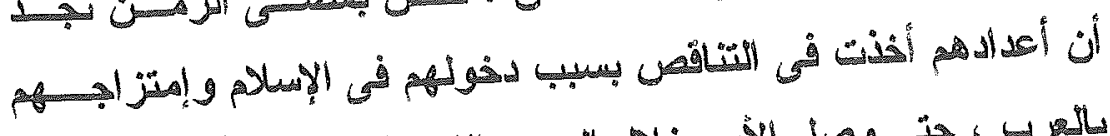

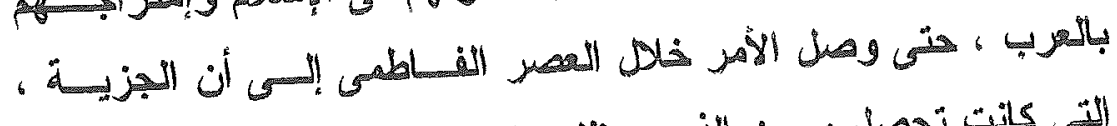

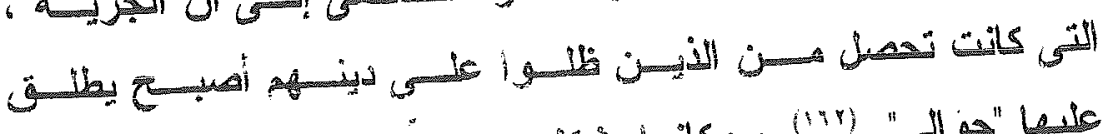

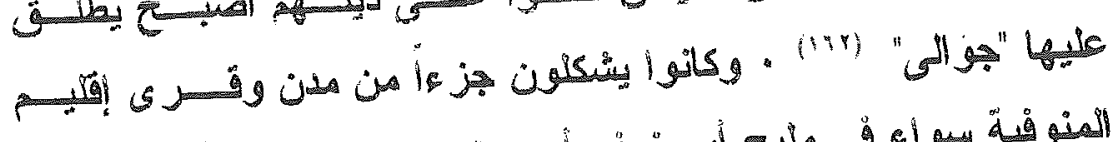

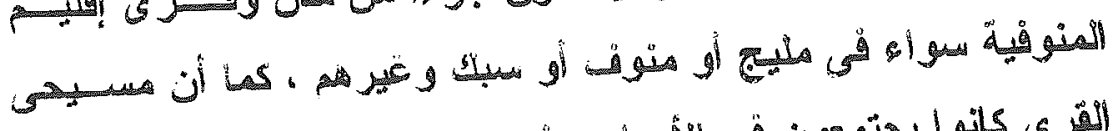

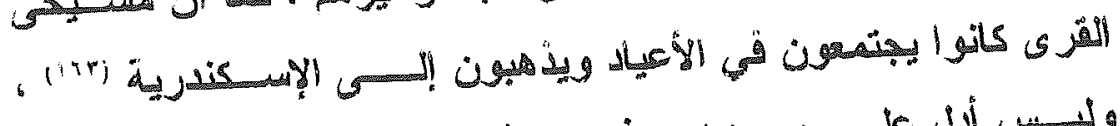

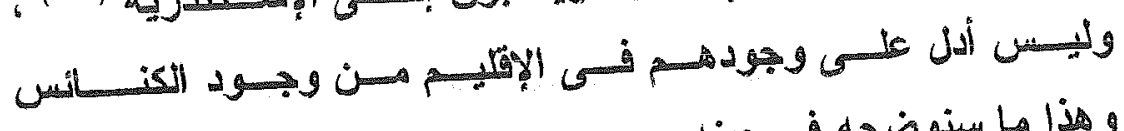

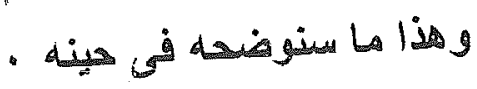

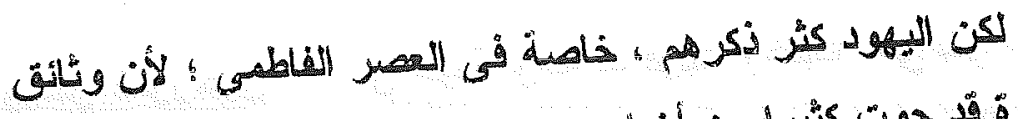

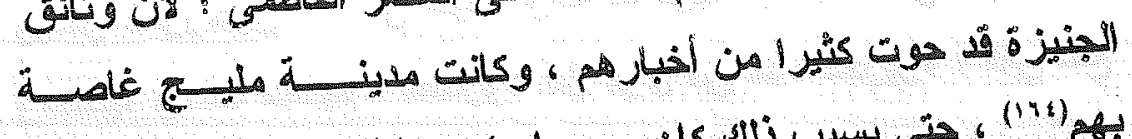

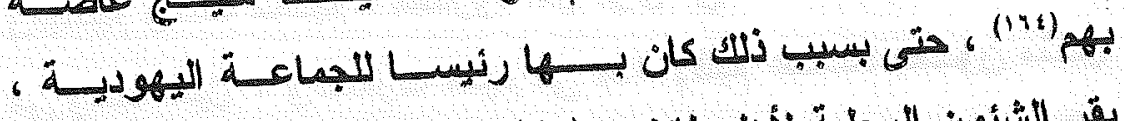

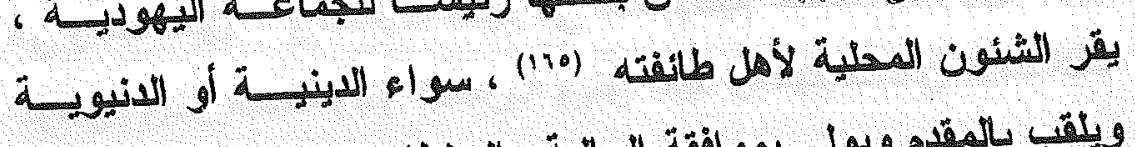

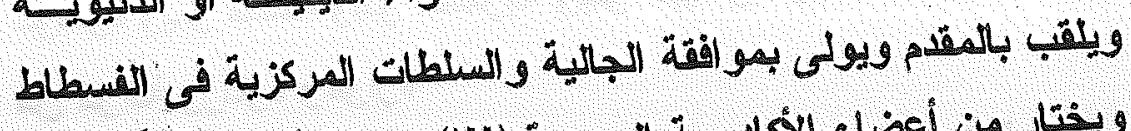

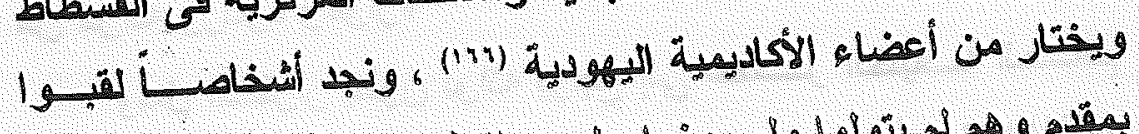

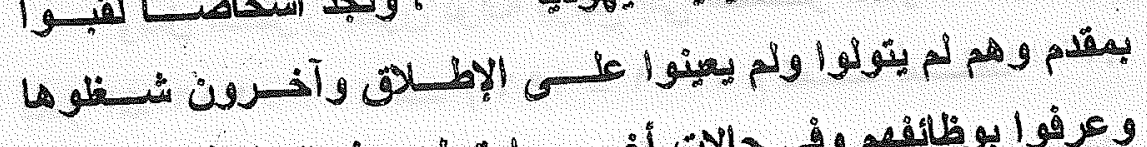

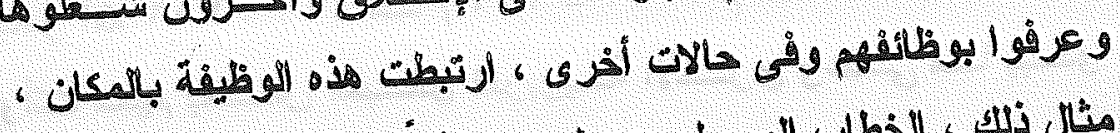

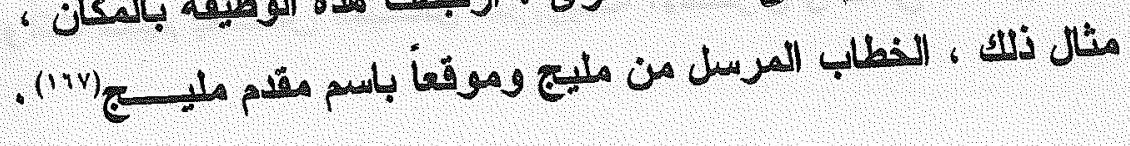




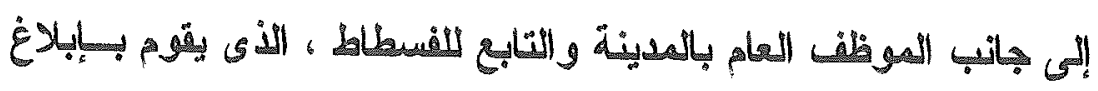

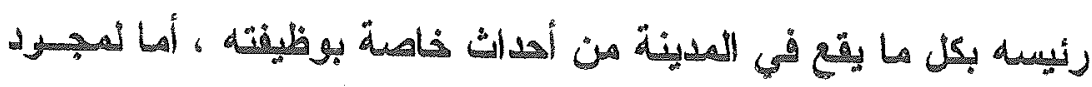

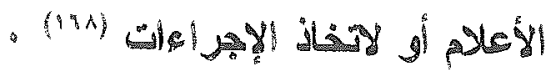

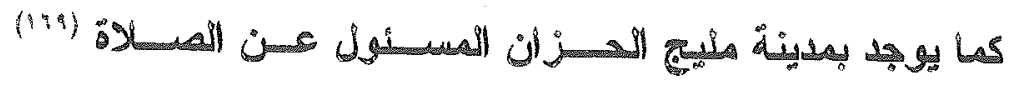

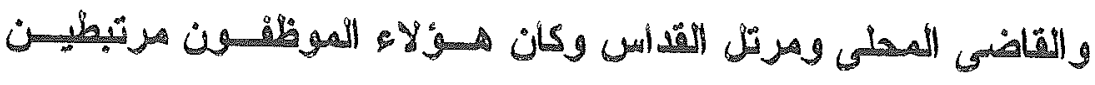

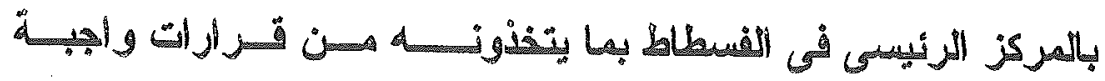

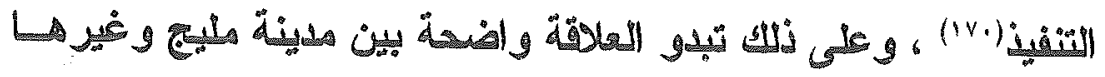

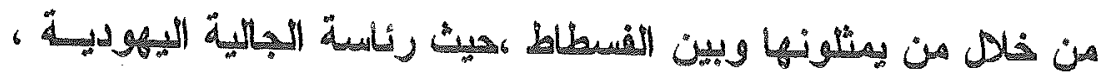

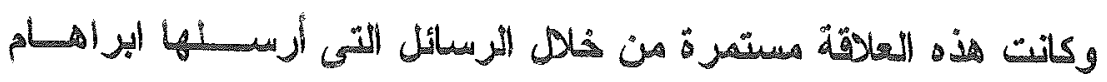

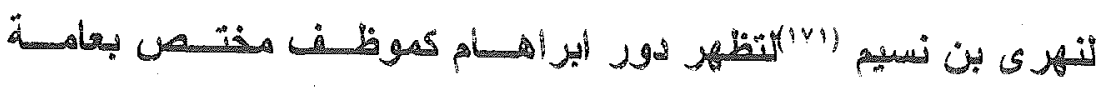

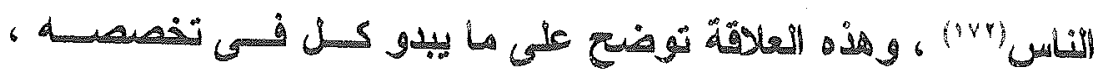

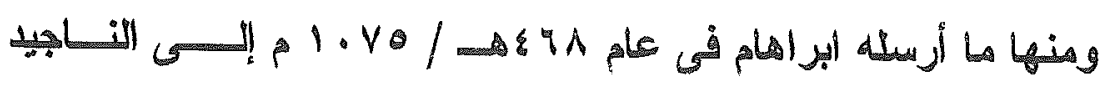

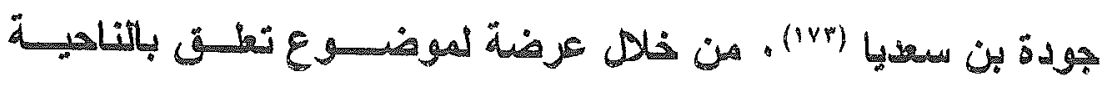

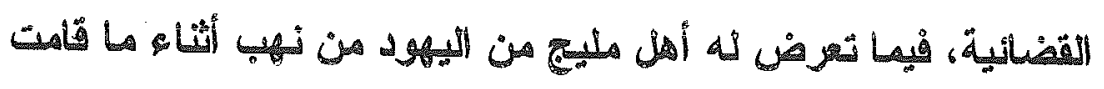

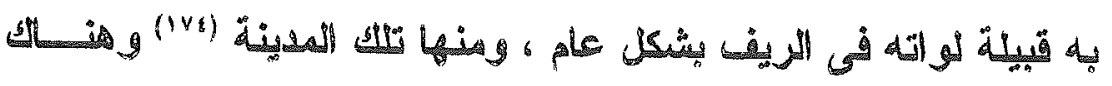

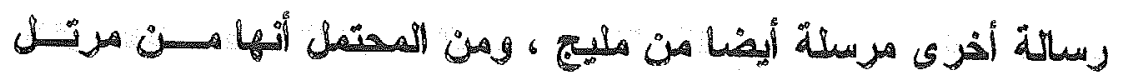

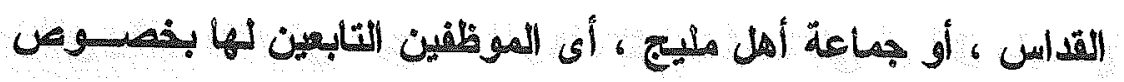

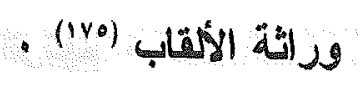

ويبدو أنه أثناء تعيين بعض رجال الدين أو الموظقفين التبايعين

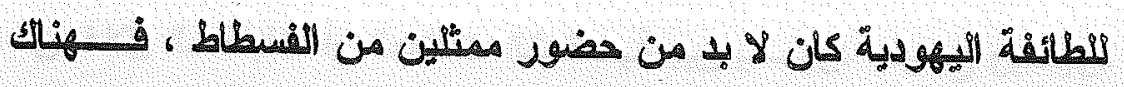

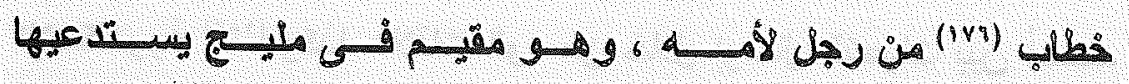

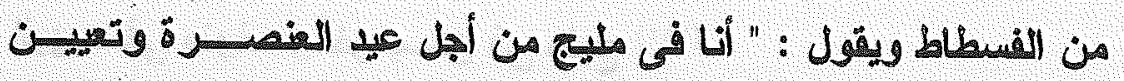

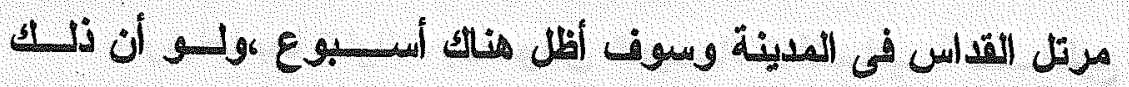

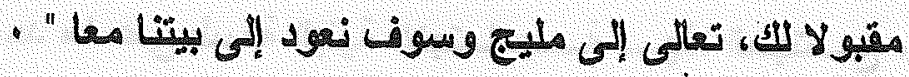




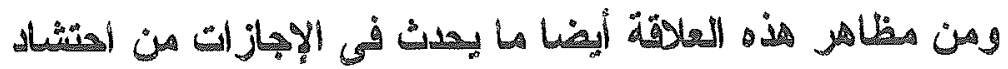

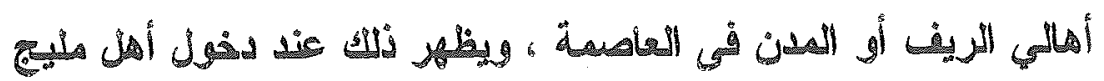

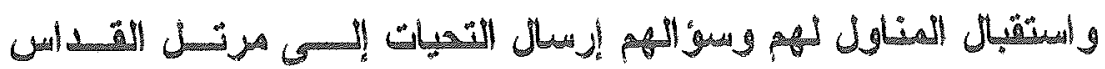

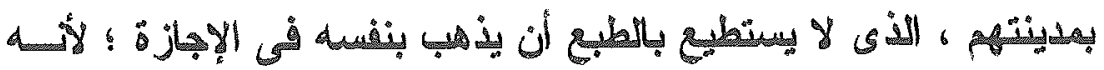

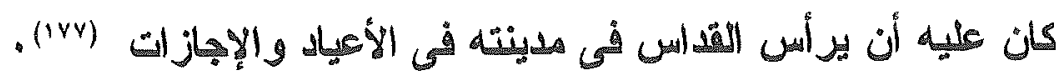

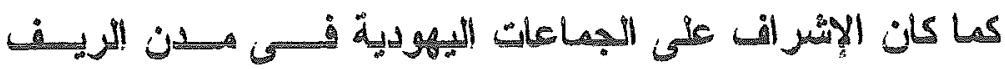

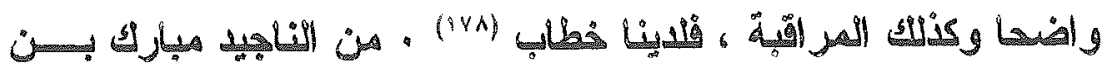

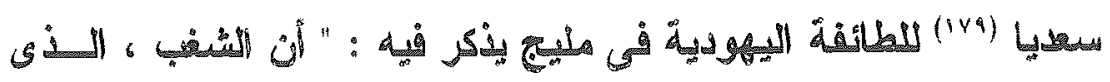

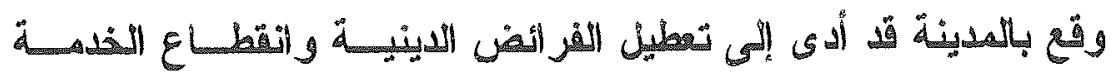

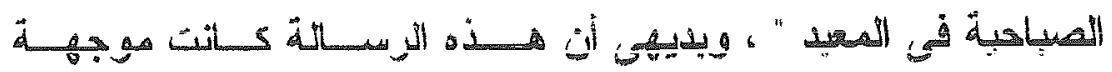

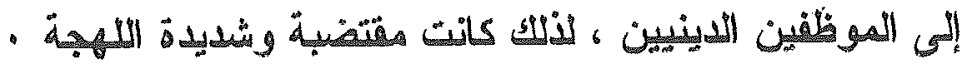

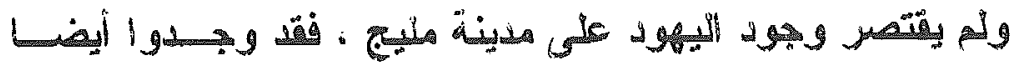

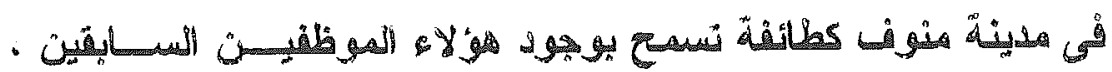

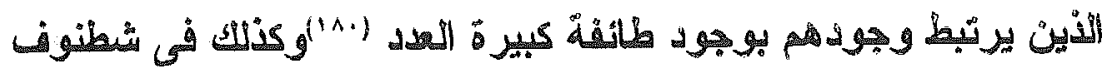

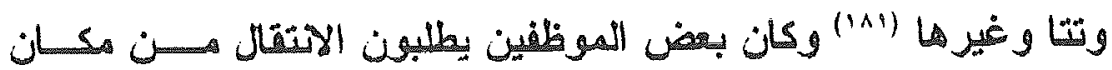

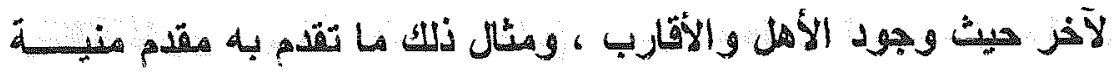

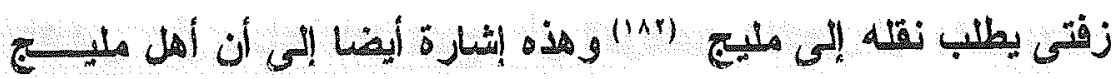

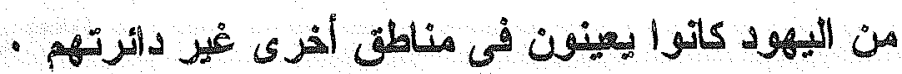

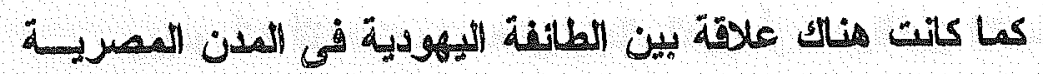

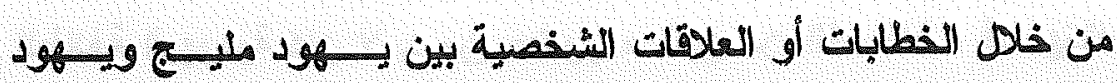

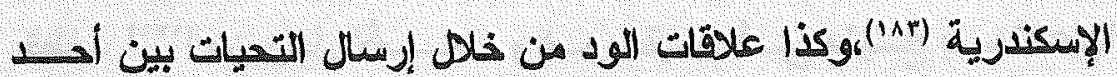

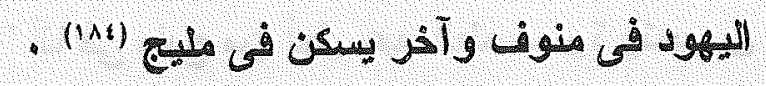

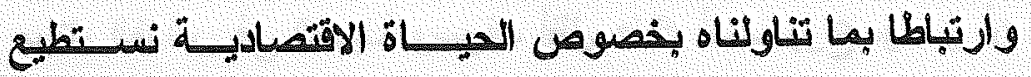

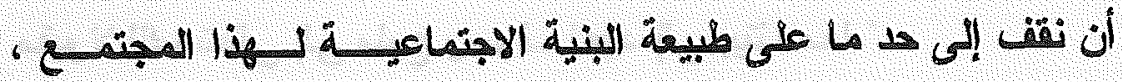




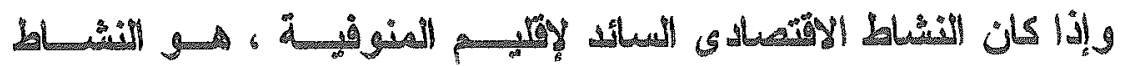

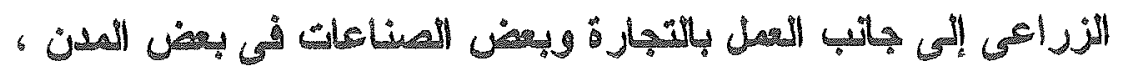

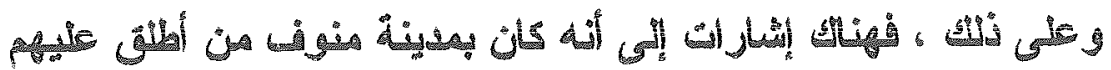
"

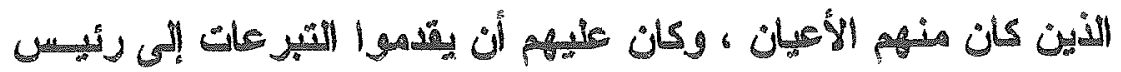

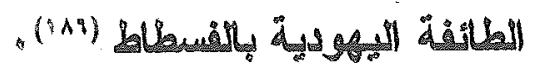

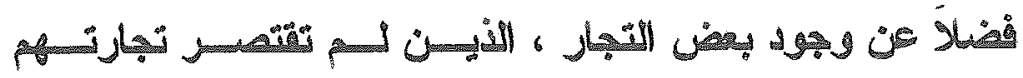

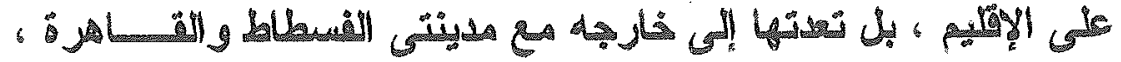

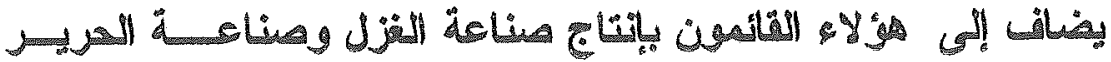

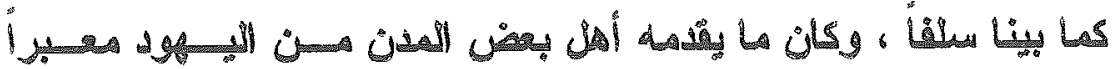

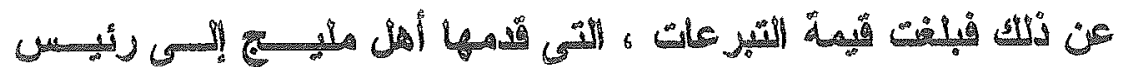
年

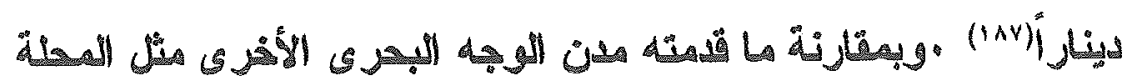

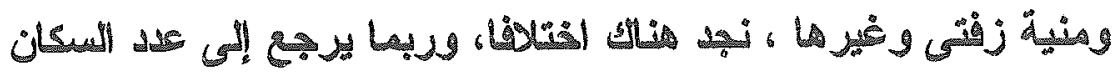

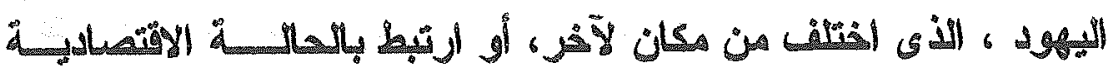

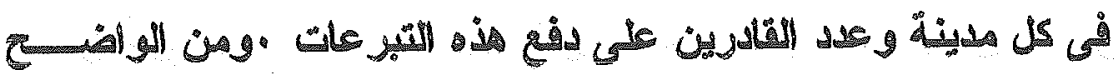

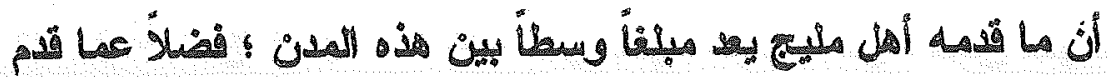

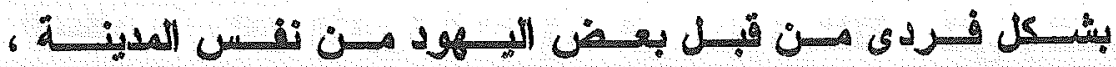

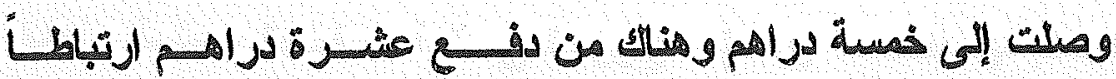

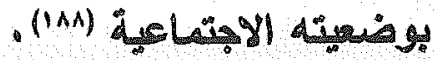

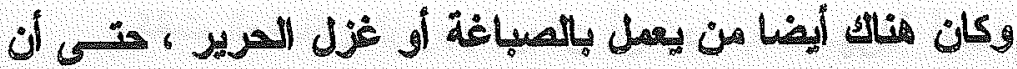

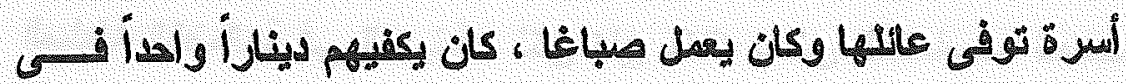

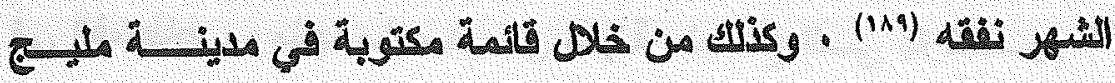

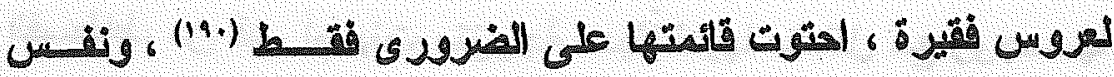




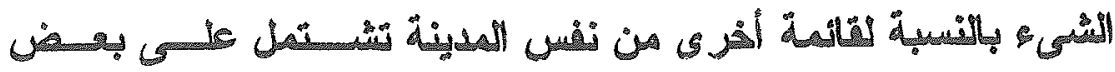

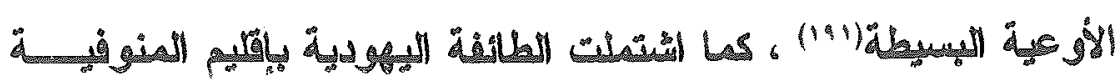

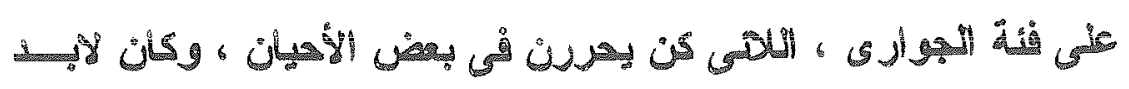

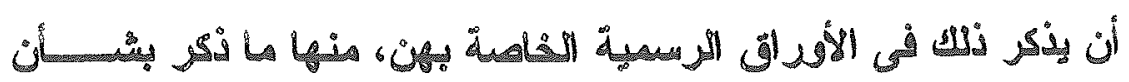

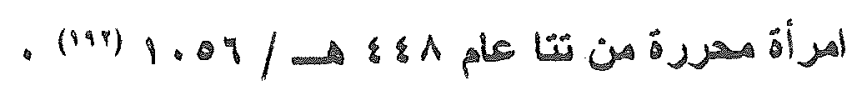

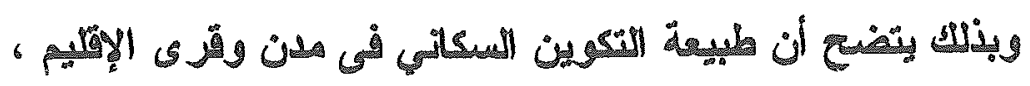

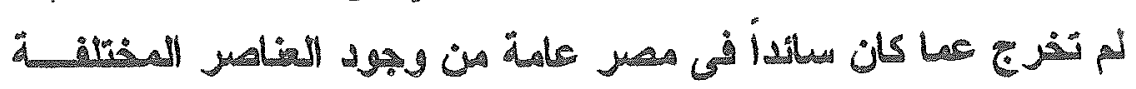

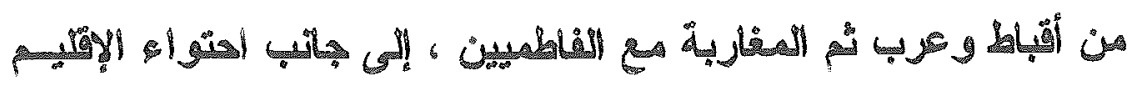

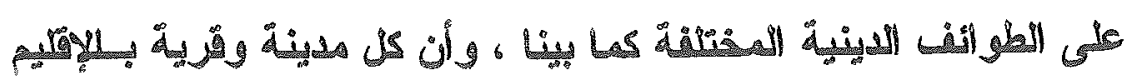

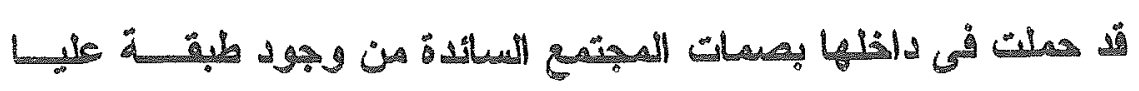

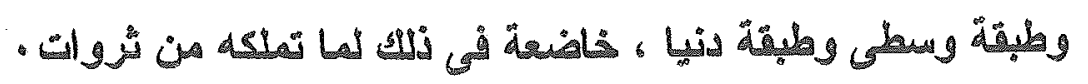

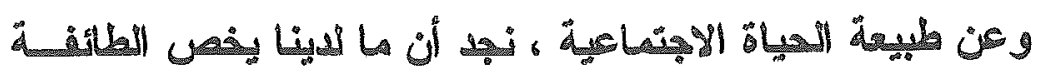

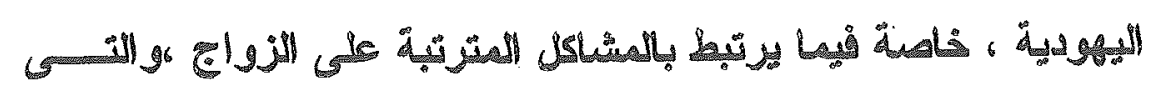

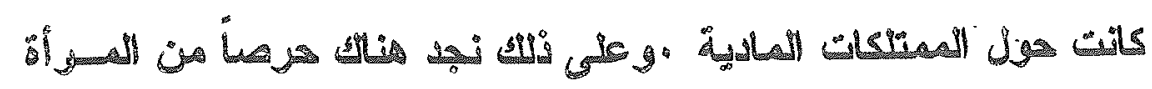

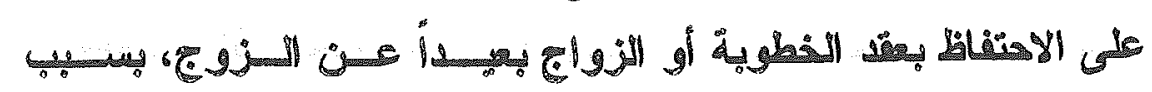

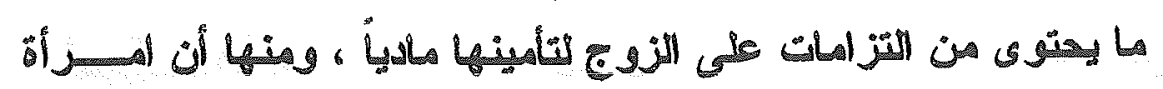

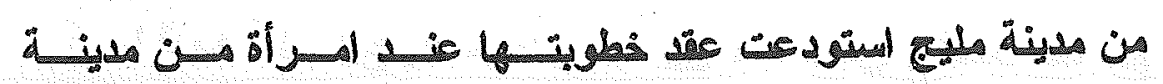

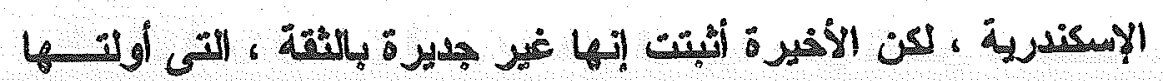

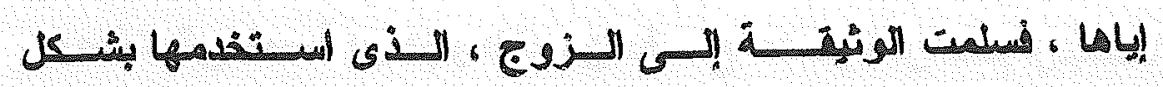

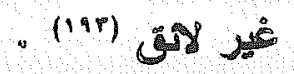

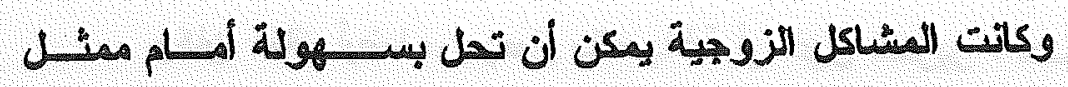

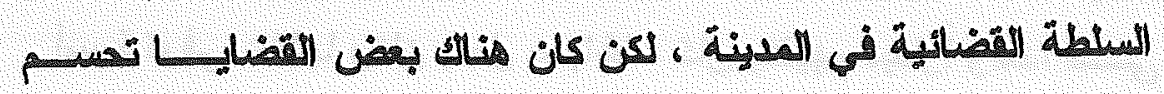

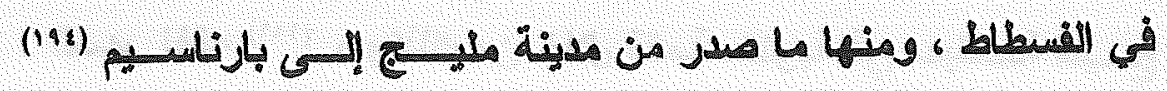

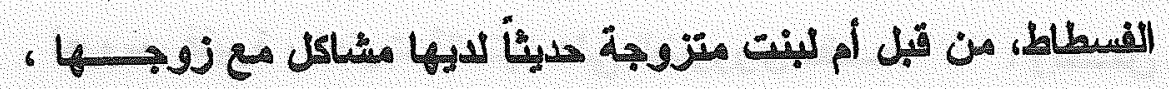




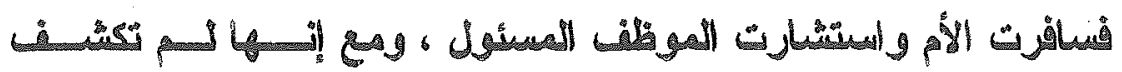

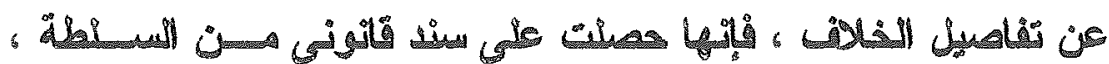

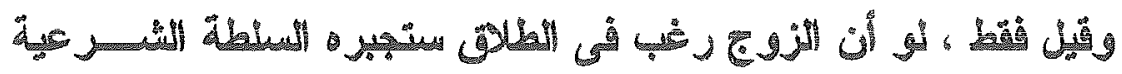

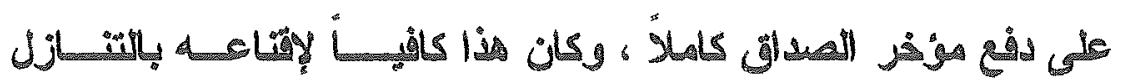

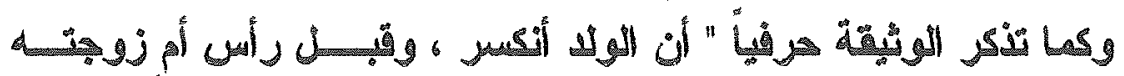

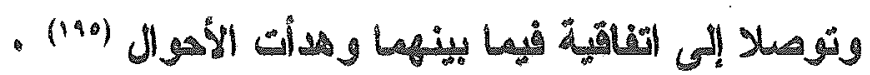

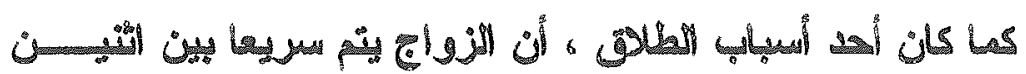

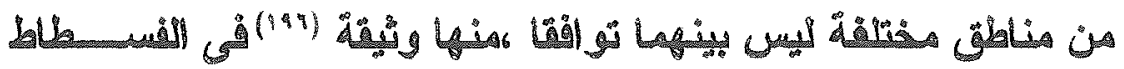

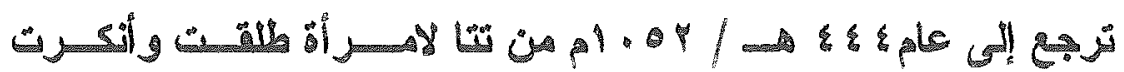

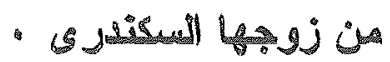

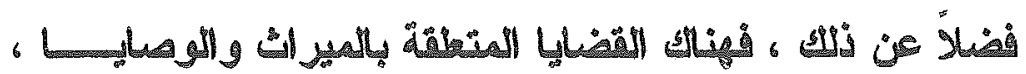

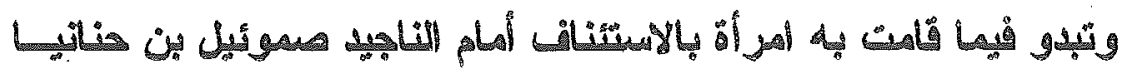

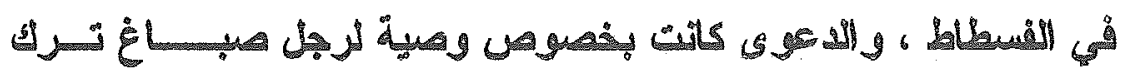

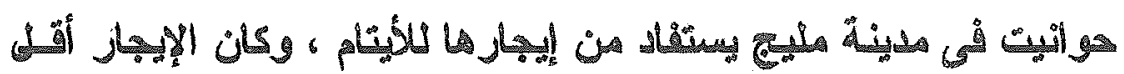

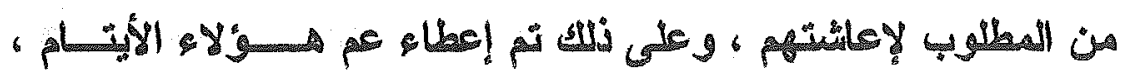

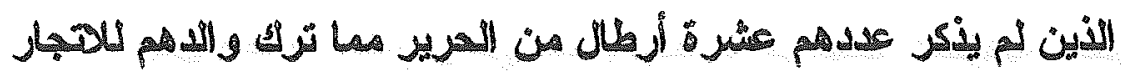

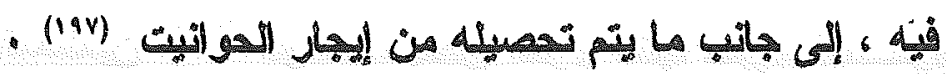

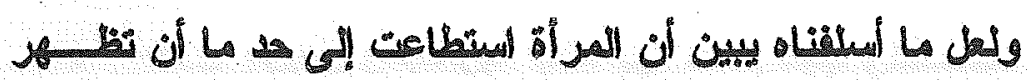

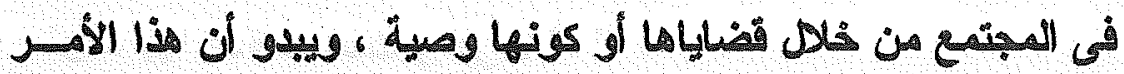

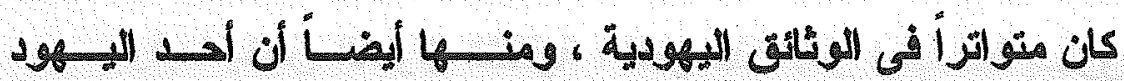

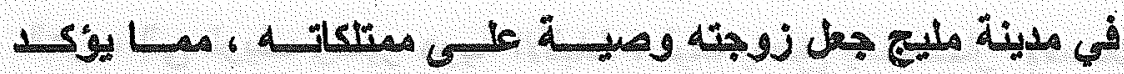

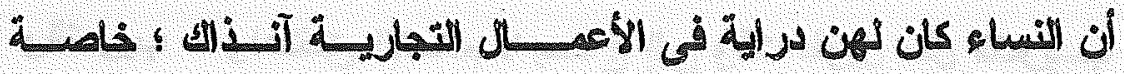

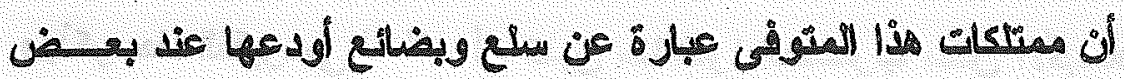

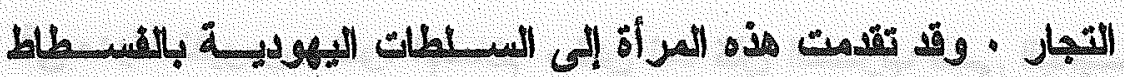




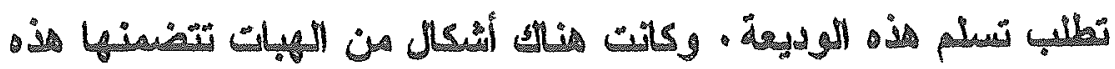

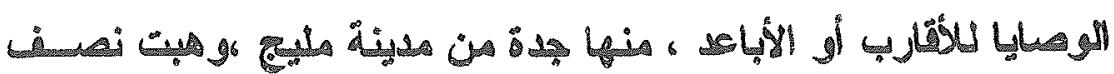

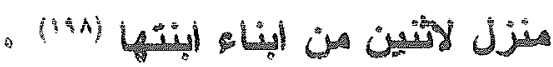

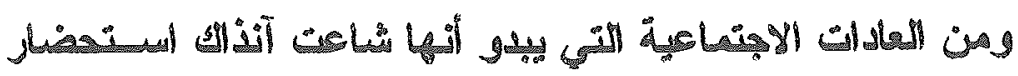

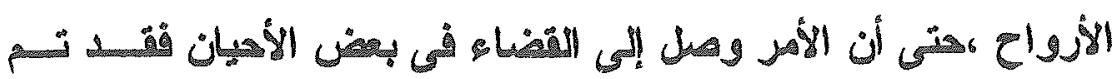

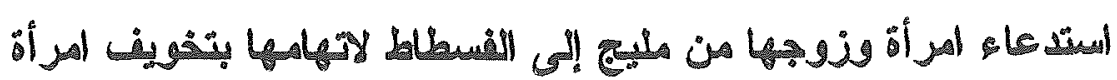

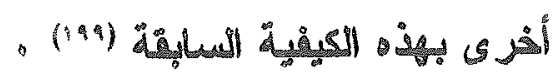

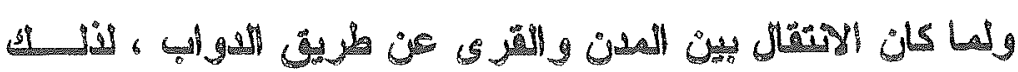

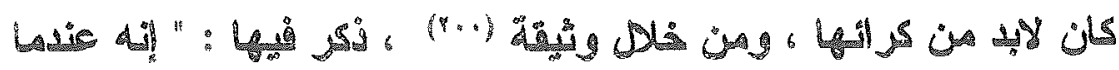

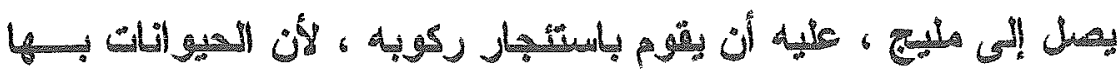

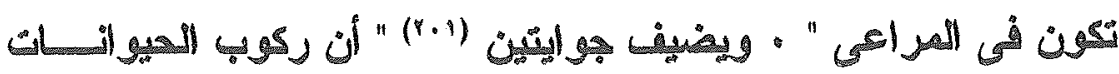

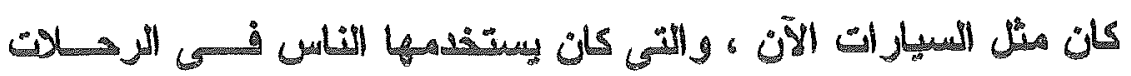

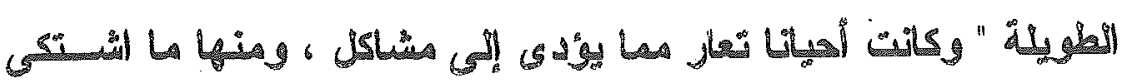

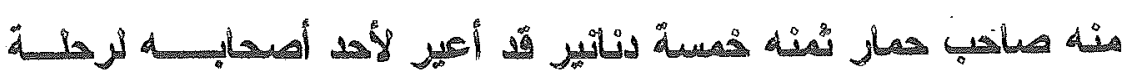

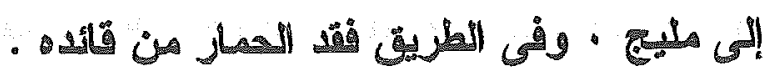

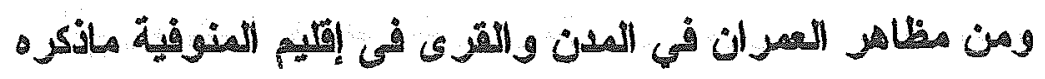

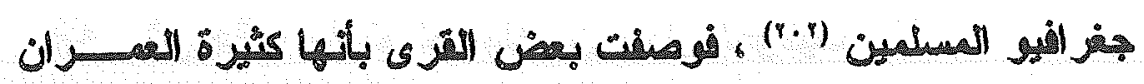

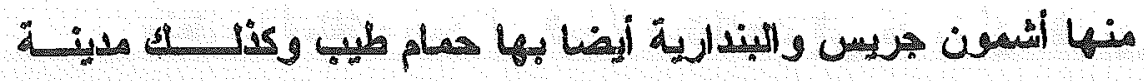

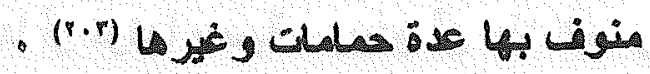

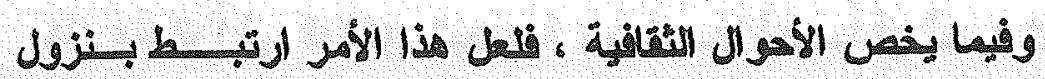

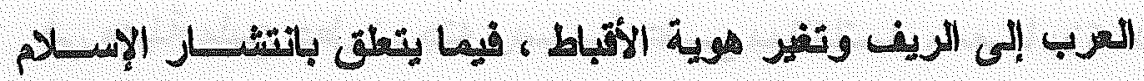

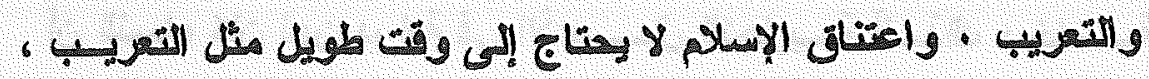

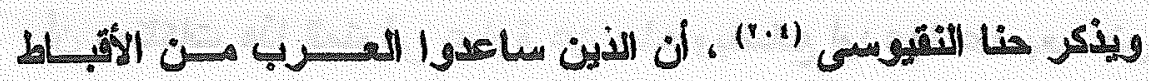

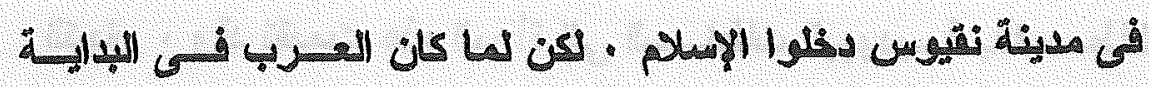




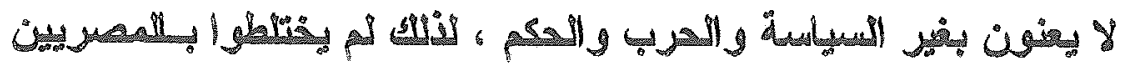

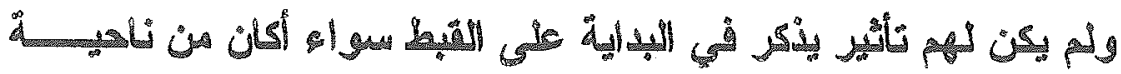

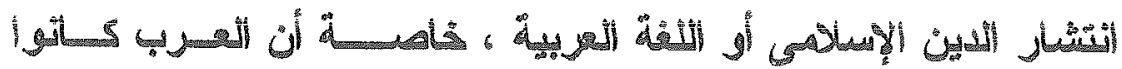

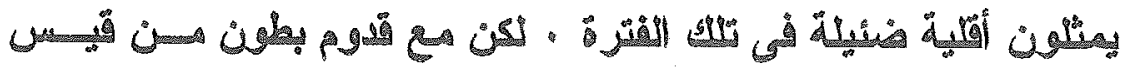

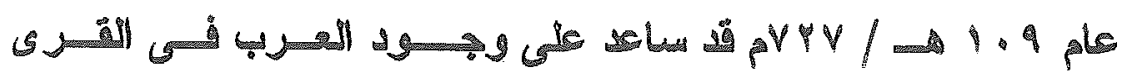

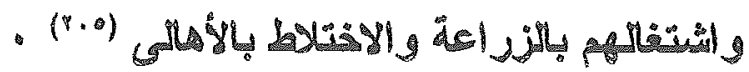

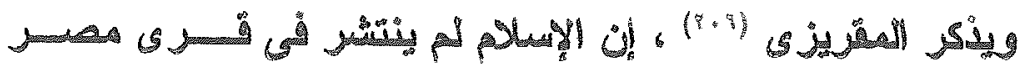

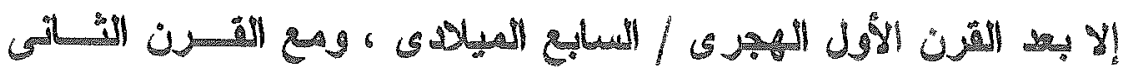

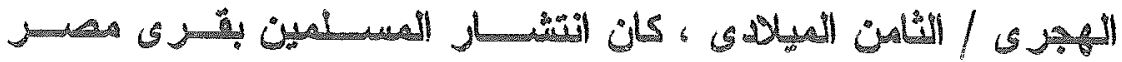

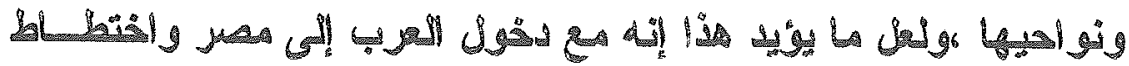

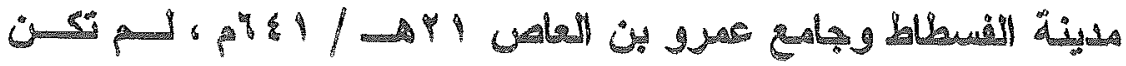

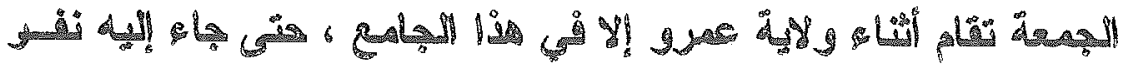

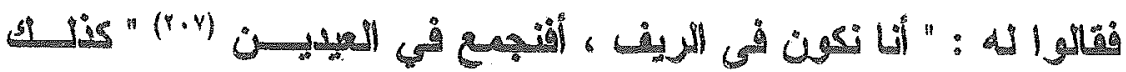

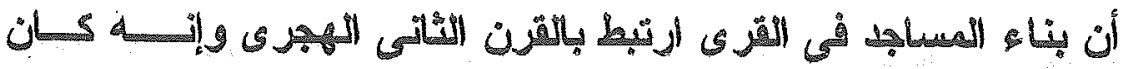

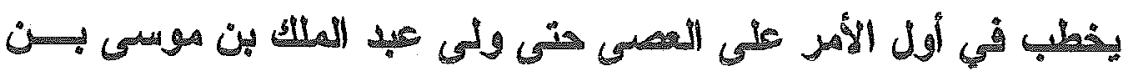

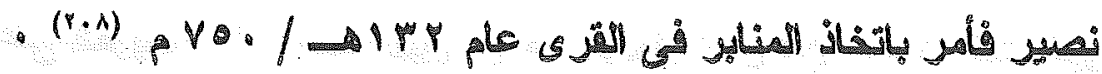

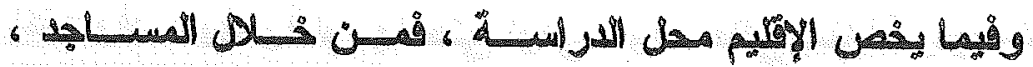

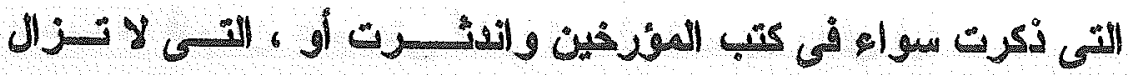

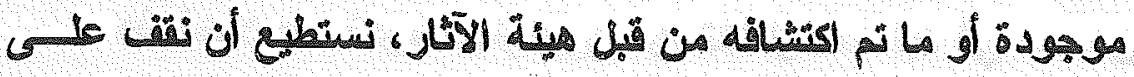

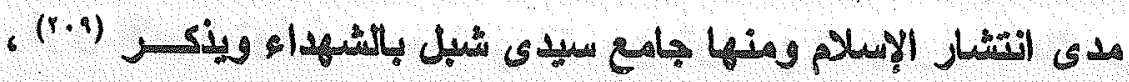

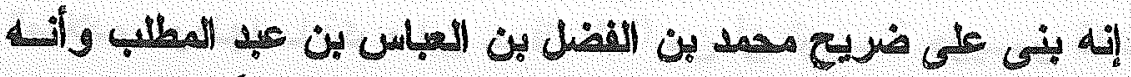

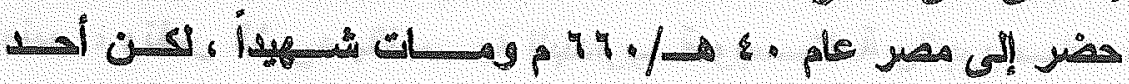

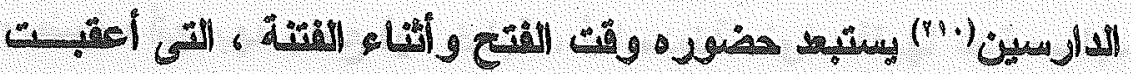

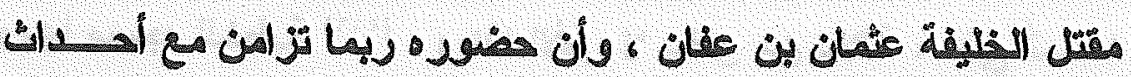




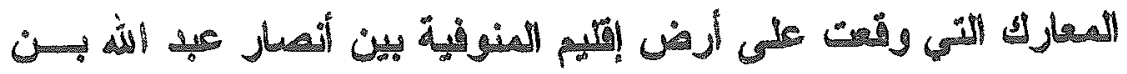

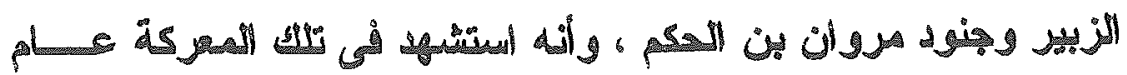

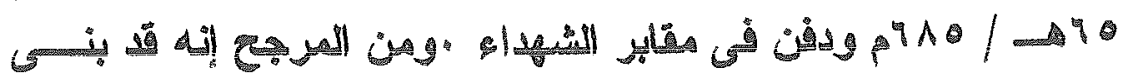

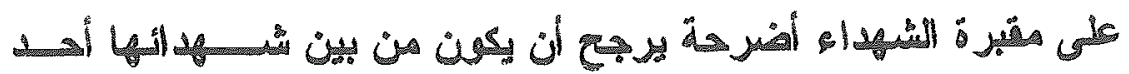

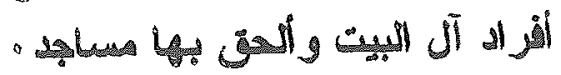

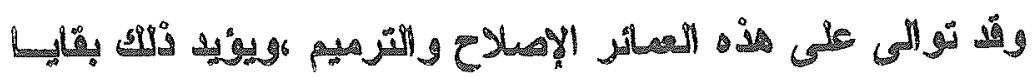

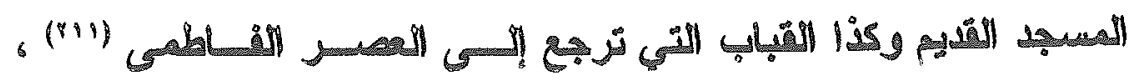

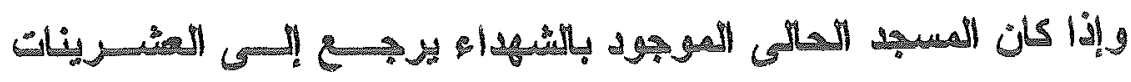

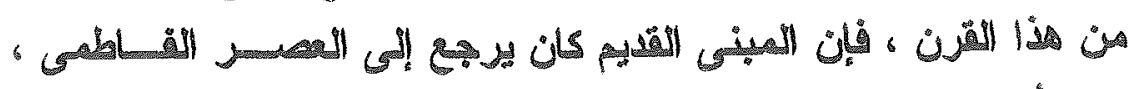

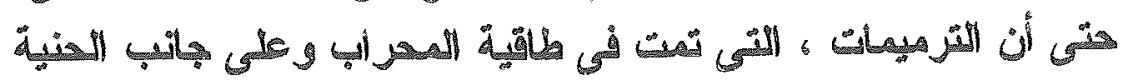

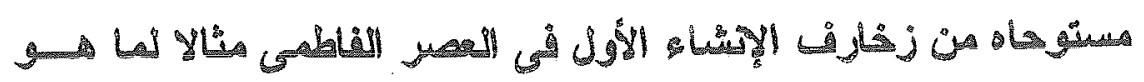

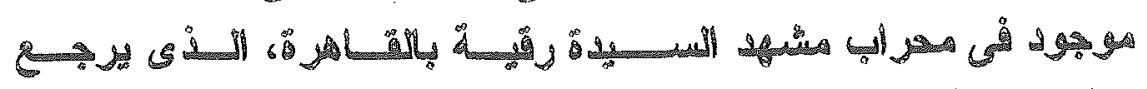

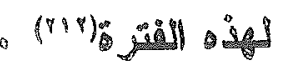

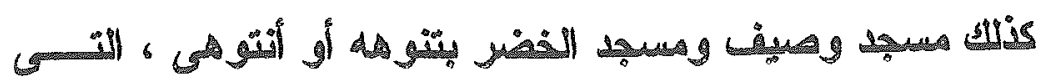

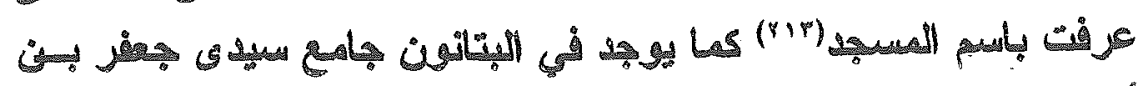

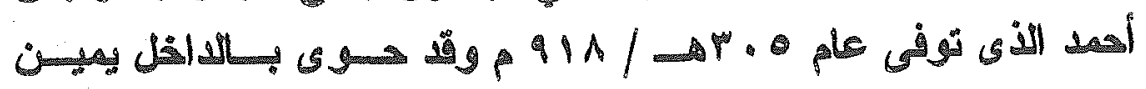

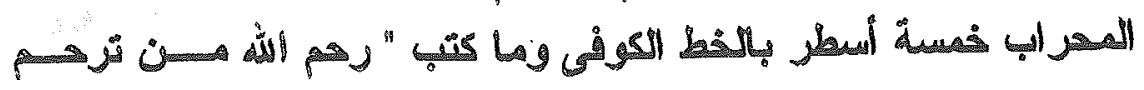

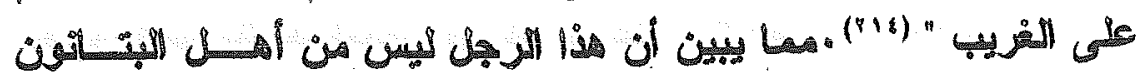

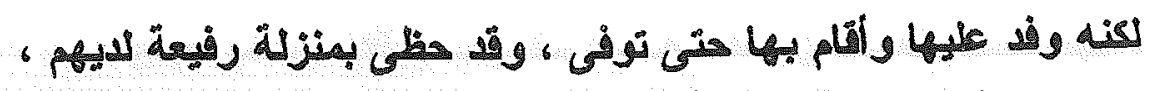

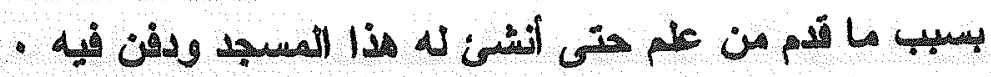

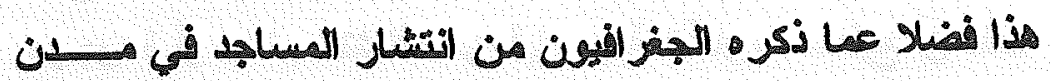

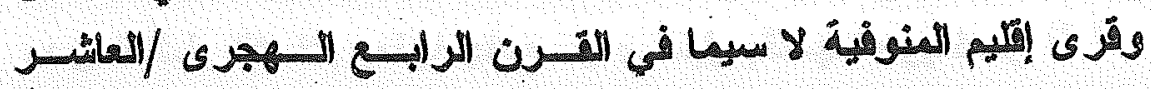

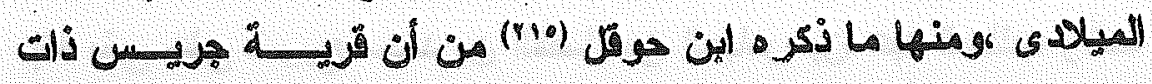

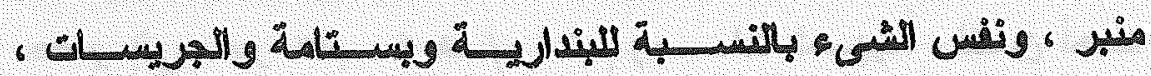

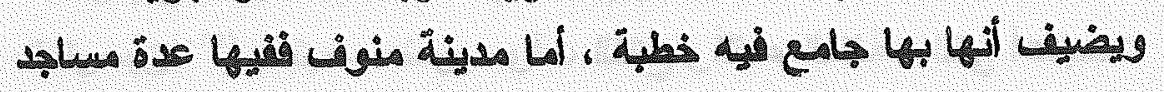

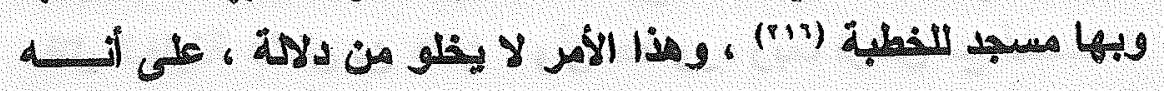




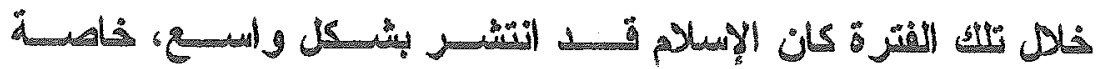

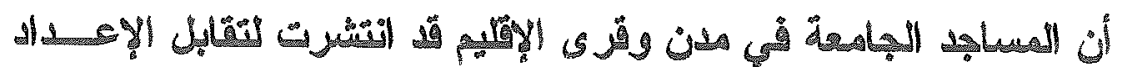

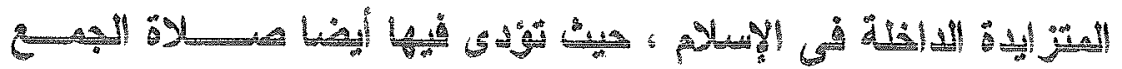

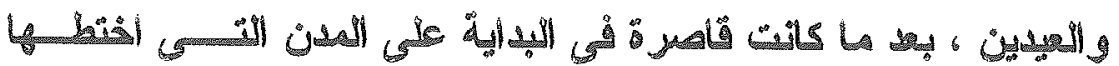
- unanod

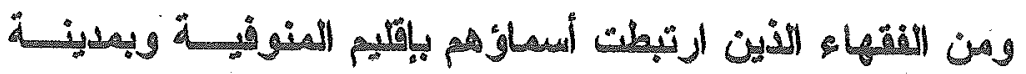

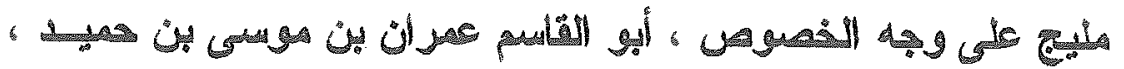

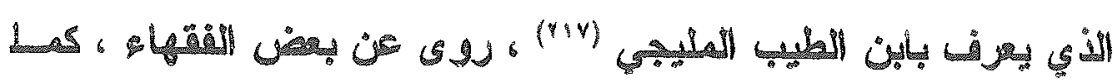
"

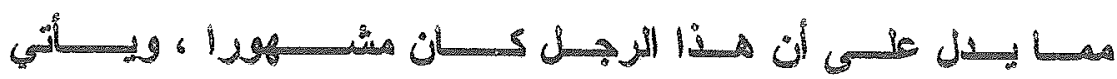

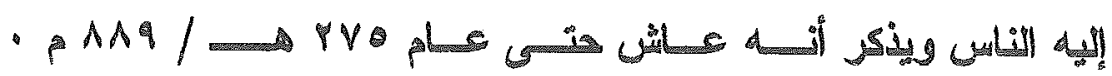

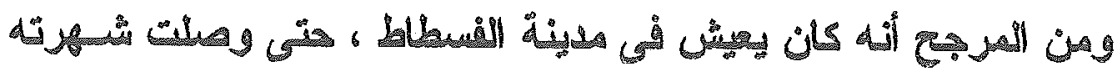

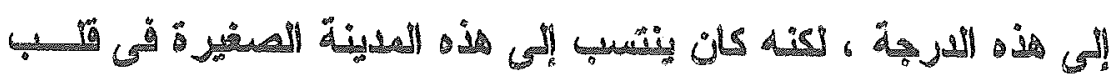

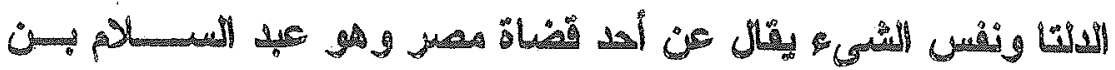

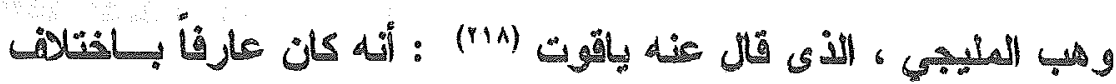

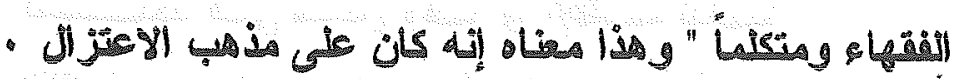

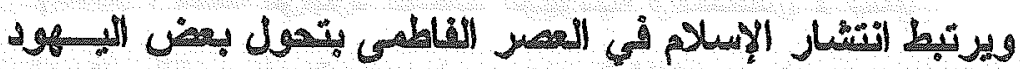

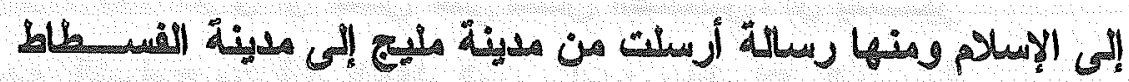

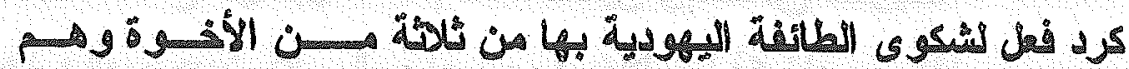

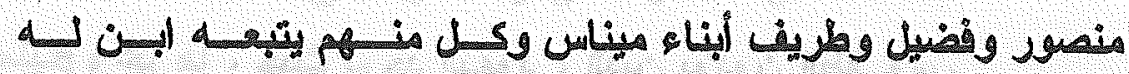

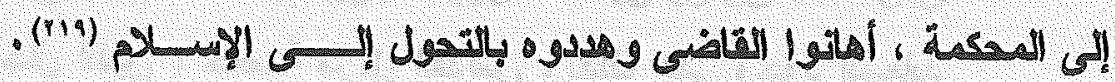

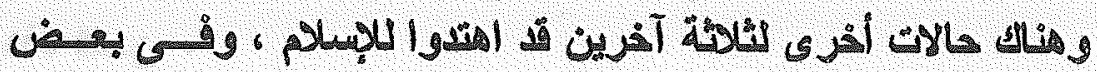




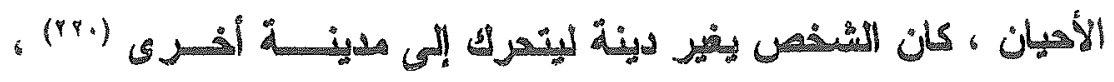

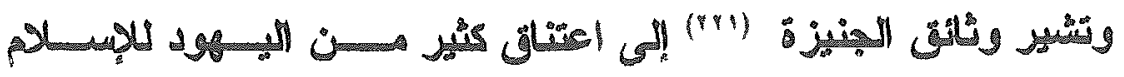

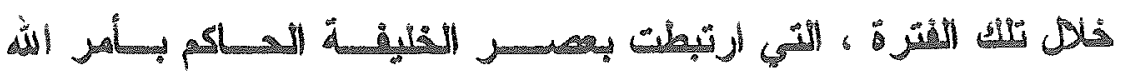

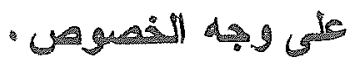

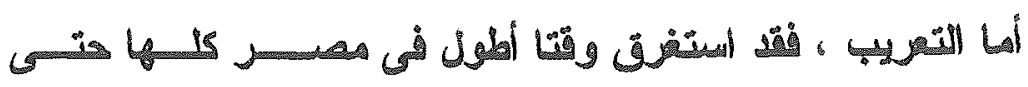

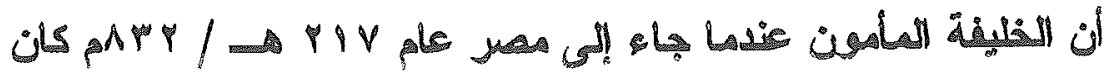

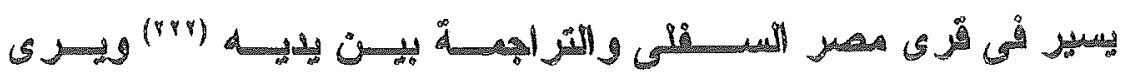

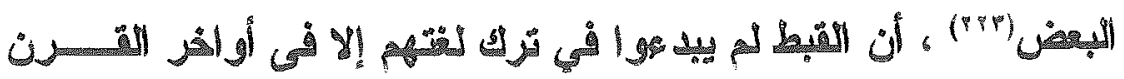

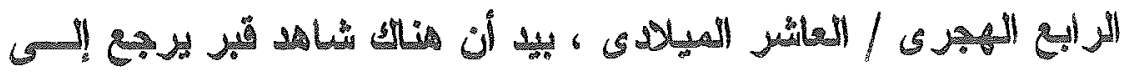

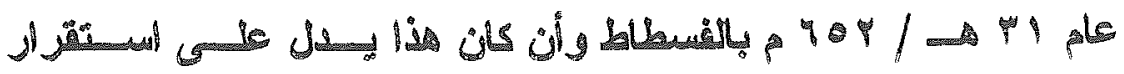

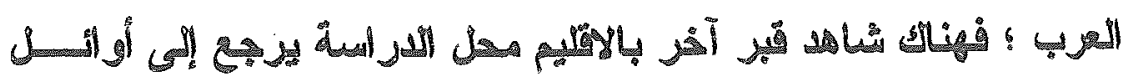

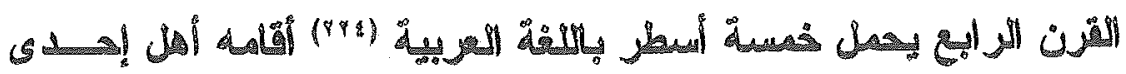

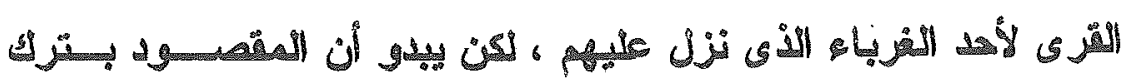

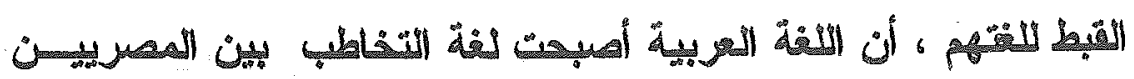

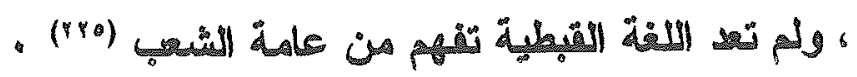

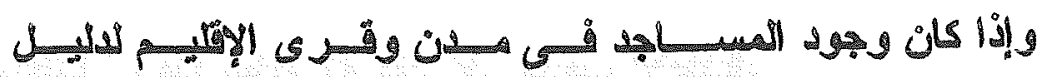

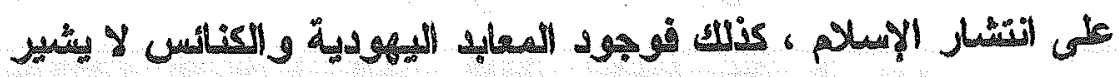

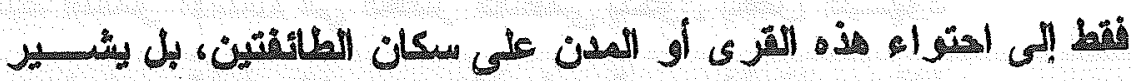

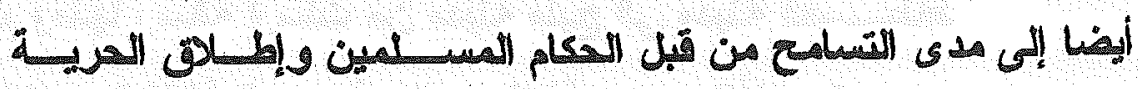

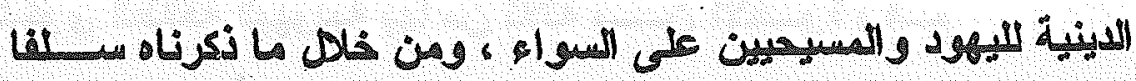

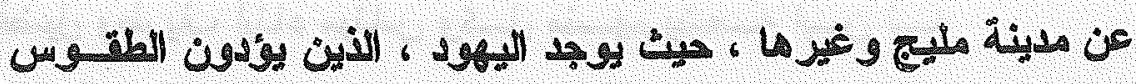

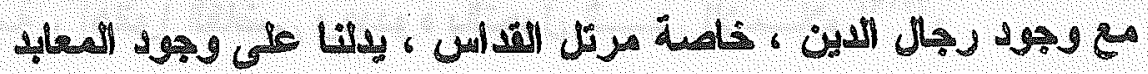
- ندال 


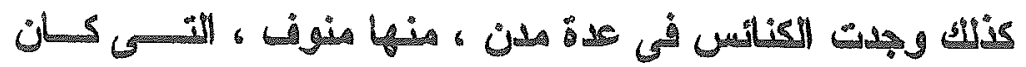

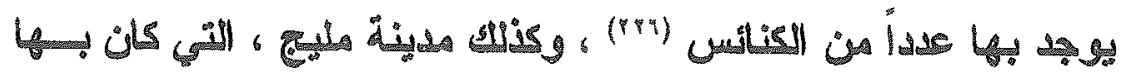

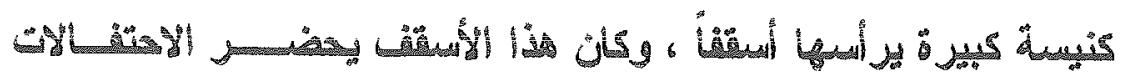

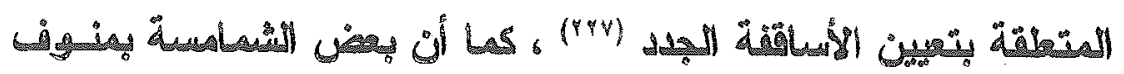

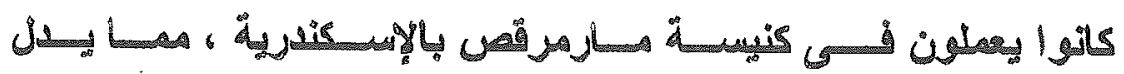

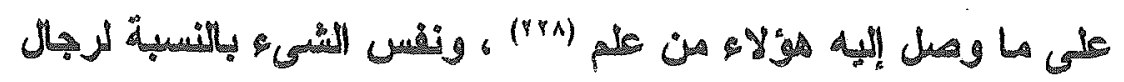

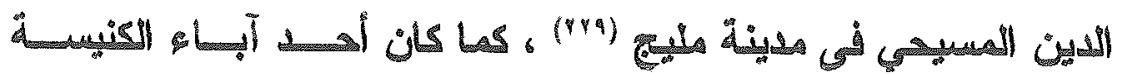

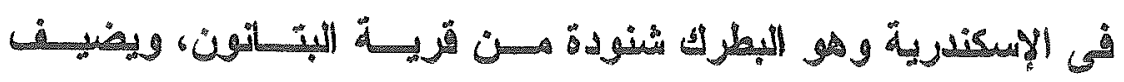

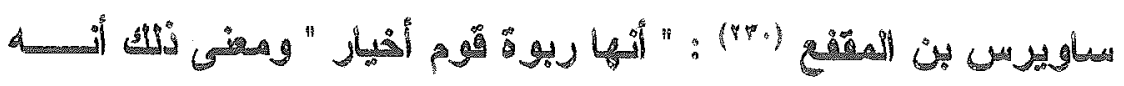
- أيضاك

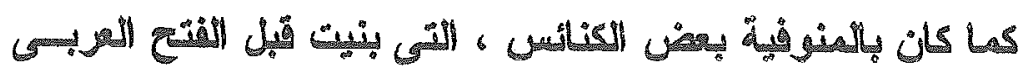

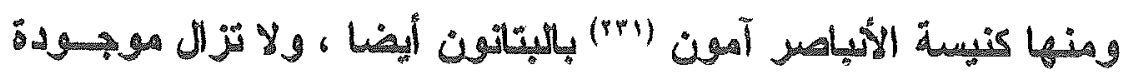

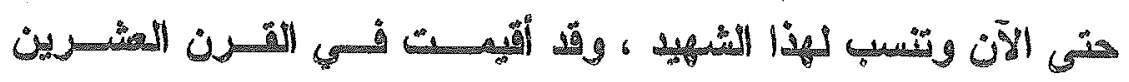

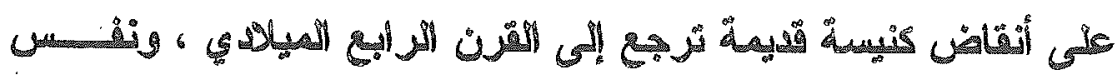

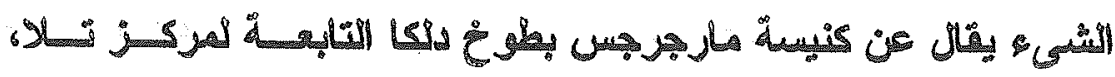

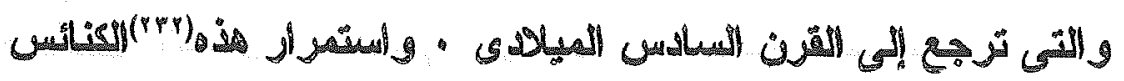

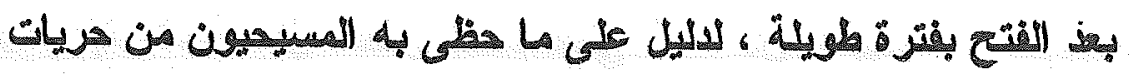

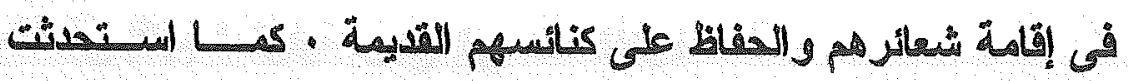

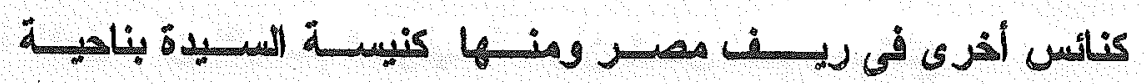
- (YPY)

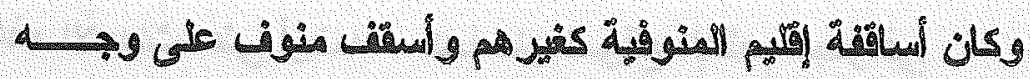

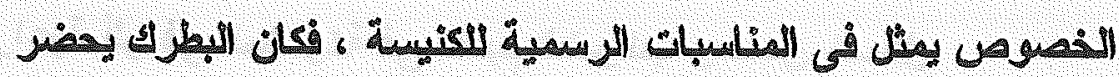

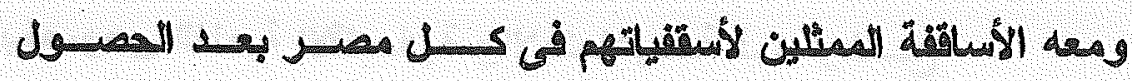

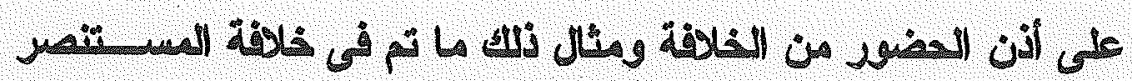




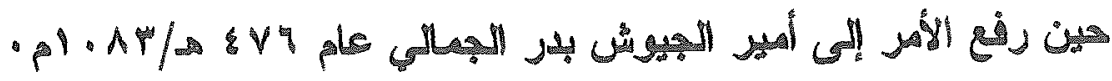

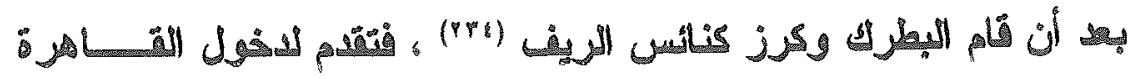

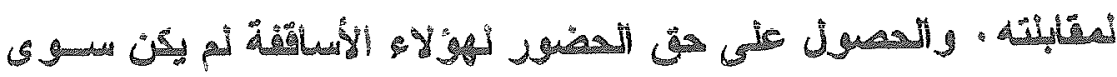

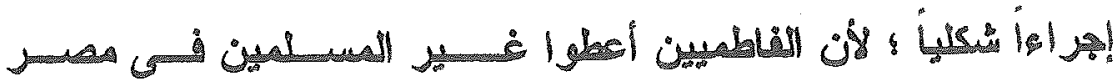

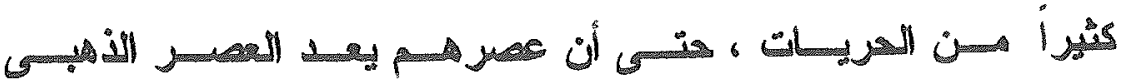

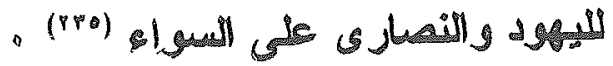

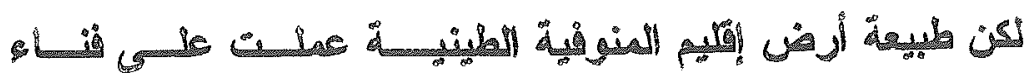

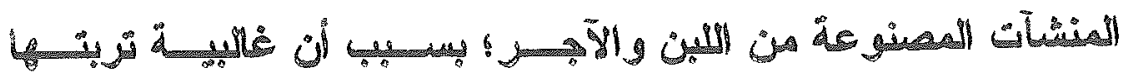

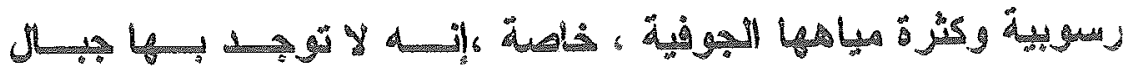

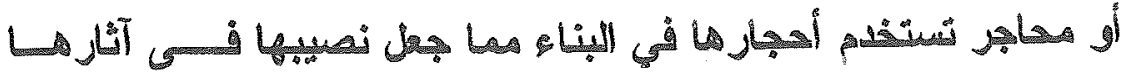
- ("น")

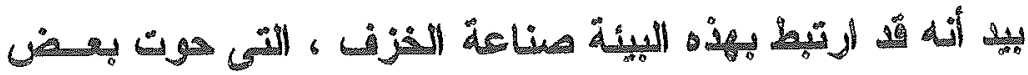

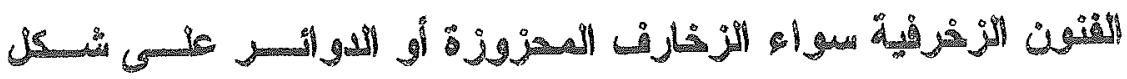

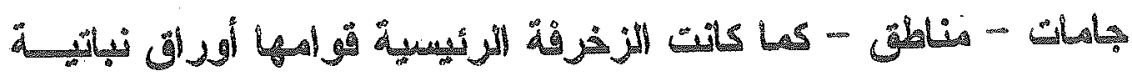

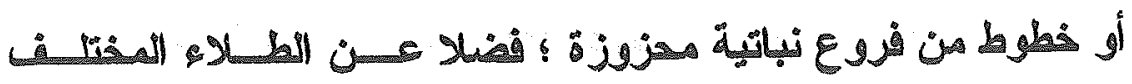

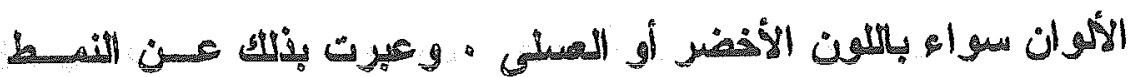

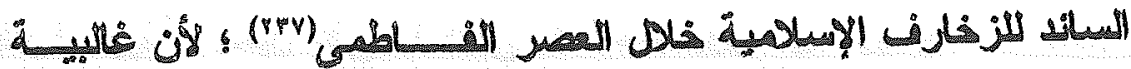

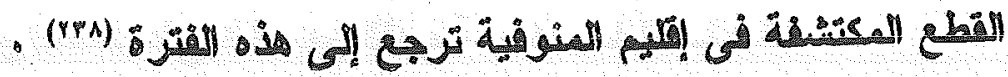

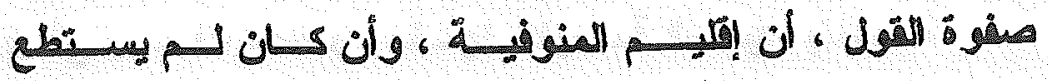

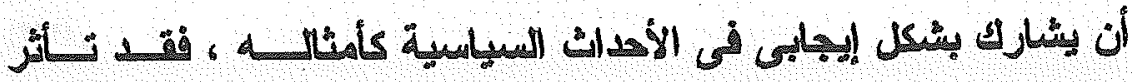

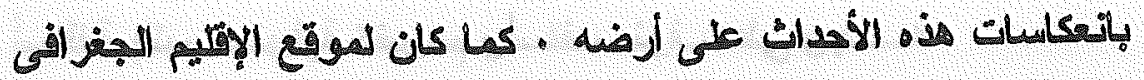

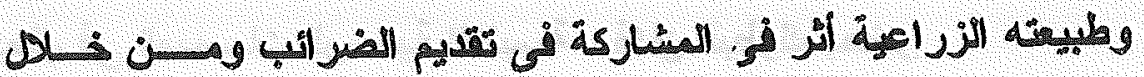

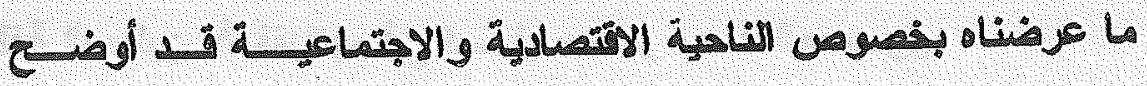




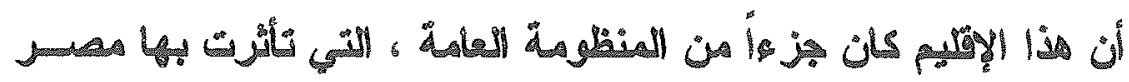

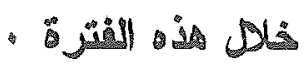

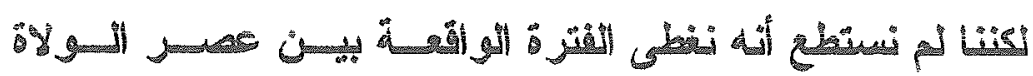

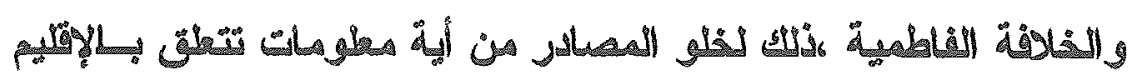

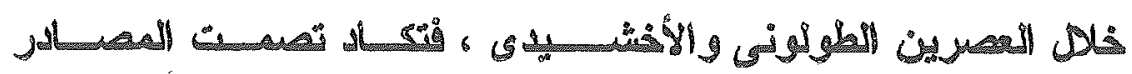

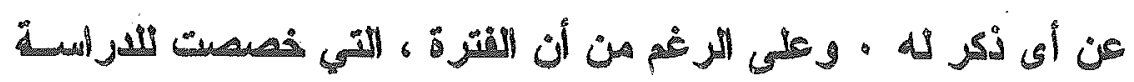

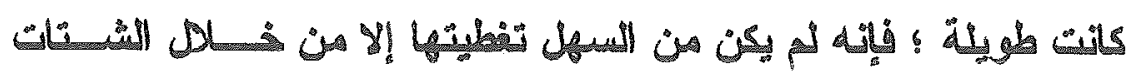

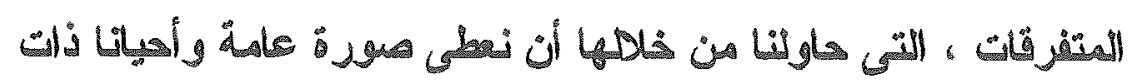

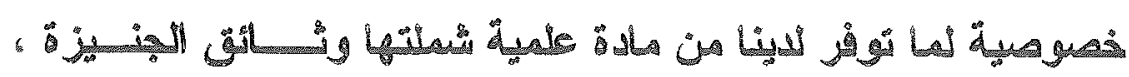

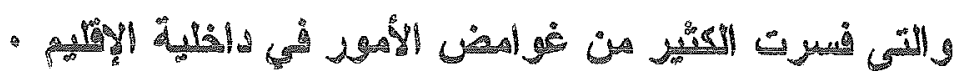




\section{sival onll}

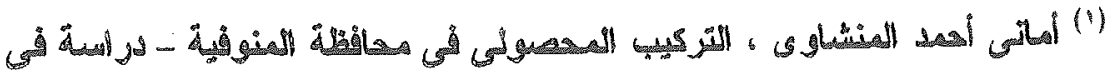

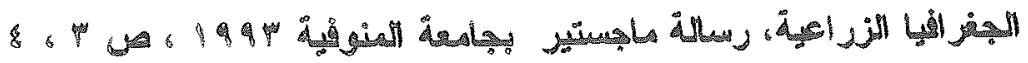

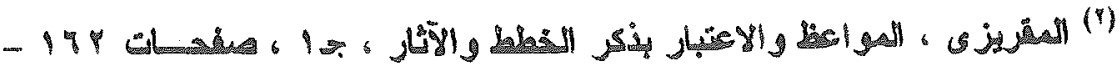

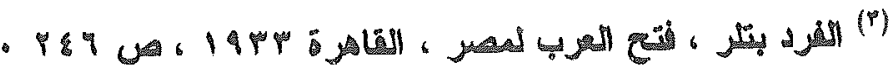

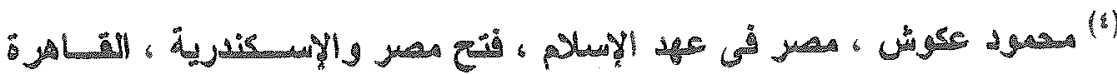

$$
\text { - Th y }
$$

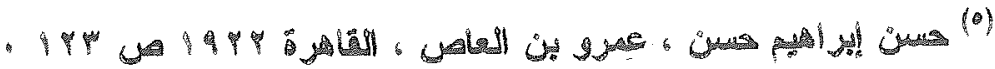

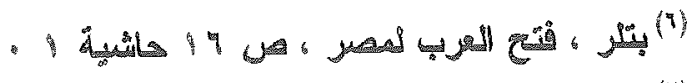

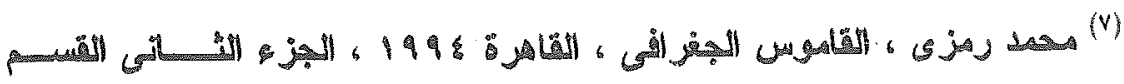

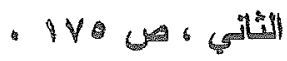

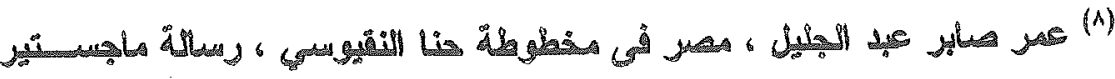

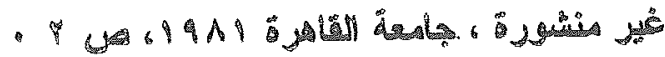

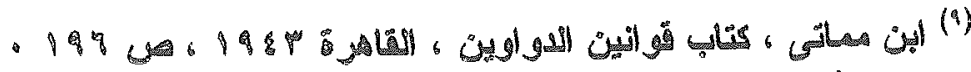

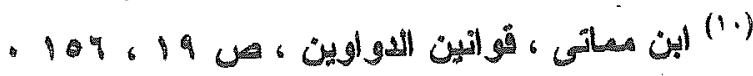

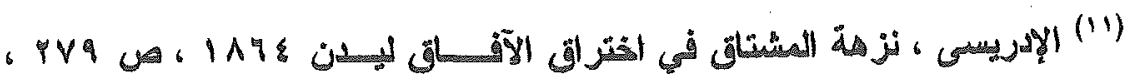

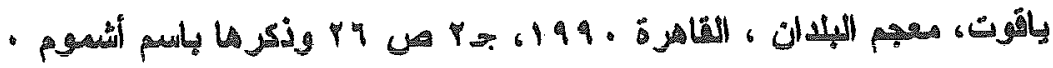

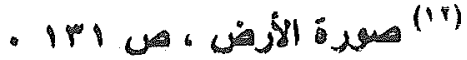

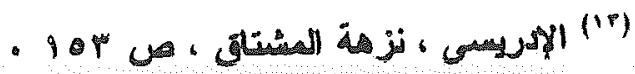

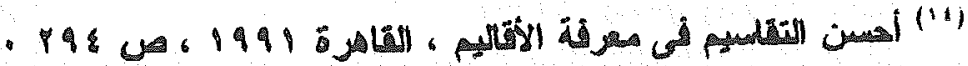

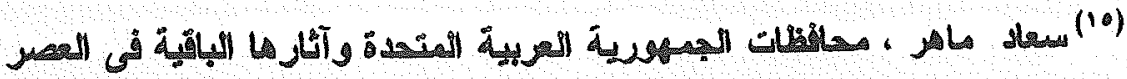

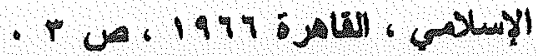

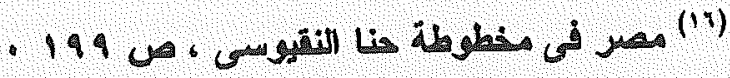

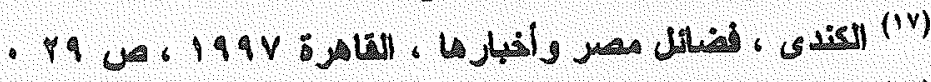

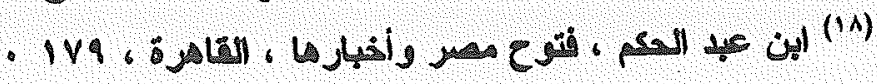




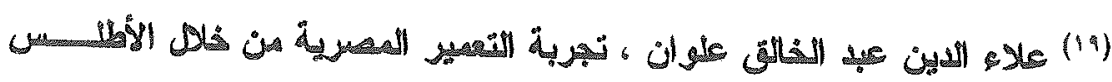

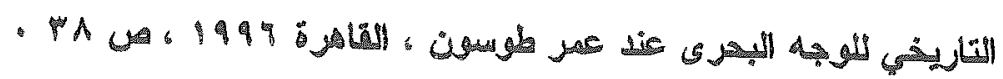

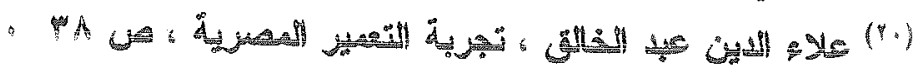

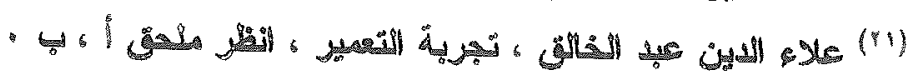

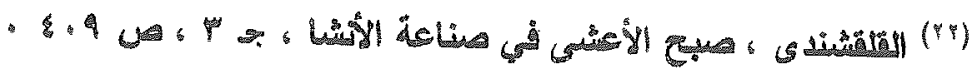

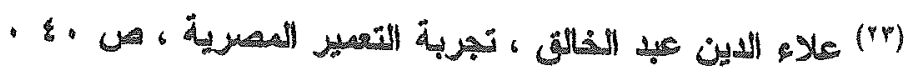

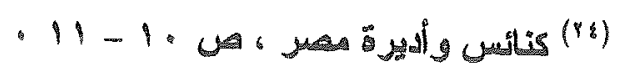

. 199 V - ए4

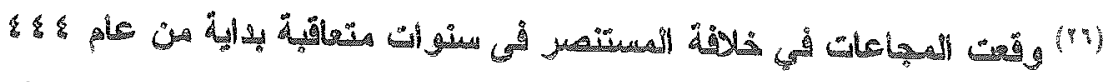

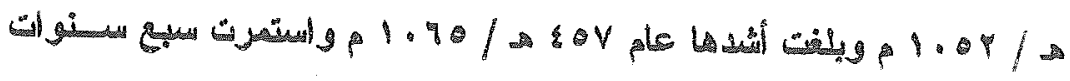

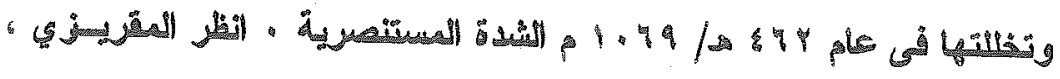

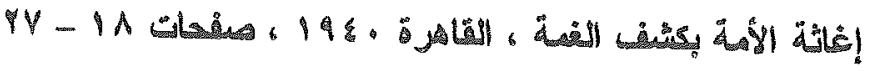

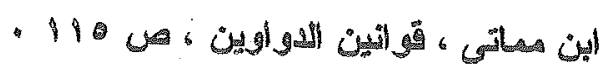

(V)

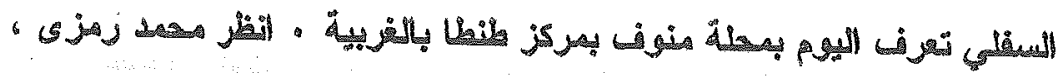

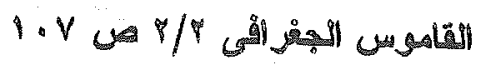

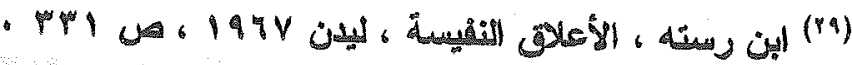

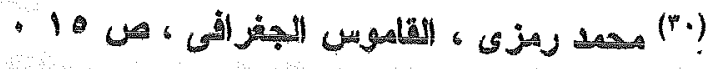

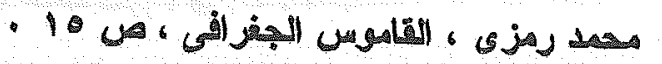

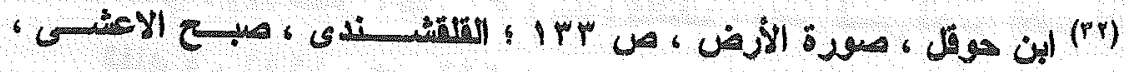

$$
\text { - Pr uno- }
$$

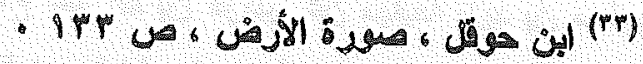

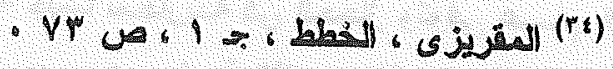

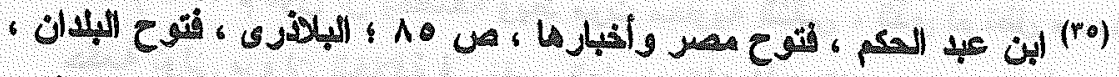

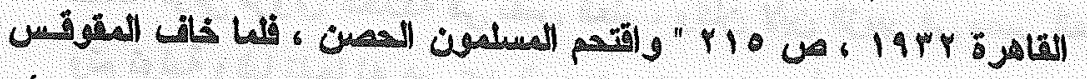

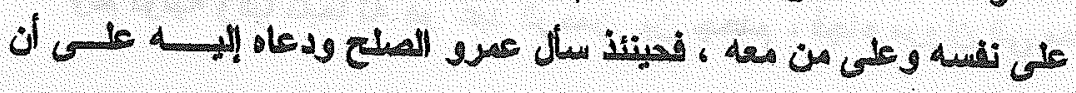




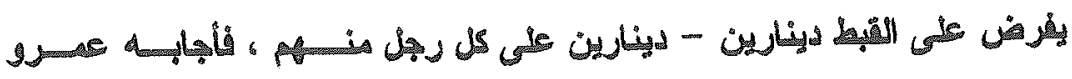
- إلى

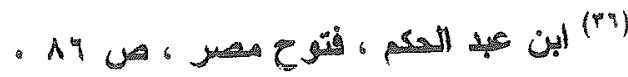

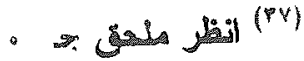

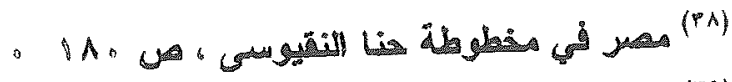

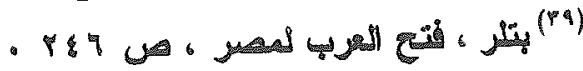

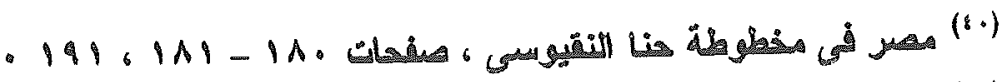

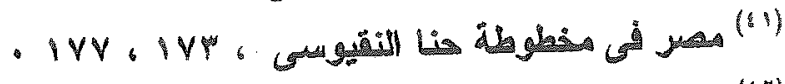

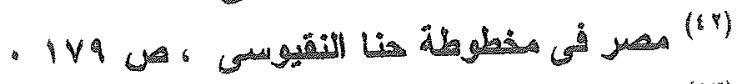

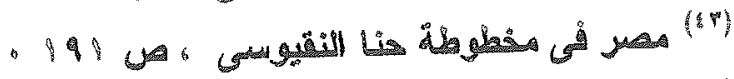

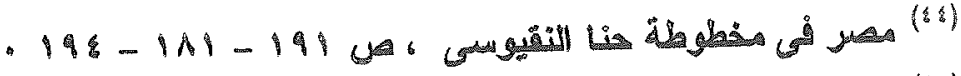

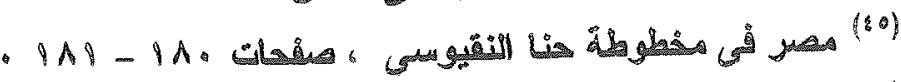

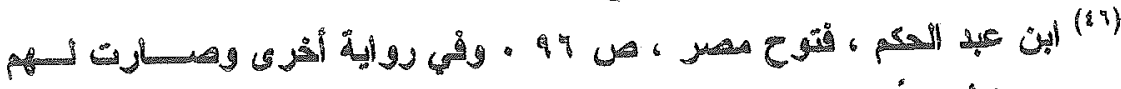

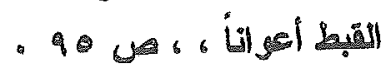

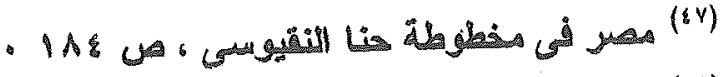

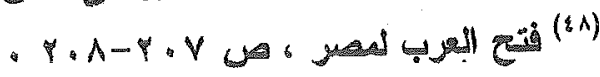

- |

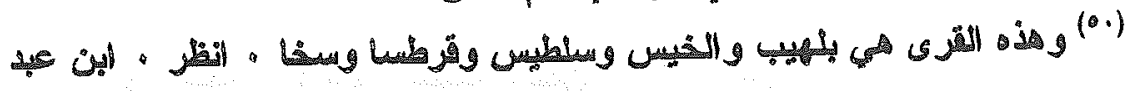

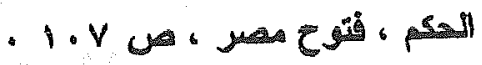

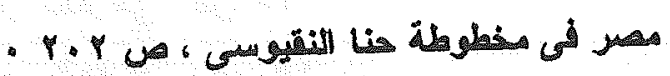

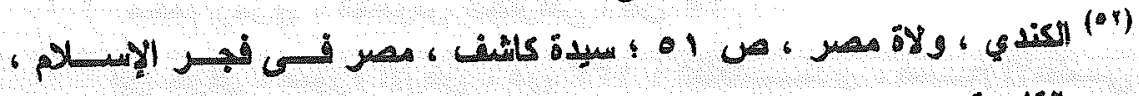

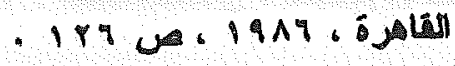

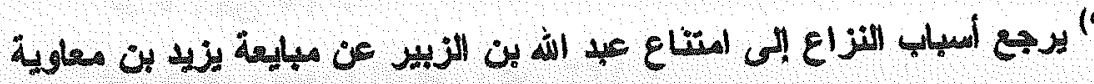

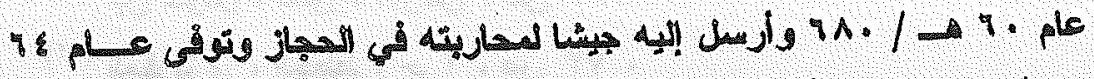

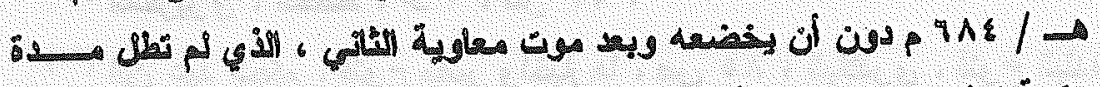

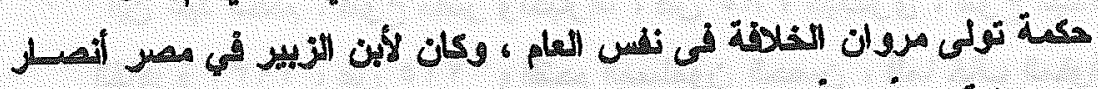

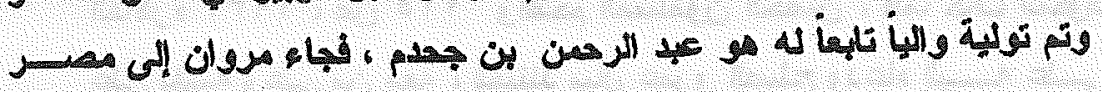




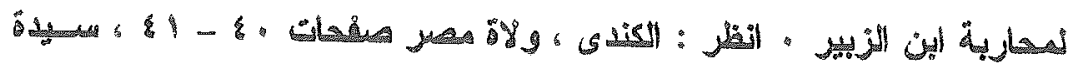

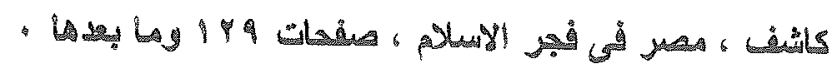

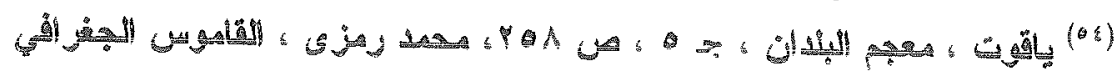
- inO vas $y / Y$

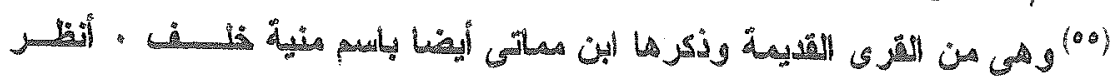

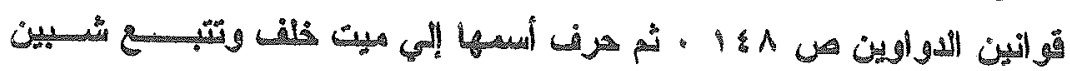

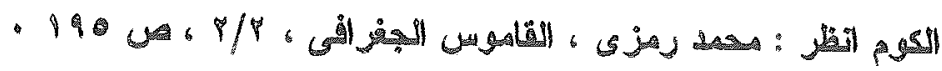

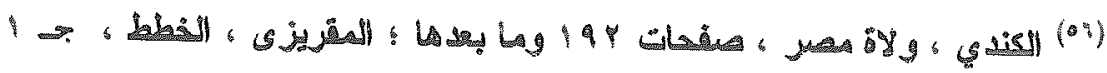
- IVA un

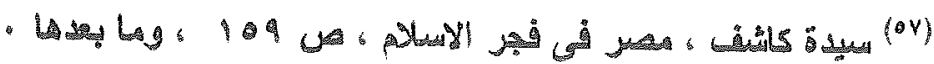

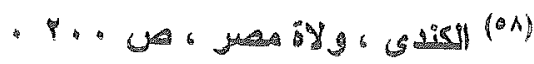

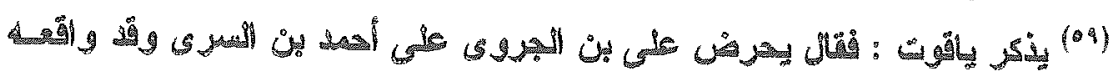

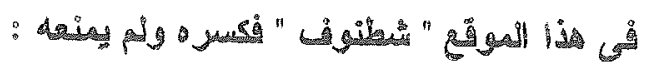

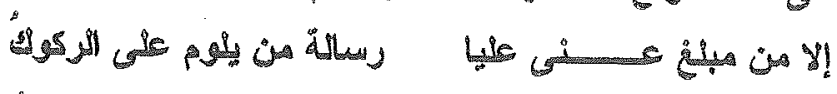

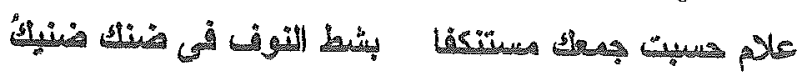

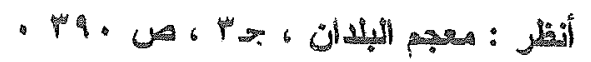

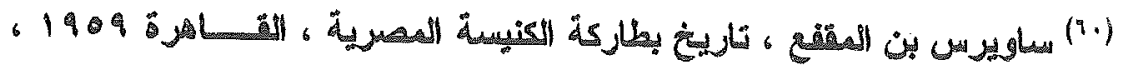

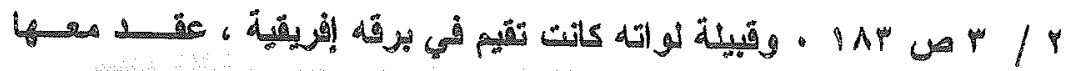

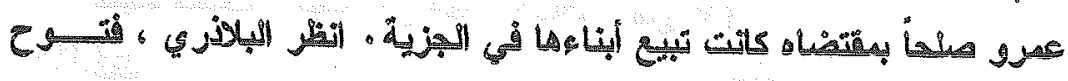

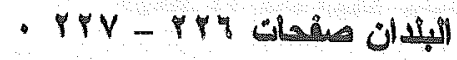

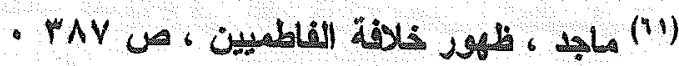

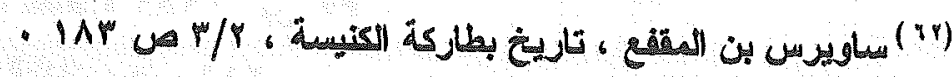

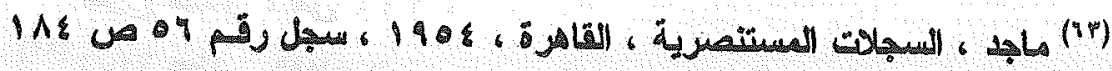

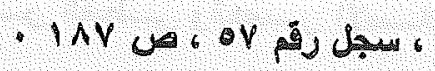

Cohen, Jewish self. Government in Medieval Egypt, New : أنظر (1) Jersy , 1980 , P59

Goitein, S.D, A Mediterranean society of the Arab world as : أز (10) portrayed in the document of Cairo geniza los Angeles V, P 524. 


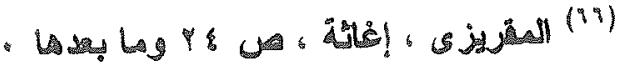

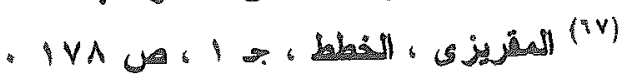

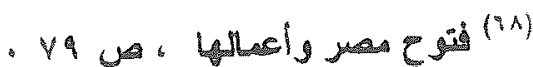

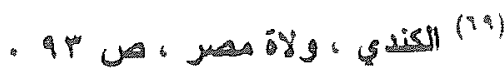

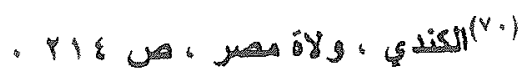

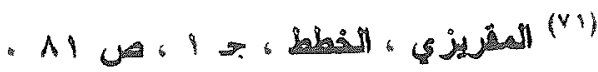

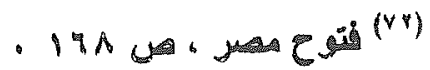

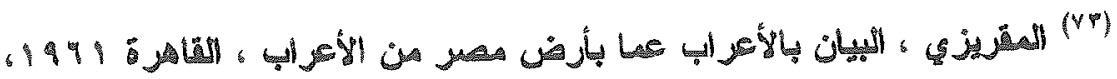

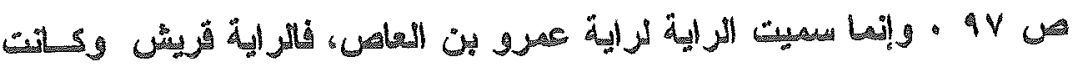

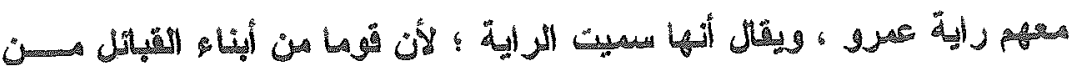

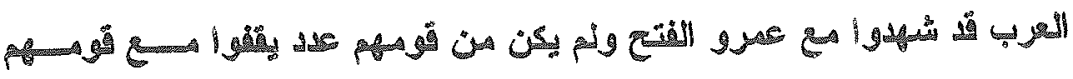

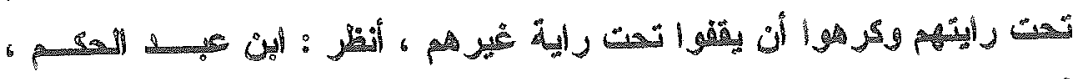

$$
\text { - Is y con con }
$$

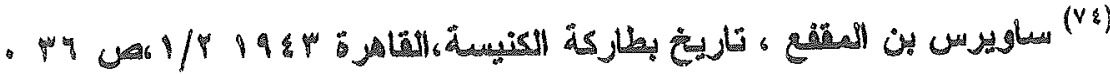

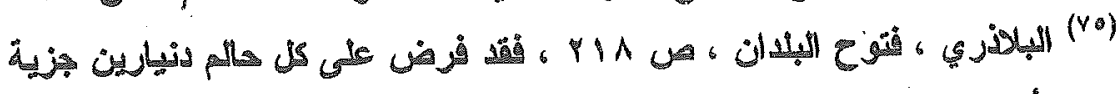

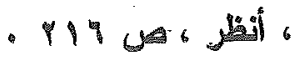

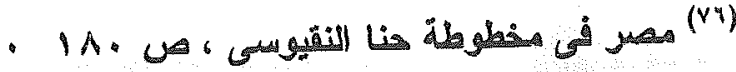

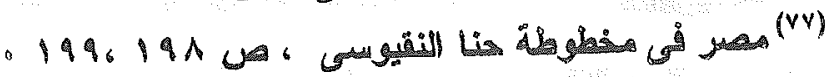

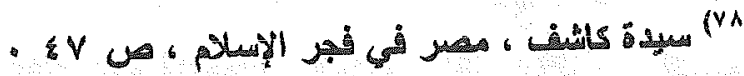

Goitein. Med soc, 11, p527.

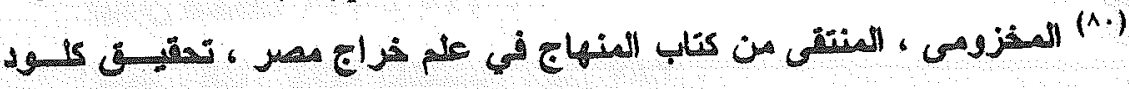

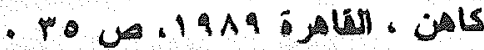

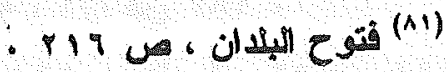

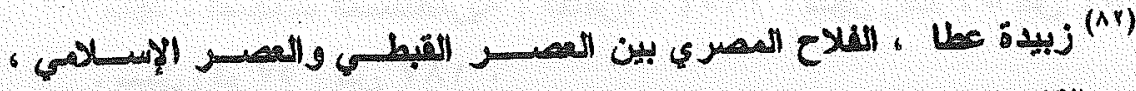

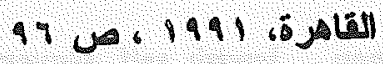

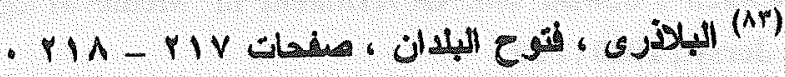

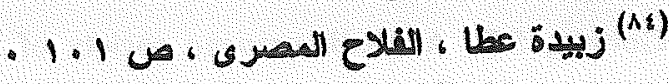


'

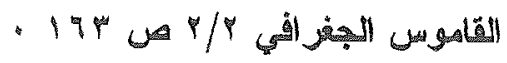

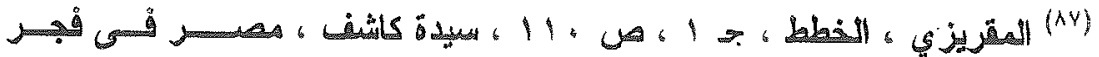

$$
\text { - YO0 yo a plest }
$$

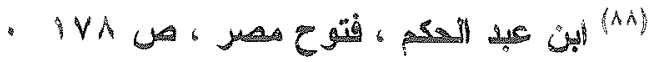

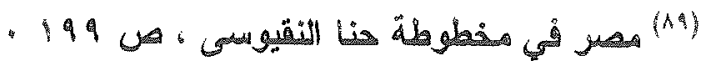

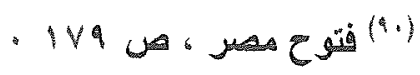

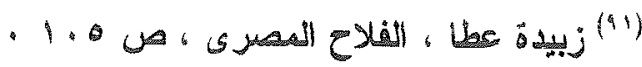

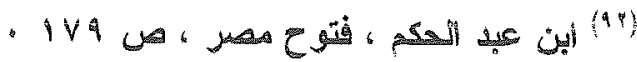

Margoliouth, Catalogue of Arabic Papyri .n 219.P.3 أنظخ (4)

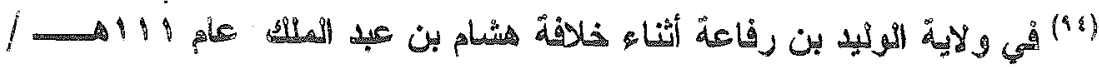

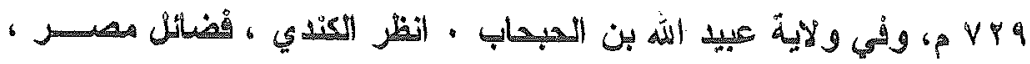

$$
\text { - rV p }
$$

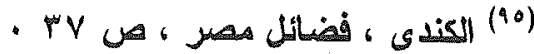

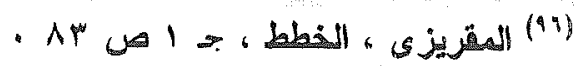

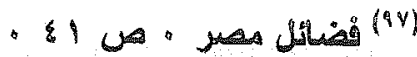

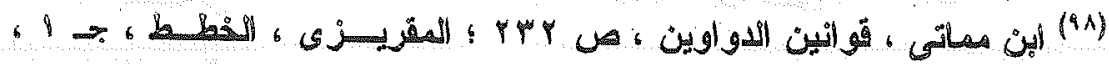

$$
1.100
$$

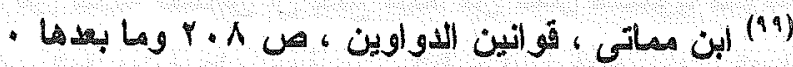

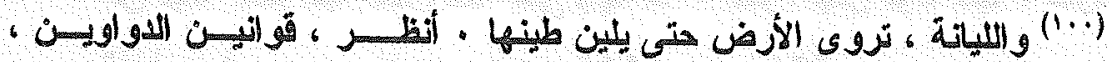

$$
\text { . } 1 \text { p, Lumb }
$$

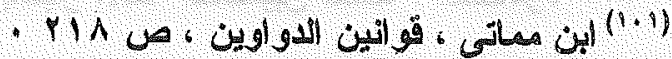

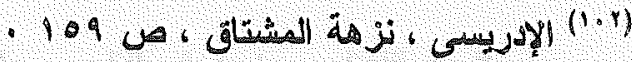

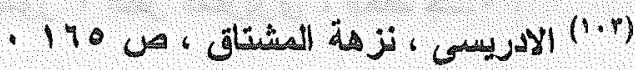




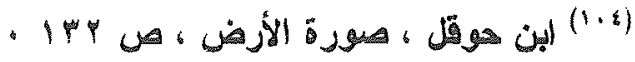

"

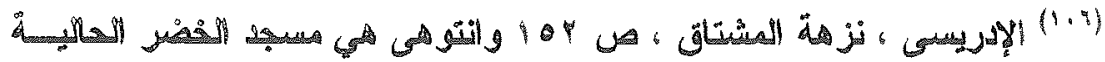

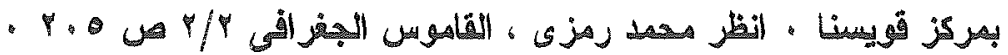

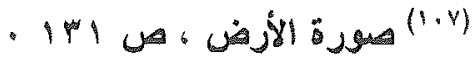

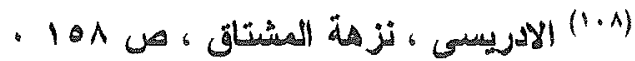

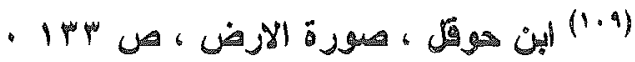

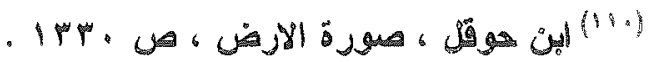

(")

.

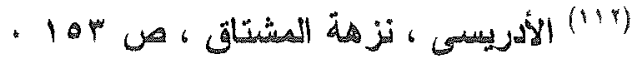

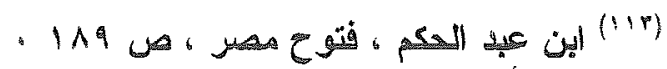

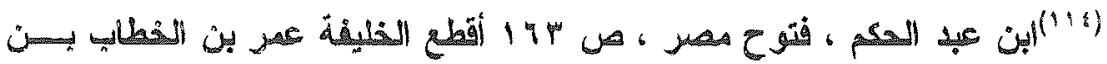

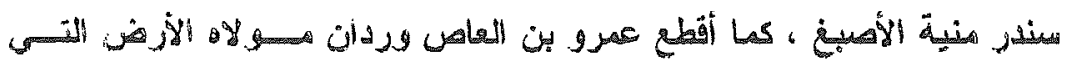

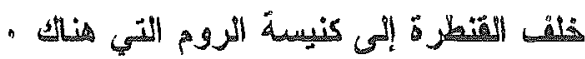

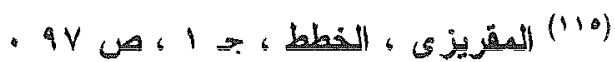

(1I1)

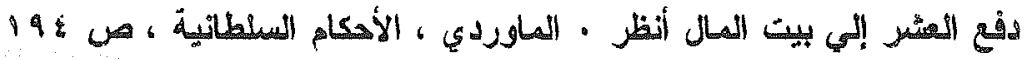

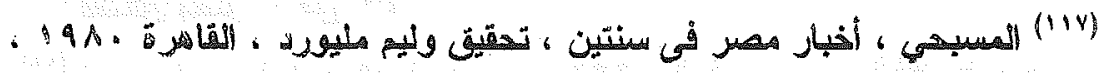
- Q i

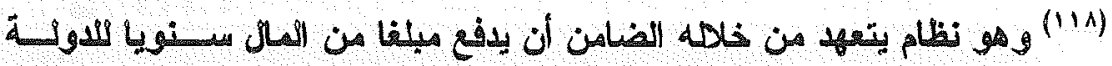

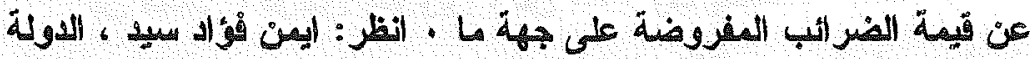

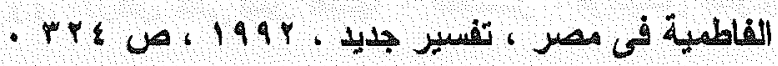

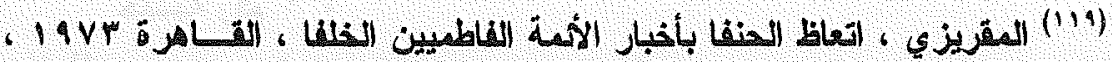

$$
\text { YVA ص० \% }
$$

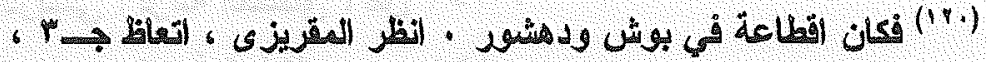

- rTtue 
Goitein, Med Soc, 111 , p 296.

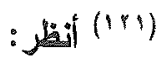

Goirein . Med soe, 1, B 362

Goiteim. Med soc, 11, 301

(18)

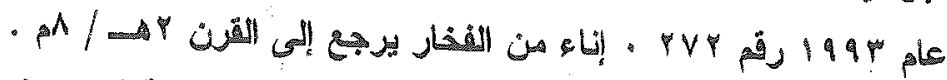

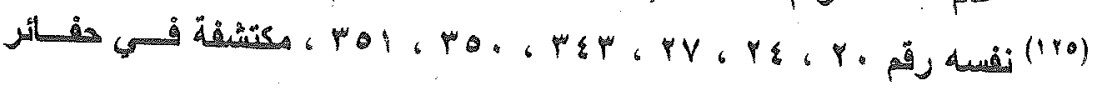

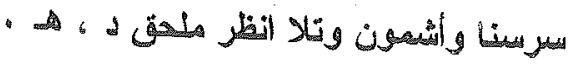

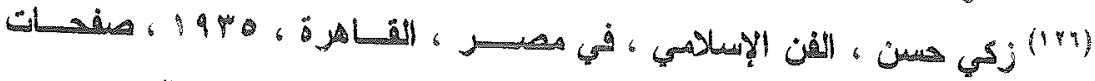

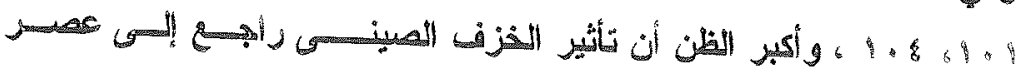

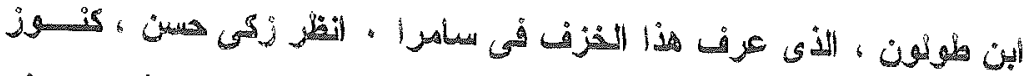
定

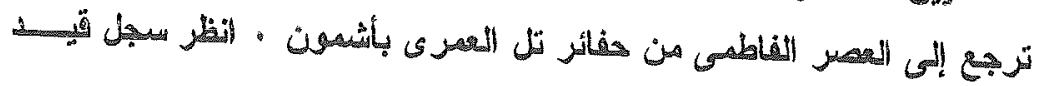

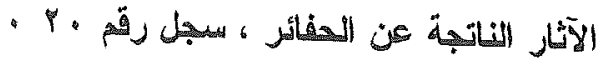

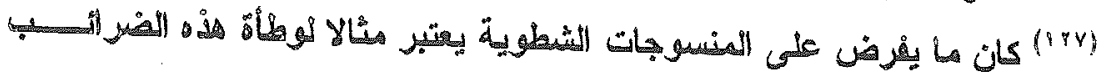

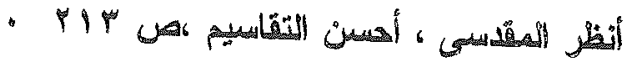

Goitein . Mied soc, 11 p.296

Goitein. Med soc, 11 p 296

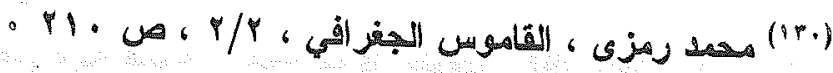

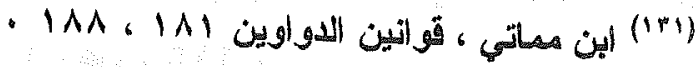

(Irr)

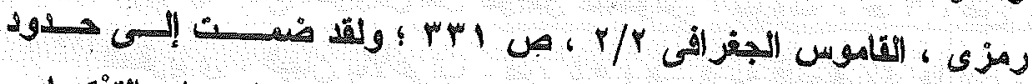

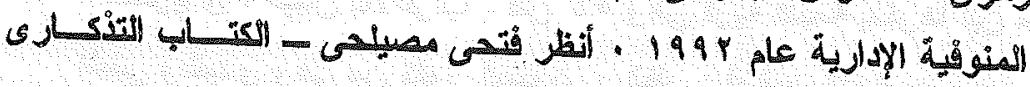

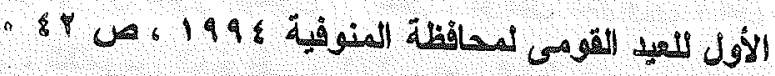

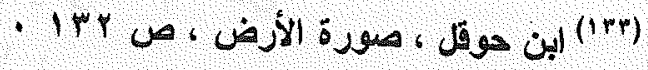

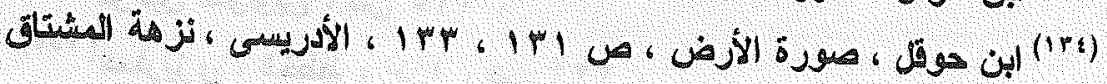
lor us.

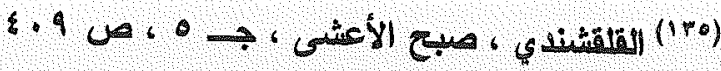


Goitein, Med Soc, 11, P296 : (1) (1)

Goitein, Med Soc 1, P. 280

Goitein, Med Soc, 11 1, p. 331

: أنظ (iNh)

Goitein, Med Soc 1, p 296

. : أن (1+Q)

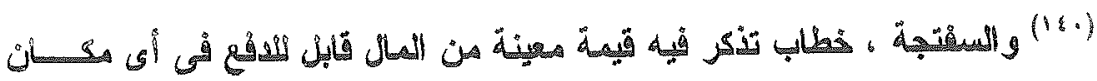

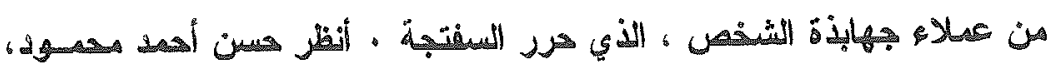

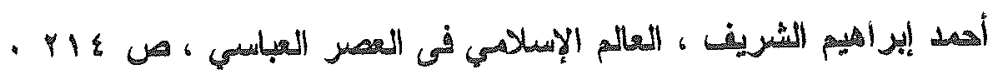

Goitein, Med Soc, 1 , p. 243 .

: $\operatorname{Sej}^{-1}(16)$

Goitein, Med Soc, 1, p. 243.

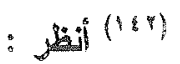

Goitein. Med Soc, 111, p 331 .

: أن (1 (1)

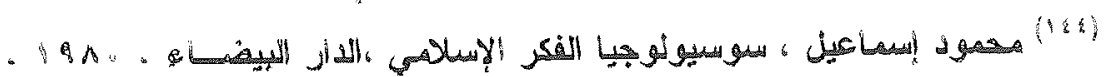

$$
\begin{aligned}
& \text {. I v : }
\end{aligned}
$$

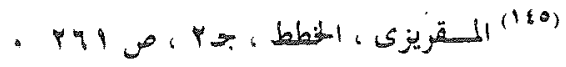

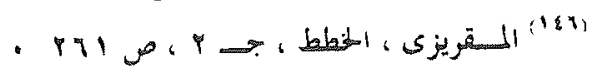

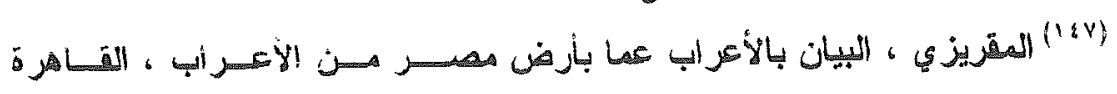

$$
\text { - is va. } 1971
$$

(18)

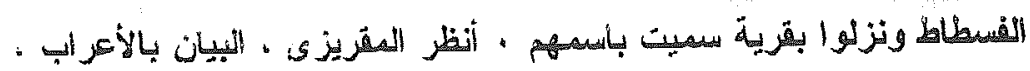

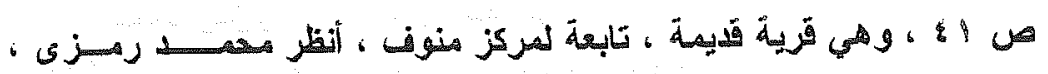

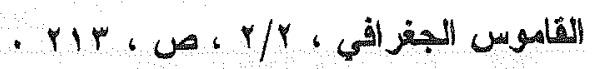

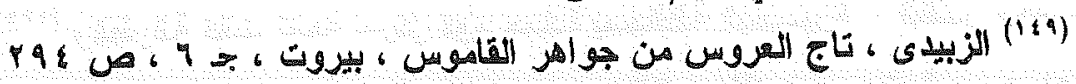

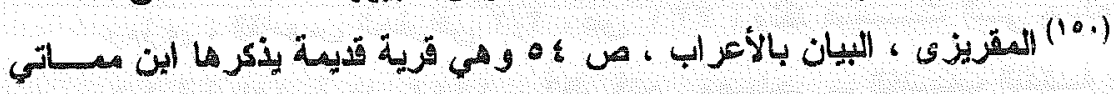

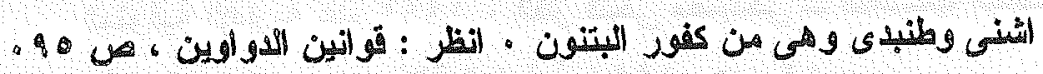

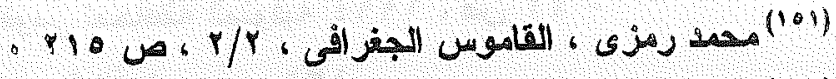

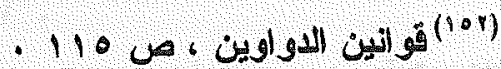

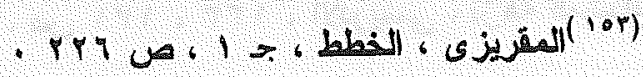




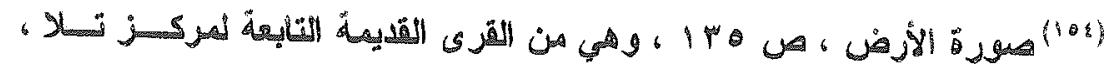

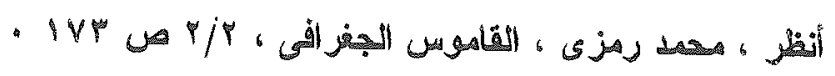

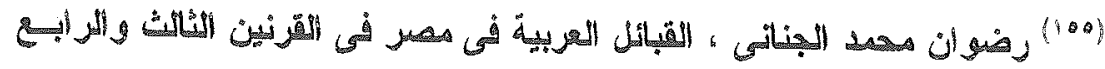

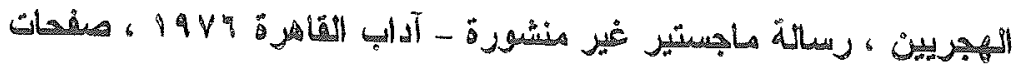

$$
\text { - } P V-8 P
$$

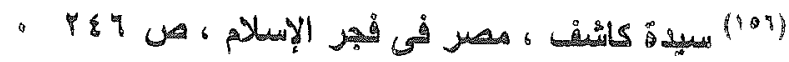

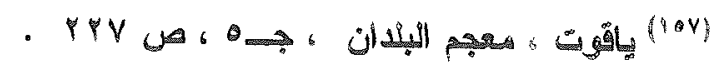

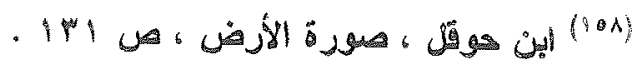

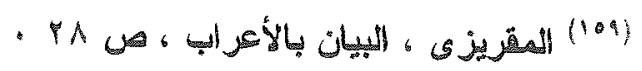

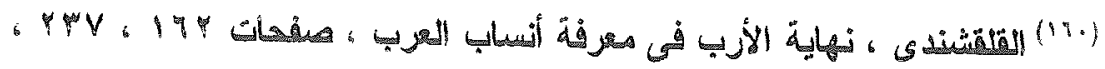

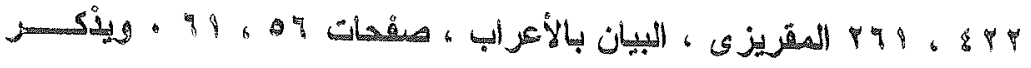

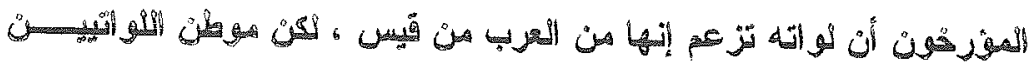

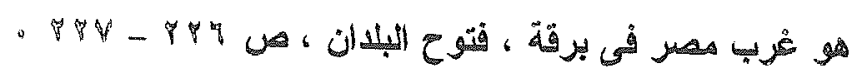

(191)

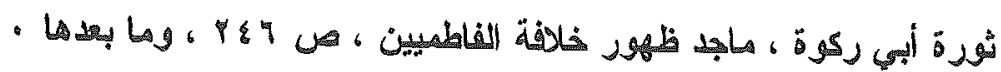

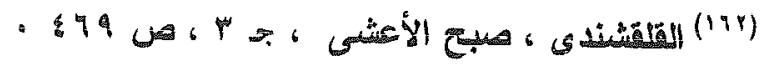

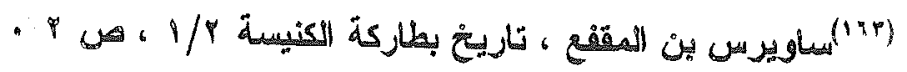

Goitein, Med soc, $\mathbb{1}, \mathbb{P} 280$.

Goitein, Med soc, 11, P 574.

: أنظو

Goitein, Med soc, 111, P 331.

Goitein, Med soc, 11, P 68.

: أن (IIV)

Goitein, Med soc, 11, P. 69.

: أنظل

Goitein, Med soc.11, p . 569.

Goitein, Med soc, 111, P 213

Goitein, Med soc, 11, P 69.

Cohen, Jewish self - Government. P. 163. 


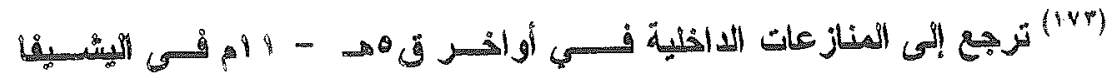

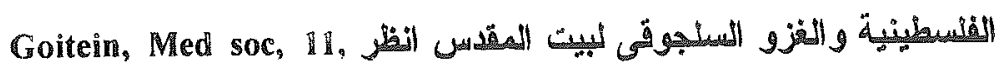
pp330-331

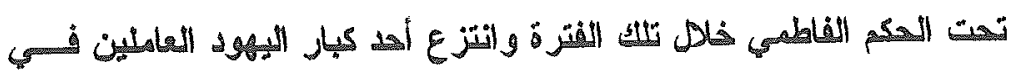

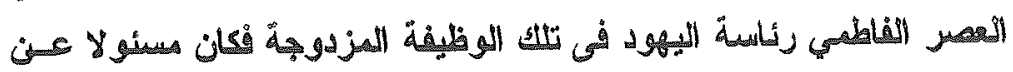

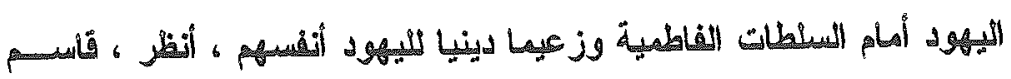

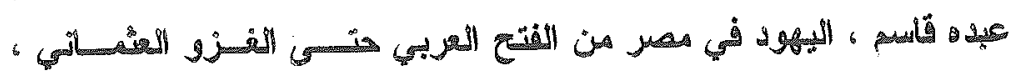
-

Cohen . Jewish self - Government P.163

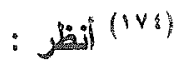

Cohen . Jewish self - Government . p. 176 : $\mathrm{Lij}^{(1 \times 0)}$

Goitein. Med soc, H. n. 338.

Goitein, Med soc, 11 1, p 507.

Goitein, Med soc. $11, p .168$.

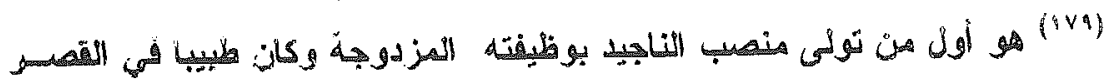

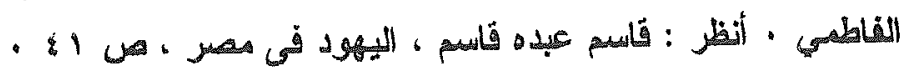

Cohen, Jewish self - Government, p.163.

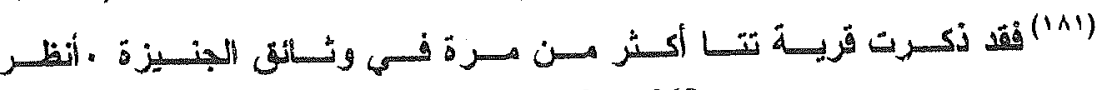
Goitein, , Med soc 11, P 49; P.436. n99, p. 262.

Goitein, Med soc, 1I, P, 49. : (NAY)

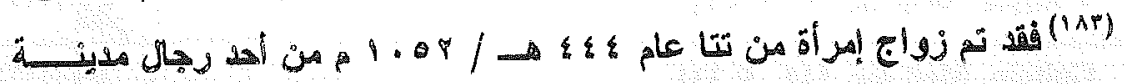
Goitein, Med soc, 111 ,p. 113.

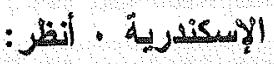

Goitein, Med soc, 11,p. 605.

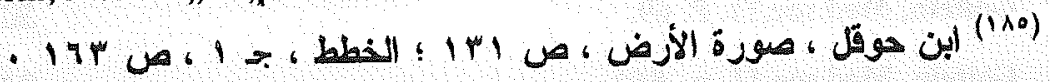

Goitein. Med soc, 11, p. 439 .

Mann, J, The Jews in Egypt and palestine under the Fatimid jil (1ny)

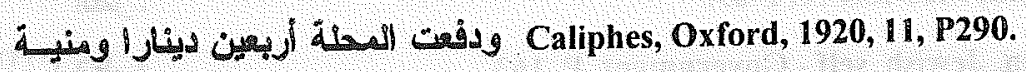

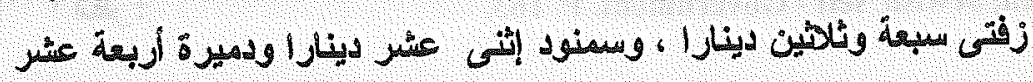




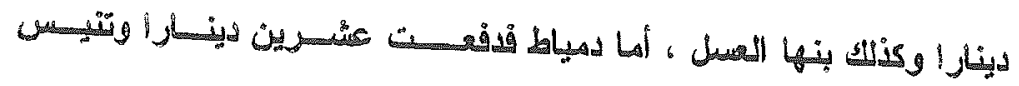

Mann. The $\mathbb{l}$ ews in Egypt . 11, p . 290.

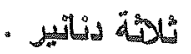

Goitein, Med soc, 111, P 296.

: أنظر (1.1)

(أنئر: (1/99)

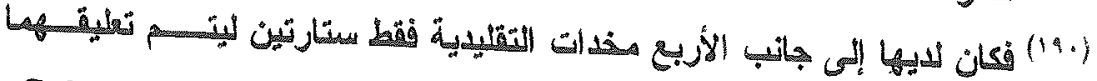

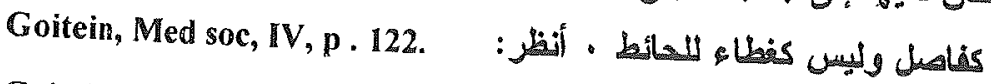

Goitein, Med socIV, p. 143

Goitein, Med soc, 111. p 213.

Goitein, Med soc , 111, pp. 113-114.

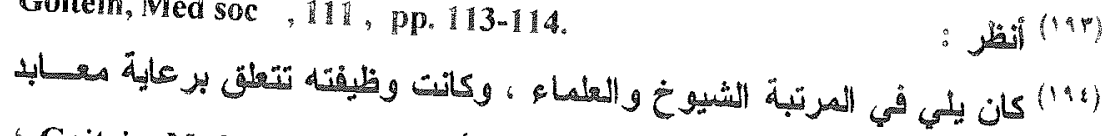
: أنس (101) $\therefore$ : أزئ)

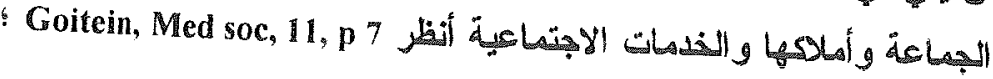

Goitein, Med soc. $811, \mathrm{p}, 213$.

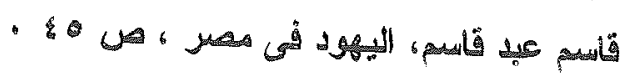

Coitein, Med sor 11 1 . . 296.

Goiteim, Med soe 111 . p. 331, 11, p. 527.

Goitein, Med soc 111 . p. 281 .

Goitein, Med soc,11, p. 332.

Goitein, Med soc. I V, pp. 264-265.

: أنظر (190) (199) : أنظر (19v) (191) (199)

Goitein, Med soc,IV, p. 264. (أنظز : (i. (r.)

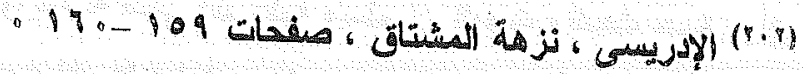

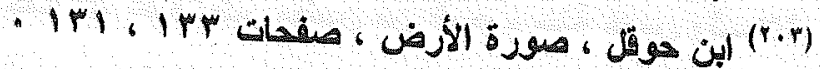

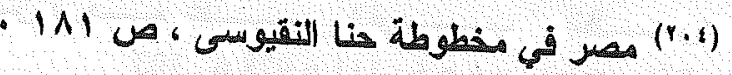

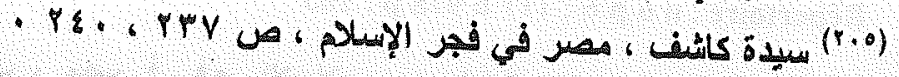

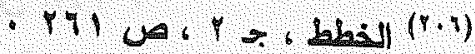

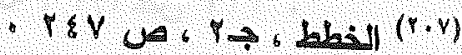

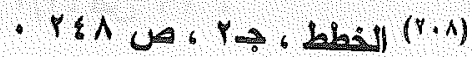

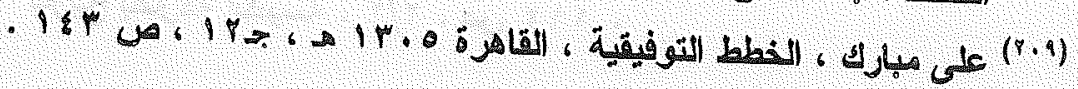




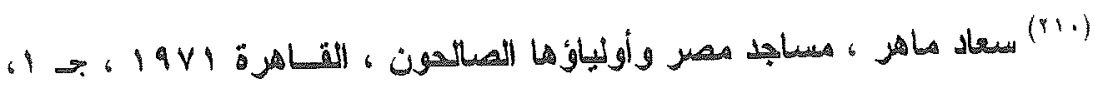

$$
\begin{aligned}
& \text { - } \wedge 1 \text { ua }
\end{aligned}
$$

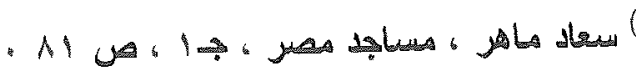

6

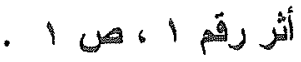

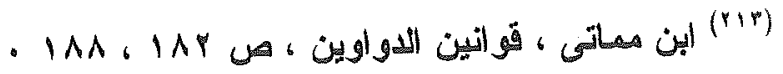

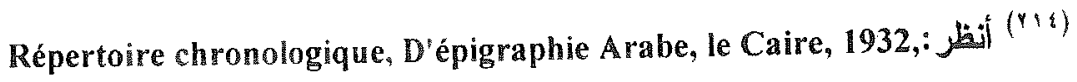
111 n $978 . p .103$

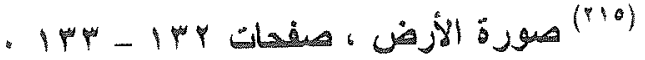

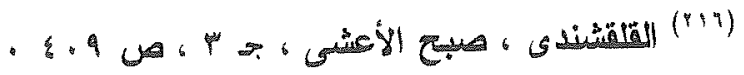

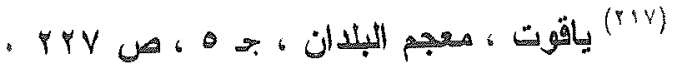

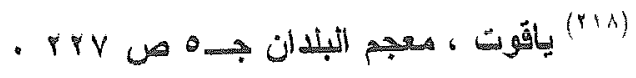

Goitein, Med soc, 11, P592.

Goitein, Med soc,11. pp $301,307$.

Goitein, Med soc, 11 , p. 303.

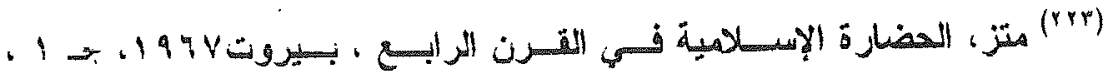

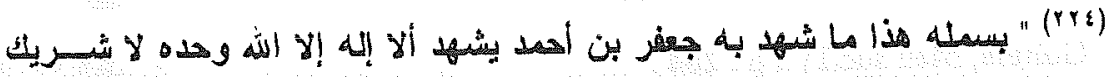

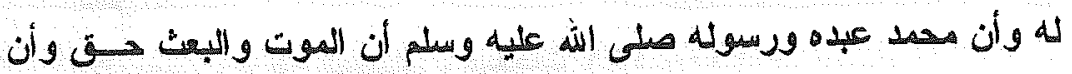

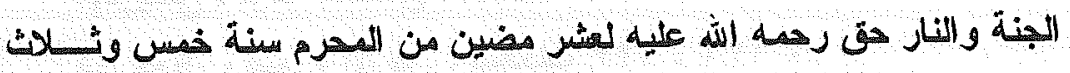

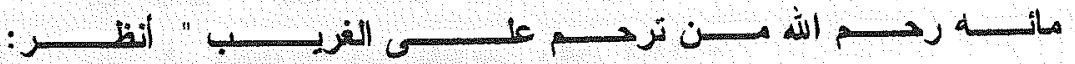
Répertoire. n 6 p $6 ; 111$ n 978 p . 103

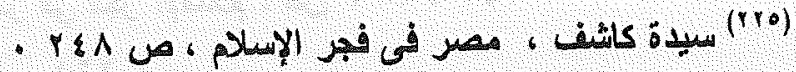

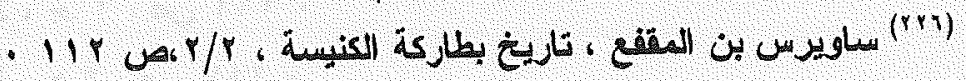

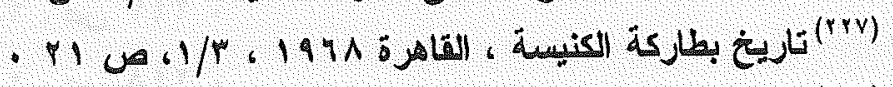

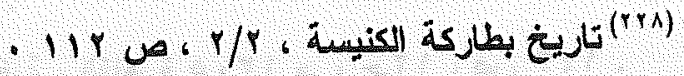




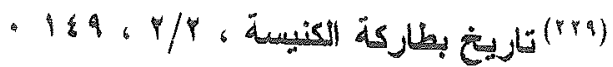

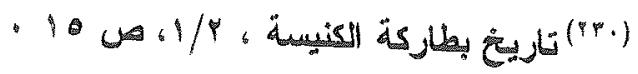

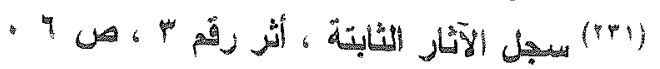

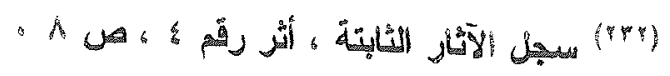

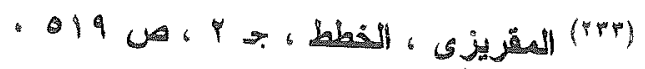

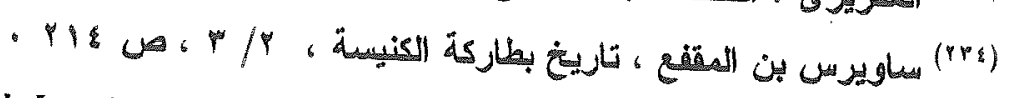

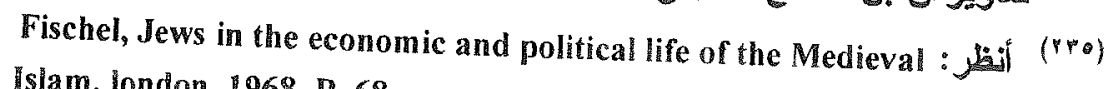
Islam, london, 1968. P. 68.

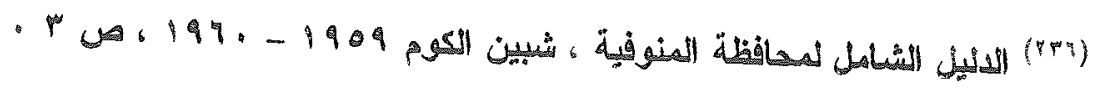

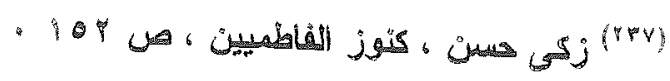

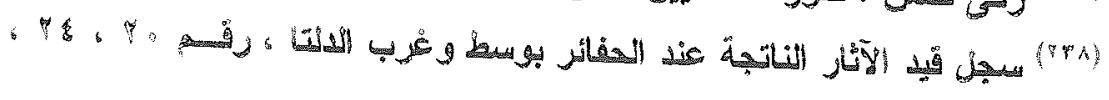

t 

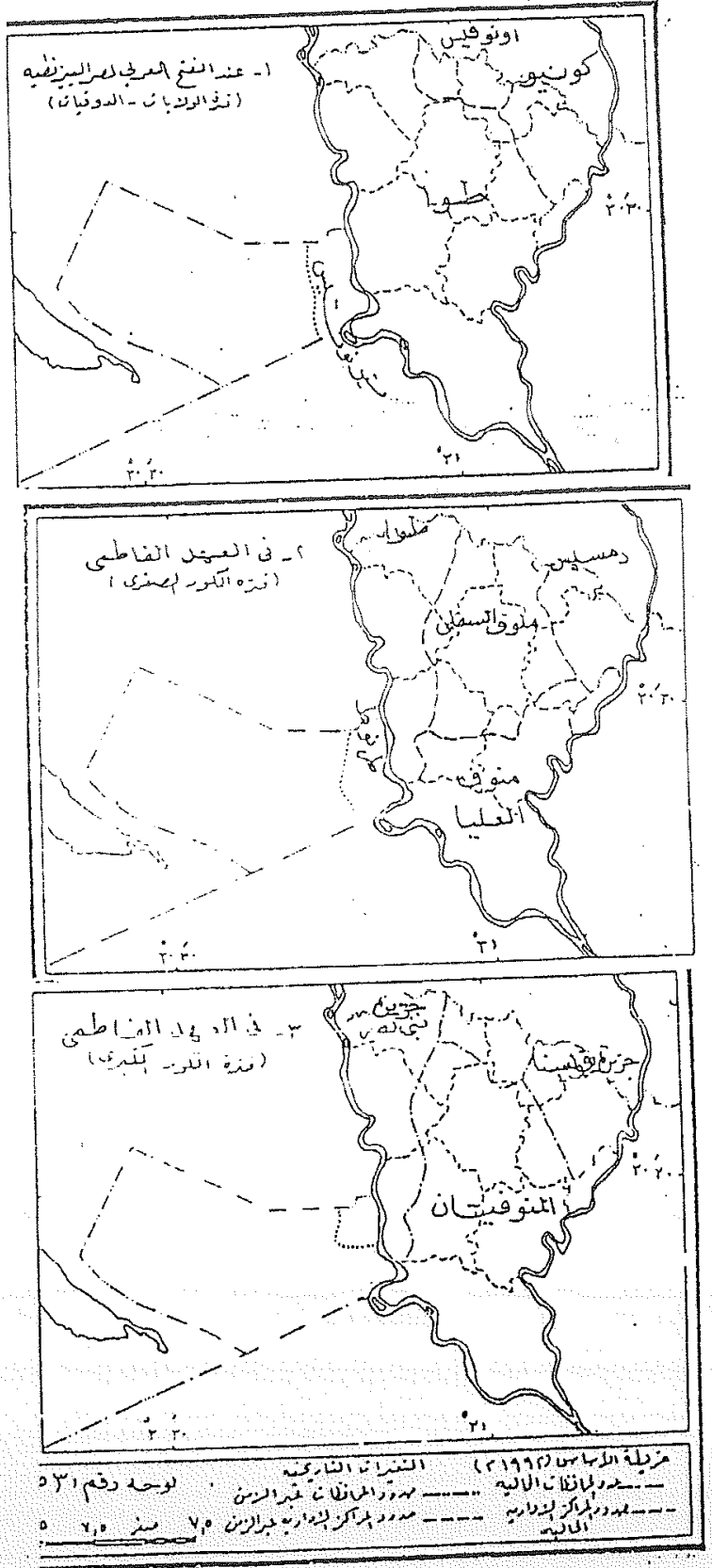

تطرد الوضع الإدادى لإقليم العنوفية حتى نهاية العصر الفاطهى

\section{ملحق (1)}

تقلا عن علاء الدين عبد الخالق ، تجربة التعمير المصرية من خلال الاطلس الناريخى للوجه

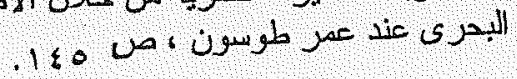




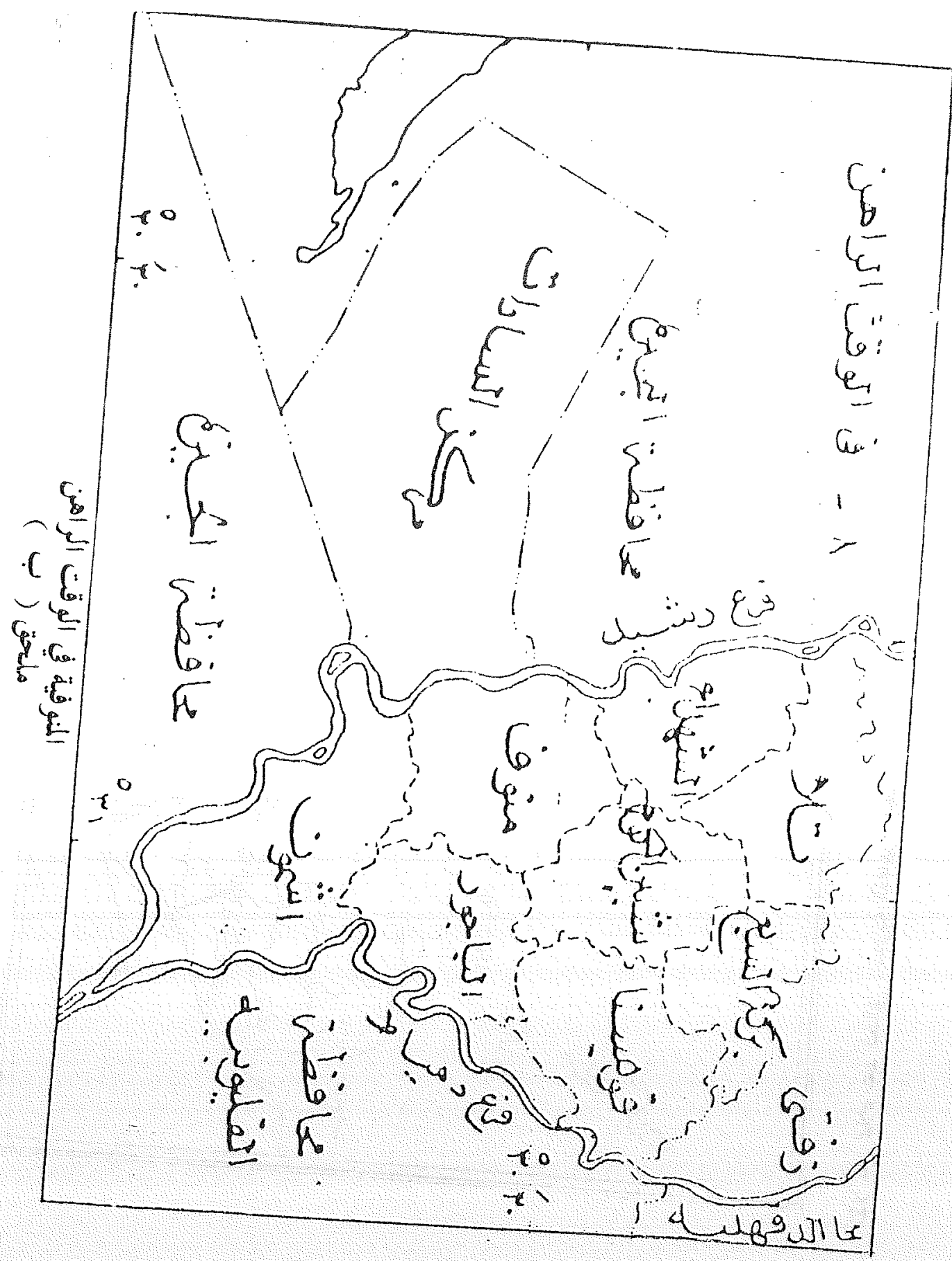

IrV 


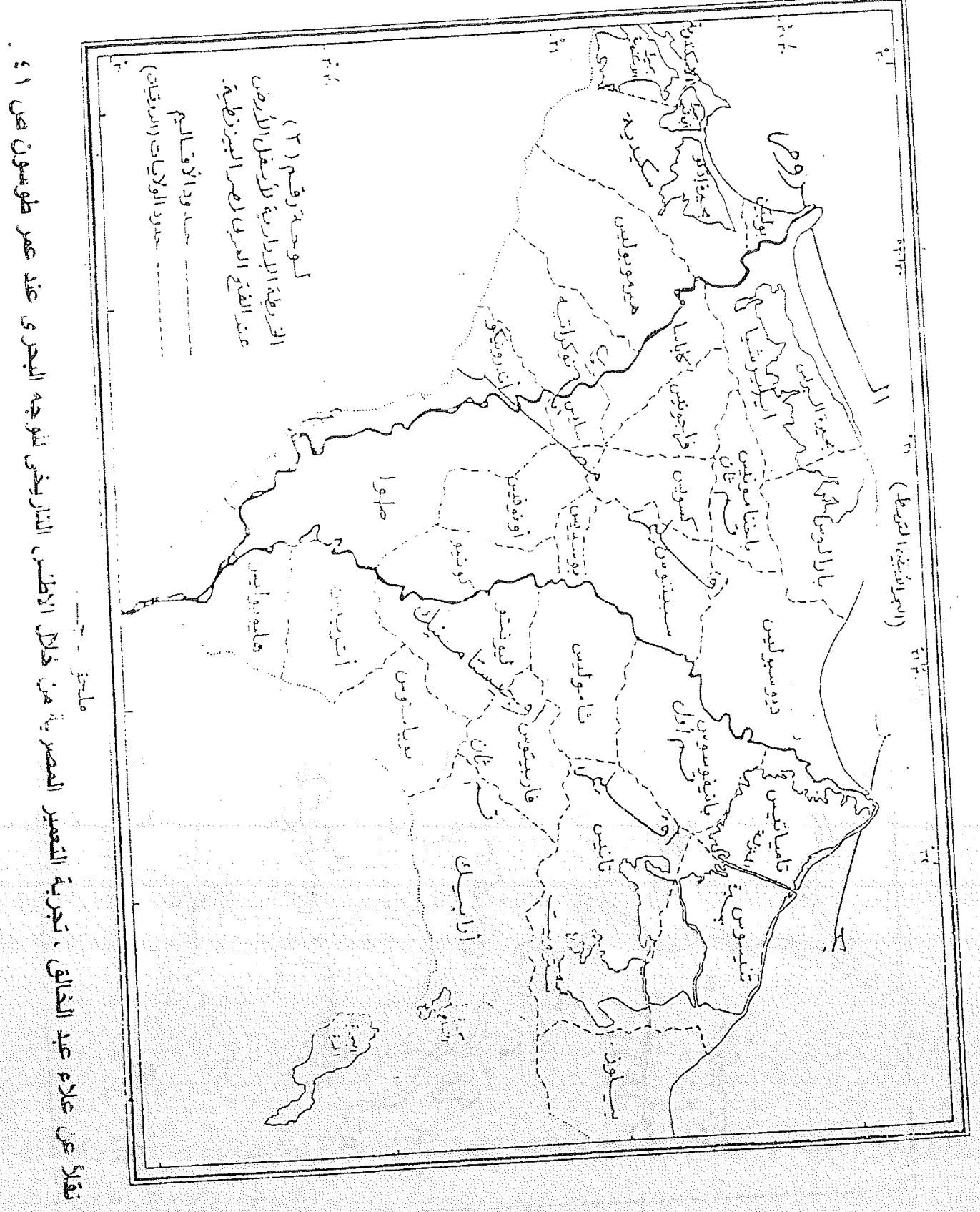




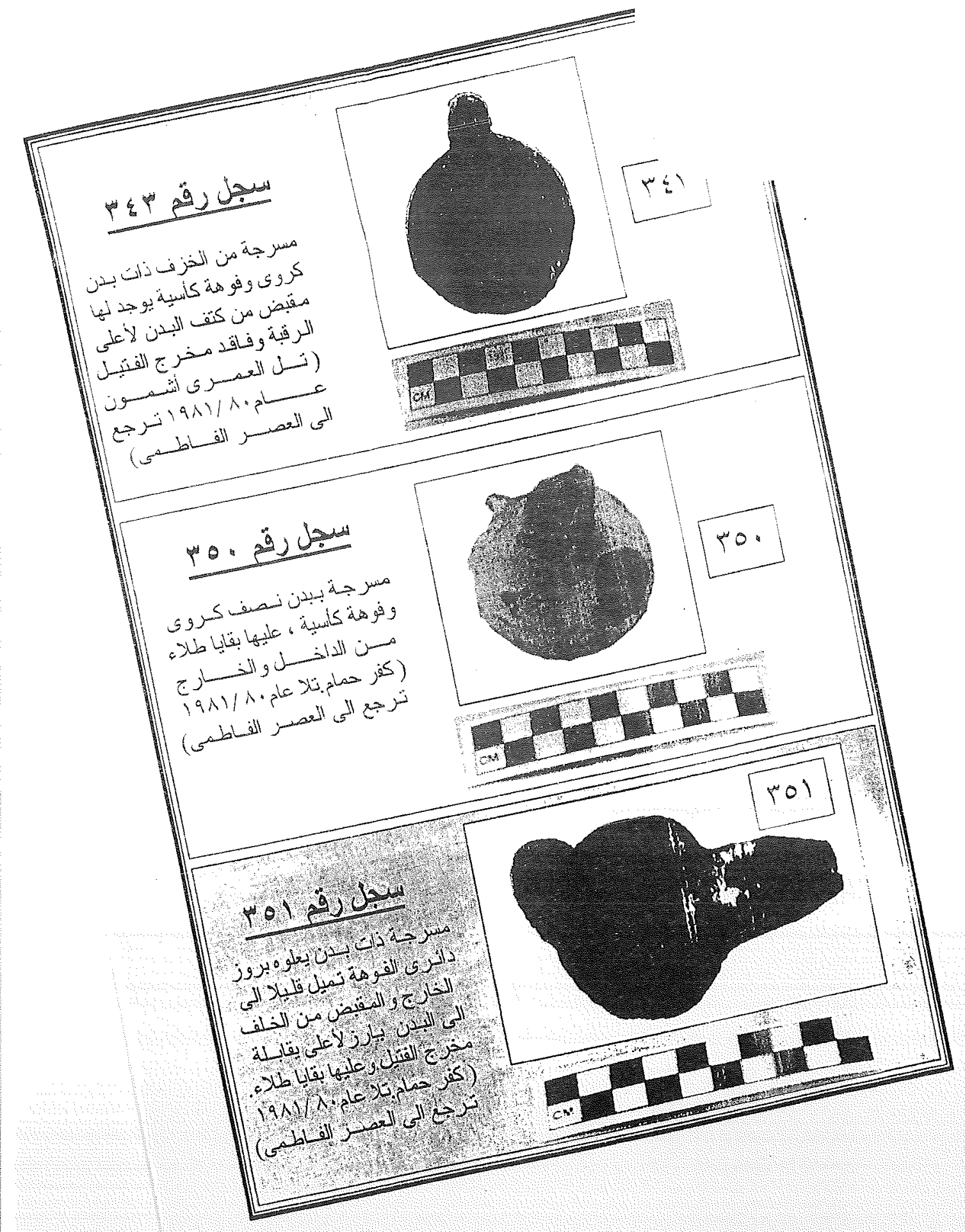





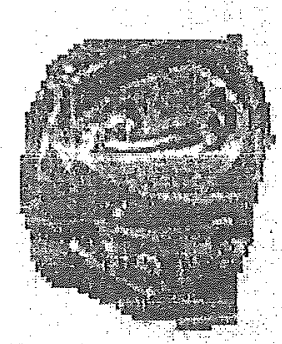

w w
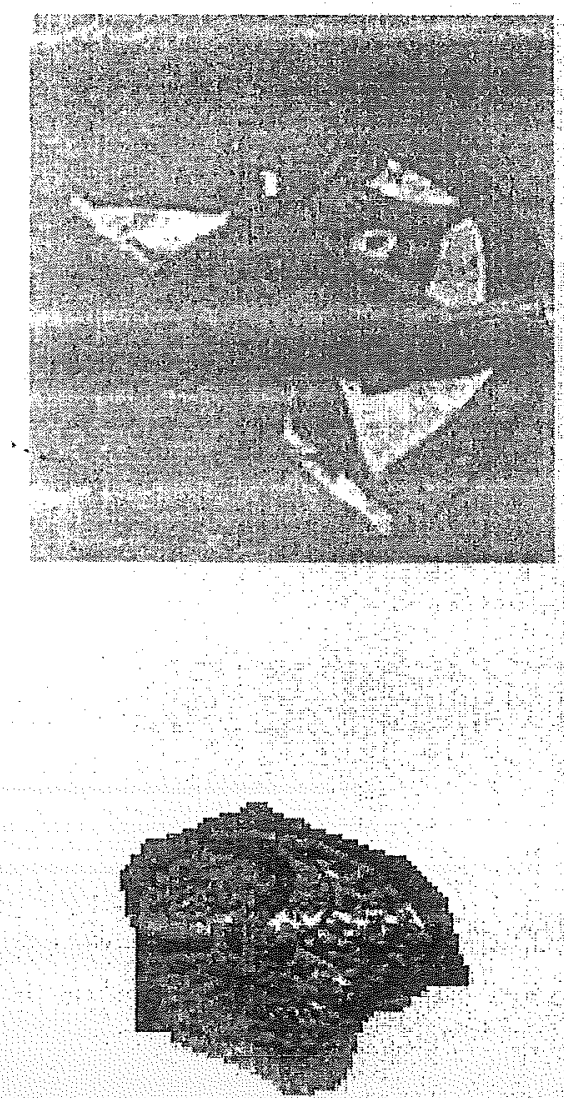

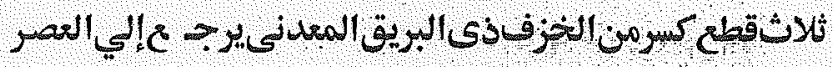

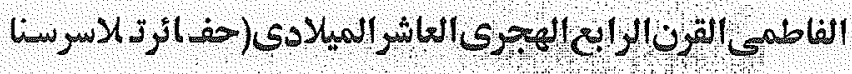

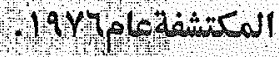

$\$$

\section{$|\varepsilon|$}


